\title{
Ergebnisse einer S2k-Konsensuskonferenz der Deutschen Gesellschaft für Gastroenterologie, Verdauungs- und Stoffwechselerkrankungen (DGVS) gemeinsam mit der Deutschen Zöliakie-Gesellschaft (DZG) zur Zöliakie, Weizenallergie und Weizensensitivität
}

\author{
Results of a S2k-Consensus Conference of the German Society of Gastroenterolgy, \\ Digestive- and Metabolic Diseases (DGVS) in Conjunction with the German Coeliac Society \\ (DZG) Regarding Coeliac Disease, Wheat Allergy and Wheat Sensitivity
}

Autoren

Institute
J. Felber ${ }^{1}$, D. Aust² ${ }^{2}$, S. Baas ${ }^{3}$, S. Bischoff ${ }^{4}$, H. Bläker ${ }^{5}$, S. Daum ${ }^{6}$, R. Keller ${ }^{7}$, S. Koletzko ${ }^{8}$, M. Laass ${ }^{9}$, M. Nothacker ${ }^{10}$, E. Roeb ${ }^{11}$, D. Schuppan ${ }^{12^{*}}$, A. Stallmach ${ }^{1 *}$

Die Institutsangaben sind am Ende des Beitrags gelistet.

Schlüsselwörter
Sprue
Nahrungsmittelintoleranz
Malabsorption
Kollagene Kolitis
Key words
sprue
food intolerance
malabsorption
collagenous colitis

eingereicht 14.4 .2014

akzeptiert 23.5.2014

\section{Bibliografie}

Dol http://dx.doi.org/ 10.1055/s-0034-1366687

Z Gastroenterol 2014; 52:

711-743 @ Georg Thieme Verlag KG Stuttgart · New York . ISSN 0044-2771

\section{Korrespondenzadresse \\ Dr. Jörg Felber}

Klinik für Innere Medizin IV, Universitätsklinikum der

Friedrich-Schiller-Universität

Jena

Erlanger Allee 101

07740 Jena

Germany

Joerg.Felber@med.uni-jena.de

\begin{tabular}{|c|c|c|}
\hline \multicolumn{2}{|c|}{ Inhaltsverzeichnis } & Seite \\
\hline \multicolumn{2}{|c|}{ Einleitung und Methodik } & 711 \\
\hline \multicolumn{2}{|c|}{ Einleitung } & 711 \\
\hline $\mathrm{E}-1$ & Hintergrund & 711 \\
\hline $\mathrm{E}-2$ & Ziele der Leitlinie & 712 \\
\hline \multicolumn{2}{|c|}{ Methodik } & 712 \\
\hline M-1 & Versorgungsbereich und Zielgruppen & 712 \\
\hline M-2 & $\begin{array}{l}\text { Zusammensetzung der Leitliniengrup- } \\
\text { pe: Beteiligung von Interessengruppen }\end{array}$ & 712 \\
\hline$M-3$ & $\begin{array}{l}\text { Beteiligte Gruppierungen und Fachge- } \\
\text { sellschaften }\end{array}$ & 713 \\
\hline M-4 & $\begin{array}{l}\text { Redaktionelle Unabhängigkeit und } \\
\text { Umgang mit potenziellen Interessens- } \\
\text { konflikten }\end{array}$ & 713 \\
\hline \multirow[t]{3}{*}{ M-5 } & Durchführung & 713 \\
\hline & $\begin{array}{l}\text { a) Recherche, Auswahl und Bewertung } \\
\text { wissenschaftlicher Belege (Evidenz- } \\
\text { basierung) }\end{array}$ & 713 \\
\hline & $\begin{array}{l}\text { b) Formulierung der Empfehlungen } \\
\text { und strukturierte Konsensfindung }\end{array}$ & 713 \\
\hline M-6 & $\begin{array}{l}\text { Externe Begutachtung und Verabschie- } \\
\text { dung }\end{array}$ & 714 \\
\hline M-7 & Verbreitung und Implementierung & 714 \\
\hline M-8 & $\begin{array}{l}\text { Gültigkeitsdauer und Aktualisierungs- } \\
\text { verfahren }\end{array}$ & 714 \\
\hline \multicolumn{2}{|c|}{ Kapitel } & 714 \\
\hline K-1 & $\begin{array}{l}\text { Klinisches Bild der Zöliakie einschließ- } \\
\text { lich Begleiterkrankungen und Spekt- } \\
\text { rum der weizenabhängigen Erkran- } \\
\text { kungen (Weizenallergie und } \\
\text { Nichtzöliakie-Nichtweizenallergie- } \\
\text { Weizensensitivität) (AG 2) }\end{array}$ & 714 \\
\hline K-2 & Diagnostik (AG 1) & 718 \\
\hline K-3 & Therapie (AG 3) & 724 \\
\hline K-4 & Pathologie (AG 4) & 729 \\
\hline K-5 & $\begin{array}{l}\text { Refraktäre Zöliakie, ulzerative } \\
\text { Jejunitis und enteropathieassoziiertes } \\
\text { T-Zelllymphom (EATL); (AG 5) }\end{array}$ & 731 \\
\hline Literat & & 737 \\
\hline
\end{tabular}

\footnotetext{
* Gleichberechtigte durch die DGVS mandatierte Koordinatoren der Leitlinie.
}

\section{Einleitung und Methodik $\nabla$}

E-1 Hintergrund

Die Zöliakie ist eine lebenslange immunologisch vermittelte chronisch-entzündliche Darmerkrankung, die sich bei Personen mit genetisch-determiniertem Risiko manifestiert. Sie ist die Folge einer fehlgerichteten Immunantwort auf Gluten und verwandte Proteine, die in Weizen, Roggen, Gerste und anderen Getreidesorten vorkommen. Die Immunreaktionen führen zu entzündlichen Veränderungen im Dünndarm und potenziell zu systemischen Komplikationen. Die intestinale Schädigung wiederum kann zu einer Malabsorption von Nahrungsstoffen und entsprechenden Folgeerkrankungen führen. In den letzten Jahren sind weitere weizenabhängige Erkrankungen, die Weizenallergie und die „Nichtzöliakie-Nichtweizenallergie-Weizensensitivität" Gegenstand wissenschaftlicher Forschung, aber auch intensiver Diskussionen in der breiten Öffentlichkeit geworden.

Historisch gesehen wurde die Zöliakie lange Zeit als eine relativ seltene Erkrankung des Kindesalters betrachtet. Verbesserte Diagnosemöglichkeiten, wie z. B. die Einführung der Endomysium- bzw. Transglutaminase-Antikörpernachweise, haben in den 1980er- und -90er-Jahren zu einer deutlichen Zunahme der erkannten Fälle geführt. Zusätzlich wurde auch eine Verschiebung des Diagnosealters hin ins Erwachsenen-, teilweise ins höhere Erwachsenenalter beobachtet [1].

Darüber hinaus gibt es epidemiologische Hinweise, dass nicht nur die Anzahl der erkannten, sondern auch die Anzahl der absoluten Erkrankungsfälle zugenommen hat [1-4].

Die Zunahme der Inzidenz in den letzten Jahren weist auf Umweltfaktoren (z. B. gastrointestinale Infektionen, veränderte Ernährungsgewohnheiten, psychosoziale Faktoren) als Risikofaktoren für die Entstehung einer Zöliakie und die mit ihr assoziierten Autoimmunerkrankungen hin [5-9]. 
Die Prävalenz der Zöliakie liegt in Deutschland bei ca. 0,3\%. Damit liegt Deutschland im Vergleich zu anderen europäischen Ländern in der unteren Quartile [10]. Zur Häufigkeit der anderen weizenabhängigen Erkrankungen gibt es keine guten epidemiologischen Daten. Experten gehen davon aus, dass zwischen 0,5 und $7 \%$ der Bevölkerung betroffen sind. Nach Selbsteinschätzung von Erwachsenen sind bis zu 13 \% der Bevölkerung betroffen [11]. Obwohl die Zöliakie in den letzten Jahren zunehmend Beachtung gefunden hat, muss immer noch von einer hohen Anzahl an erkrankten, aber nicht diagnostizierten Personen ausgegangen werden. Dieses ist um so mehr von klinischer Relevanz, da fortgesetzte Glutenexposition bei nicht diagnostizierten Zöliakiebetroffenen das Risiko für weitere Autoimmunerkrankungen, wie z.B. den Diabetes mellitus Typ 1 oder die Autoimmunthyreoiditis, erhöhen kann [12].

Der erhöhten klinischen Relevanz der Zöliakie wurde in den letzten Jahren durch die Entwicklung internationaler Leitlinien Rechnung getragen. So haben u.a. 2012/2013 die Europäische Gesellschaft für Pädiatrische Gastroenterologie, Hepatologie und Ernährung [13], die Amerikanische Gesellschaft für Gastroenterologie [14] und die World Gastroenterology Organization [155] Leitlinien vorgestellt. Die S2k-Leitlinie Zöliakie der Deutschen Gesellschaft für Verdauungs- und Stoffwechselerkrankungen (DGVS), die gemeinsam mit der Deutschen Zöliakie-Gesellschaft (DZG) entwickelt wurde, versteht sich ganz bewusst als Ergänzung zu diesen bereits existierenden Leitlinien. Die aktuellen Publikationen, die nach Veröffentlichung o.g. Leitlinien erschienen sind, wurden kritisch gewürdigt und haben - wenn sinnvoll - Eingang in die Empfehlungen dieser Leitlinie gefunden.

\section{E-2 Ziele der Leitlinie}

Das Ziel der interdisziplinären S2k-Leitlinie „Zöliakie, Weizenallergie und Weizensensitivität“ ist es, den aktuellen Kenntnisstand zu klinischem Bild, Diagnostik, Therapie, Pathologie und refraktärer Zöliakie einschließlich der mit Zöliakie assoziierten Malignome bei Kindern, Jugendlichen und Erwachsenen auf Basis der wissenschaftlichen Evidenz zusammenzufassen, im Expertenkonsens zu bewerten und daraus praxisrelevante Empfehlungen abzuleiten. Die Leitlinie soll einen Handlungskorridor für häufige Entscheidungen liefern. Sie soll zudem der evidenzbasierten Fort- und Weiterbildung dienen und somit eine Verbesserung der medizinischen Versorgung von Zöliakiebetroffenen Personen erreichen.

Hierzu seien weitere erläuternde Vorbemerkungen vorangestellt.

1. Das Krankheitsbild, die Diagnostik und Therapie der Zöliakie können sich in verschiedenen Aspekten zwischen Kindern und Erwachsenen unterscheiden. Vor diesem Hintergrund wurden die besonderen Empfehlungen zu Kindern und Jugendlichen von den Empfehlungen zu adulten Patienten abgegrenzt. Eine separate Leitlinie für Kinder und Jugendliche oder für Erwachsene erschien den Koordinatoren und den Vertretern der beteiligten Fachgesellschaften wegen der weiträumigen Überschneidungen nicht sinnvoll.

2. Die Qualität der wissenschaftlichen Evidenz zur Weizenallergie und zur Nichtzöliakie-Nichtweizenallergie-Weizensensitivität wird als nicht so hoch eingeschätzt wie die Qualität der wissenschaftlichen Evidenz zur Zöliakie. Insbesondere in diesem Bereich fehlen klare international akzeptierte Definitionen, sodass häufig lediglich Expertenmeinungen Grundlage für die Empfehlungen bilden können.

3. Die Gültigkeit dieser Leitlinie beträgt 5 Jahre. Eine Revision ist für 2018/2019 geplant.

\section{Methodik}

$\nabla$

\section{M-1 Versorgungsbereich und Zielgruppen}

Die Leitlinie gilt sowohl für die ambulante als auch die stationäre Versorgung. Die Empfehlungen richten sich an alle an der Diagnostik und Therapie beteiligten Berufsgruppen (insbesondere Hausärzte, Allgemeinmediziner, Internisten, Gastroenterologen, Kinderärzte, Kindergastroenterologen, Pathologen, endoskopisch tätige Chirurgen und Ernährungsberater) ebenso wie an alle betroffenen Personen.

\section{M-2 Zusammensetzung der Leitliniengruppe:}

Beteiligung von Interessengruppen

Die Deutsche Gesellschaft für Verdauungs- und Stoffwechselkrankheiten (DGVS) beauftragte Andreas Stallmach und Detlef Schuppan mit der Leitung der Leitlinienerstellung. Diese legten die Eckpunkte des Konsentierungsverfahrens fest, luden andere Fachgesellschaften ein und wählten die Mitglieder der Arbeitsgruppen aus. Dabei erfolgte die Auswahl der AG-Mitglieder primär nach fachlicher Expertise. Es wurde Wert darauf gelegt, dass in jeder Arbeitsgruppe zwei Patientenvertreter, die von der DZG benannt wurden, teilnahmen ( 0 Tab. $\mathbf{M}-\mathbf{2}$ ).

Tab. M-2 Mitarbeiter der Leitlinie.

\begin{tabular}{|c|c|c|}
\hline \multicolumn{3}{|c|}{ Mitarbeiter der Leitlinie } \\
\hline $\begin{array}{l}\text { AG } 1 \\
\text { „Diagnostik“ }\end{array}$ & $\begin{array}{l}\text { Martin W. Laaß (GPGE, } \\
\text { Dresden) } \\
\text { Detlev Schuppan (DGVS, } \\
\text { Mainz) }\end{array}$ & $\begin{array}{l}\text { Hubert Allgayer (Bad Mergent- } \\
\text { heim) } \\
\text { Stephanie Baas (DZG, } \\
\text { Hamburg) } \\
\text { Thomas Mothes (Leipzig) } \\
\text { Barbara Schäfer (DZG, } \\
\text { Bergatreute) }\end{array}$ \\
\hline $\begin{array}{l}\text { AG } 2 \\
\text { „Klinisches } \\
\text { Bild“ }\end{array}$ & $\begin{array}{l}\text { Elke Roeb (DGVS, Gieß- } \\
\text { en) } \\
\text { Andreas Stallmach } \\
\text { (DGVS, Jena) }\end{array}$ & $\begin{array}{l}\text { Mirijam Eiswirth (DZG, Bremen) } \\
\text { Winfried Häuser (Saarbrücken) } \\
\text { Wolfgang Holtmeier (Köln) } \\
\text { Klaus-Michael Keller (GPGE, } \\
\text { Wiesbaden) } \\
\text { Bernhard Lembcke (Gladbeck) } \\
\text { Heide Mecke (DZG, Villingen- } \\
\text { Schwenningen) }\end{array}$ \\
\hline $\begin{array}{l}\text { AG } 3 \\
\text { „Therapie“ }\end{array}$ & $\begin{array}{l}\text { Stephan C. Bischoff } \\
\text { (DGEM, Stuttgart) } \\
\text { Sibylle Koletzko (GPGE, } \\
\text { München) }\end{array}$ & $\begin{array}{l}\text { Maria Brandstätter (DZG, Neu- } \\
\text { Ulm / Burlafingen) } \\
\text { Walburga Dieterich (Erlangen) } \\
\text { Dan Kühnau (DZG, Berlin) } \\
\text { Jürgen von Schönfeld (Bergisch- } \\
\text { Gladbach) }\end{array}$ \\
\hline $\begin{array}{l}\text { AG } 4 \\
\text { „Pathologie“ }\end{array}$ & $\begin{array}{l}\text { Daniela E. Aust (DGP, } \\
\text { BDP, Dresden) } \\
\text { Nikolaus Gaßler (DGP, } \\
\text { BDP, Aachen) }\end{array}$ & $\begin{array}{l}\text { Sofia Beisel (DZG, Stuttgart) } \\
\text { Hendrik Bläker (Berlin) } \\
\text { Falko Fend (Tübingen) } \\
\text { Ilka-Barbara Mlosch (DZG, Berlin) } \\
\text { Jürgen Stein (Frankfurt a. Main) }\end{array}$ \\
\hline $\begin{array}{l}\text { AG } 5 \\
\text { „Refraktäre } \\
\text { Zöliakie“ }\end{array}$ & $\begin{array}{l}\text { Severin Daum (DGVS, } \\
\text { Berlin) } \\
\text { Wolfgang Fischbach } \\
\text { (DGVS, Aschaffenburg) }\end{array}$ & $\begin{array}{l}\text { Jörg Felber (Jena) } \\
\text { Gerhard Fessler (DZG, Ost- } \\
\text { fildern) } \\
\text { Christoph-Thomas Germer } \\
\text { (Würzburg) } \\
\text { Ulrike Oelhoff (DZG, Mannheim) } \\
\text { Arnd-Oliver Schäfer (Freiburg) } \\
\text { Michael Schumann (Berlin) }\end{array}$ \\
\hline AWMF & $\begin{array}{l}\text { Monika Nothacker } \\
\text { (Marburg) }\end{array}$ & \\
\hline DGVS & $\begin{array}{l}\text { Petra Lynen-Jansen } \\
\text { (Berlin) }\end{array}$ & \\
\hline
\end{tabular}




\section{M-3 Beteiligte Gruppierungen und Fachgesellschaften} Federführung und Koordination

Deutsche Gesellschaft für Gastroenterologie, Verdauungs- und Stoffwechselkrankheiten e.V. (DGVS)

\section{Mitarbeit}

Gesellschaft für Pädiatrische Gastroenterologie und Ernährung e.V. (GPGE)

Deutsche Gesellschaft für Innere Medizin e.V. (DGIM)

Deutsche Gesellschaft für Ernährungsmedizin e.V. (DGEM)

Bundesverband Deutscher Pathologen e.V. (BDP)

Deutsche Gesellschaft für Pathologie e.V. (DGP)

Deutsche Zöliakie-Gesellschaft e.V. (DZG)

\section{M-4 Redaktionelle Unabhängigkeit und Umgang mit potenziellen Interessenskonflikten}

Die Leitlinie wurde finanziert von der DGVS und der DZG. Vertreter der pharmazeutischen Industrie wurden nicht am Prozess der Leitlinienentwicklung beteiligt, um Neutralität und Unabhängigkeit zu wahren.

Vor dem Hintergrund der zunehmenden Bedeutung von Leitlinien zur Diagnostik und Therapie von Erkrankungen werden potenzielle Interessenskonflikte der an der Leitlinie mitarbeitenden Personen immer wichtiger. Interessenskonflikte sind als Situationen definiert, die das Risiko beinhalten, dass das professionelle Urteilsvermögen, welches sich auf ein primäres Interesse bezieht, durch sekundäre Interessen unangemessen beeinflusst wird [16]. Sekundäre Interessen, die mit dem primären Interesse der evidenzbasierten Leitlinienerstellung in Konflikt geraten können, sind zum Beispiel materielle Interessen wie das Interesse an der Aufrechterhaltung einer Beziehung zu einem pharmazeutischen Unternehmen. Zu den immateriellen Interessen gehören ggf. die mandatierende Organisation (z. B. Fachgesellschaft), der Arbeitgeber und der wissenschaftliche Schwerpunkt der betroffenen Person. Ebenso können soziale oder intellektuelle Interessen als sekundäre Interessen zu einem Interessenkonflikt führen. Bezüglich potenzieller Interessenskonflikte bei den Teilnehmern der S2k-Leitlinienkonferenz Zöliakie sei an dieser Stelle kurz zusammengefasst, dass vor Beginn der Leitlinienkonferenz alle Teilnehmer ihre potenziellen Interessenskonflikte offen gelegt haben (siehe PDF-Datei Online-Version: http://www.awmf.org/leitlinien/detail/11/021 - 021.html). Hierfür wurden Interessenkonflikte schriftlich mithilfe eines Formblattes der Arbeitsgemeinschaft der Wissenschaftlichen Medizinischen Fachgesellschaften e.V. (AWMF), das materielle und immaterielle Interessen umfasst, offen gelegt. Diese Interessenskonflikte wurden auf der Leitlinienkonferenz unter Moderation der AWMF (vertreten durch M. Nothacker) offen diskutiert und es wurde einstimmig beschlossen, dass Personen mit potenziellen Interessenskonflikten bei Abstimmungen über Empfehlungen, die von diesen Interessenskonflikten berührt werden könnten, sich ihrer Stimme enthalten.

\section{M-5 Durchführung}

a) Recherche, Auswahl und Bewertung wissenschaftlicher Belege (Evidenzbasierung)

Es erfolgte eine systematische Literaturrecherche. Auf Grundlage von Stichwörtern, die von den Arbeitsgruppenleitern benannt wurden, erfolgte im November 2012 eine Literatursuche nach „MeSH-terms“ in PubMed (Einschränkungen: Human, 10 Jahre; keine Editorials, historische Artikel, Kommentare oder Fallberichte). Die gefundenen Artikel wurden aufgrund Abstract und
Tab. M-3 Literatursuche.

\begin{tabular}{|c|c|c|c|}
\hline \multicolumn{4}{|l|}{ Literatursuche } \\
\hline Arbeitsgruppe & Stichwörter & $\begin{array}{l}\text { gefun- } \\
\text { dene } \\
\text { Artikel }\end{array}$ & $\begin{array}{l}\text { verwen- } \\
\text { dete } \\
\text { Artikel }\end{array}$ \\
\hline $\begin{array}{l}\text { AG } 1 \\
\text { „Diagnostik“ }\end{array}$ & $\begin{array}{l}\text { celiac-specific antibody tests } \\
\text { anti-TG2, tissue transglutaminase } \\
\text { type } 2 \text { (TG2) antibodies. } \\
\text { endomysial antibodies (EMA) } \\
\text { anti-DGP } \\
\text { IgA deficiency } \\
\text { HLA typing for HLA-DQ2 and HLA- } \\
\text { DQ8 } \\
\text { gluten-related disorders } \\
\text { glutensensitivity }\end{array}$ & 1177 & 149 \\
\hline $\begin{array}{l}\text { AG } 2 \text { „Klinisches } \\
\text { Bild“ }\end{array}$ & $\begin{array}{l}\text { celiac disease } \\
\text { AND } \\
\text { symptoms } \\
\text { complications (kein MeSH-term) } \\
\text { clinical picture } \\
\text { autoimmune disease } \\
\text { co-morbidities }\end{array}$ & 3610 & 172 \\
\hline AG 3 „Therapie“ & $\begin{array}{l}\text { celiac disease } \\
\text { AND } \\
\text { gluten free therapy } \\
\text { drug therapy } \\
\text { gluten free cereals } \\
\text { gluten free product } \\
\text { oats } \\
\text { vitamine deficiency } \\
\text { iron deficiency } \\
\text { prevention drug } \\
\text { adherence to diet } \\
\text { quality of life } \\
\text { endopeptidase } \\
\text { vaccine }\end{array}$ & 1399 & 171 \\
\hline $\begin{array}{l}\text { AG } 4 \\
\text { "Pathologie“ }\end{array}$ & $\begin{array}{l}\text { seronegative celiac disease } \\
\text { (histological) response to gluten- } \\
\text { free diet } \\
\text { critical value of intraepithelial } \\
\text { lymphocytes }\end{array}$ & 238 & 37 \\
\hline $\begin{array}{l}\text { AG } 5 \text { „Refraktäre } \\
\text { Zöliakie“ }\end{array}$ & $\begin{array}{l}\text { refractory sprue } \\
\text { refractory celiac disease } \\
\text { intestinal t-cell lymphoma } \\
\text { enteropathy-associated t-cell lym- } \\
\text { phoma }\end{array}$ & 518 & 87 \\
\hline
\end{tabular}

Titel bewertet und entweder in das Literaturverzeichnis aufgenommen oder verworfen. Die Details dieser Literatursuche sind in $\bullet$ Tab. M-3 dargestellt. Außerdem wurden alle Teilnehmer der Arbeitsgruppen gebeten, zusätzliche, relevante Literatur hinzuzufügen. Die so gefundene Literatur wurde allen Teilnehmern über eine Online-Plattform zur Verfügung gestellt.

Eine systematische Evidenzbewertung der so gefundenen Literatur nach vorher festgelegten Regeln erfolgte nicht.

\section{b) Formulierung der Empfehlungen und strukturierte} Konsensfindung

Die Arbeitsgruppenleiter wurden gebeten, einen Fragenkatalog möglichst klinisch orientierter Fragen zu erstellen. Die Fragen der einzelnen Arbeitsgruppen wurden in einen gemeinsamen Fragenkatalog überführt. Im Sinne eines Delphi-Verfahrens wurden alle an der Erstellung der Leitlinien Beteiligten gebeten, die Fragen aller Arbeitsgruppen zu beantworten. Pro Frage gab es 
5 Antwortmöglichkeiten (ja, eher ja, unentschieden, eher nein, nein). Bei Zustimmung konnte, bei Ablehnung musste ein erläuternder Kommentar geschrieben werde. Die Rückmeldungen wurden zentral gesammelt und die Gesamtergebnisse der Abstimmung und die dazugehörenden Kommentare an die Arbeitsgruppen übermittelt. Das Ziel war es, strittige Punkte bei der Erstellung der Leitlinie zu identifizieren, um diese in den Arbeitsgruppen vor Beginn der Leitlinienkonferenz zu klären. Auf der Basis der Antworten des Delphi-Verfahrens und der Diskussion in den Arbeitsgruppen, erfolgte die Ausarbeitung der Empfehlungen durch die Arbeitsgruppenleiter.

Im Rahmen einer zweitägigen Leitlinienkonferenz wurden diese Empfehlungen zunächst im Sinne eines nominalen Gruppenprozesses innerhalb der Arbeitsgruppen diskutiert und überarbeitet. Zur Erleichterung der Arbeit wurden die Arbeitsgruppen 1 (Diagnostik) und 2 (klinisches Bild) und die Arbeitsgruppen 4 (Pathologie) und 5 (refraktäre Zöliakie) zusammengefasst. Die Arbeitsgruppe 3 (Therapie) diskutierte und überarbeitete die Empfehlungen alleine. Die Diskussionen wurden jeweils von einem unbeteiligten AG-Leiter der Leitliniengruppe oder von dem AWMF-Moderator geleitet, aber nicht inhaltlich beeinflusst. Innerhalb dieser 3 Gruppen wurden die Empfehlungsvorschläge vorgestellt, diskutiert, Änderungsvorschläge aufgenommen und dann vorabgestimmt.

In einer anschließenden Plenarsitzung wurden alle Empfehlungen durch den jeweiligen Arbeitsgruppenleiter vorgestellt und die Hintergründe der Empfehlungen erläutert. Nach Diskussion und ggf. Aufnahme von Änderungsvorschlägen, erfolgte anonym eine finale Abstimmung. Das Abstimmungsergebnis wurde digital protokolliert.

Die Konsensstärken sind in $\bullet$ Tab. M-4 dargestellt.

Nach der Leitlinienkonferenz wurden die einzelnen Empfehlungen von den Arbeitsgruppenleitern mit Kommentaren und Literaturverweisen versehen.

Bei allen Handlungsempfehlungen ist die Stärke der Empfehlung anhand der Formulierung ersichtlich. Die Formulierungen und Bedeutung der Empfehlungsstärken sind in $\bullet$ Tab. $\mathbf{M}-\mathbf{5}$ dargelegt. In allen Kommentaren wurden die Empfehlungen mit der jeweils zugrunde liegenden Literatur verknüpft. Evidenz- oder Empfehlungsgrade wurden in dieser S2k-Leitlinie nicht vergeben (० Tab. M-6).

Bei der Erstellung des Manuskripts hat sich aufgrund einer potenziell besseren Lesbarkeit des Textes eine Umstellung der Ar-

Tab. M-4 Konsensusstärke.

\section{Konsensusstärke}

starker Konsensus

Konsens

Zustimmung von $>95 \%$ der Teilnehme

mehrheitliche

Zustimmung

kein Konsens von $>75-95 \%$ der Teilnehmer

Zustimmung von $>50-75 \%$ der Teilnehmer

Zustimmung von weniger als $50 \%$ der Teilnehmer

Tab. M-5 Empfehlungsstärken.

\begin{tabular}{|l|l|}
\hline Empfehlungsstärke & Formulierung \\
\hline starke Empfehlung & „soll“ \\
\hline Empfehlung & "sollte“ \\
\hline Empfehlung offen & "kann“ \\
\hline negative Empfehlungen werden entsprechend formuliert
\end{tabular}

Tab. M-6 Zeitplan der Leitlinie.

\begin{tabular}{|c|c|}
\hline \multicolumn{2}{|l|}{ Zeitplan } \\
\hline bis Ende Juli 2012 & $\begin{array}{l}\text { Zusammenstellung der Gruppen: Auswahl, Anfra- } \\
\text { gen, Zu-/Absagen (Gruppen und Teilnehmer siehe } \\
\text { Punkt 3) und Anfrage bei den anderen unterstüt- } \\
\text { zenden Fachgesellschaften (siehe Punkt 2) }\end{array}$ \\
\hline bis Dezember 2012 & $\begin{array}{l}\text { Entwurf der Statements UND der begleitenden } \\
\text { Kommentare }\end{array}$ \\
\hline bis Januar 2013 & $\begin{array}{l}\text { Sichtung und Kommentierung der Entwürfe über } \\
\text { Online-Plattform (Delphi) }\end{array}$ \\
\hline bis Mitte April 2013 & Überarbeitung der Statements \\
\hline 26. und 27. April 2013 & 2-tägige Konsensuskonferenz in Berlin \\
\hline bis November 2013 & Erstellung aller Kommentare \\
\hline bis Dezember 2013 & $\begin{array}{l}\text { Fertigstellung des Manuskriptes durch Einarbeitung } \\
\text { der Literatur und Ergänzung des Methodenteils }\end{array}$ \\
\hline bis Februar 2014 & $\begin{array}{l}\text { Begutachtung durch die beteiligten Fachgesell- } \\
\text { schaften }\end{array}$ \\
\hline
\end{tabular}

beitsgruppen ergeben. Die AG 1 „Diagnostik“ und die AG 2 „Klinisches Bild“ wurden getauscht, sodass die Empfehlungen und Kommentare der AG 1 „Diagnostik“ als zweites Kapitel erscheinen.

\section{M-6 Externe Begutachtung und Verabschiedung}

Die Leitlinie wurde allen beteiligten Fachgesellschaften zur Stellungnahme vorgelegt und von diesen verabschiedet. Die endgültige Verabschiedung erfolgte durch die AWMF.

\section{M-7 Verbreitung und Implementierung}

Die Leitlinie wird auf der Homepage der DGVS (www.dgvs.de) und der AWMF (www.awmf.de) zum freien Download zur Verfügung gestellt. Die Langversion der Leitlinie wird in der „Zeitschrift für Gastroenterologie" in deutscher Sprache publiziert. Zusätzlich soll eine Kompaktversion im „Deutschen Ärzteblatt“ in deutscher und englischer Sprache publiziert werden.

\section{M-8 Gültigkeitsdauer und Aktualisierungsverfahren}

Die Gültigkeit der Leitlinie beträgt 5 Jahre. Eine Aktualisierung ist für Mai 2019 vorgesehen und wird über die DGVS Geschäftsstelle koordiniert werden. Eine Überarbeitung der Leitlinie bei veränderter Datenlage erfolgt gegebenenfalls auch früher.

\section{Kapitel 1: Klinisches Bild der Zöliakie einschließlich Begleiterkrankungen, und Spektrum der weizenab- hängigen Erkrankungen (Weizenallergie und Nicht- zöliakie-Nichtweizenallergie-Weizensensitivität) (Arbeitsgruppe 2)}

Die klinischen Symptome der Zöliakie und der entsprechende Schweregrad des Krankheitsbildes können sehr unterschiedlich sein, was die Definition von typischen oder charakteristischen Symptomen, aus denen sich eine Verdachtsdiagnose ableitet, sehr erschwert. Aufgrund der unterschiedlichen Erscheinungsbilder - in diesem Zusammenhang wird auch vom „Chamäleon der Gastroenterologie“ gesprochen - wird die Diagnose einer Zöliakie häufig (zu) spät oder gar nicht gestellt. Auch wird im klinischen Alltag und in der Literatur eine Vielzahl von verschiedenen Bezeichnungen für unterschiedliche Krankheitssituationen verwandet, die teilweise überlappend, teilweise auch widersprüchlich sind. 


\section{Empfehlung 1.1.: Formen der Zöliakie}

Die Zöliakie umfasst potenzielle, subklinische, symptomatische, klassische und refraktäre Formen. Die Bezeichnung „einheimische Sprue“, aber auch die Differenzierung in „overte“, „silente“, „latente“, „atypische“, „asymptomatische“ oder „oligosymptomatische“ Formen sollte nicht mehr verwandet werden.

[starker Konsens, Empfehlung]

Vor diesem Hintergrund schlägt die Konsensuskonferenz auch unter besonderer Berücksichtigung aktueller Ergebnisse einer internationalen Arbeitsgruppe zur Definition der Zöliakie [17] vor, grundsätzlich nur noch zwischen der

a) potenziellen,

b) subklinischen,

c) symptomatischen,

d) klassischen und

e) refraktären

Form zu unterscheiden. Ältere Bezeichnungen wie „overte“ „silente“, „latente“, „atypische“, „asymptomatische“ oder „oligosymptomatische“ Formen sollten nicht mehr verwandet werden. Auch ist der immer noch verwandete Begriff der „einheimischen Sprue des Erwachsenen“ nicht mehr zu gebrauchen (॰ Tab. K-1, K-2).

\section{Klassische und symptomatische Zöliakie}

Unter der Bezeichnung „symptomatische Zöliakie“ werden sowohl Betroffene mit einer „klassischen“ oder „typischen“ Verlaufsform als auch Betroffene mit untypischen Symptomen, z. B. extraintestinalen Symptomen zusammengefasst. Die Bezeichnungen „klassische Zöliakie“ und „typische Verlaufsform“ sind

\begin{tabular}{ll}
\hline $\begin{array}{l}\text { Tab. K-1 } \\
\text { Historische Bezeichnungen }\end{array}$ & Empfohlene Bezeichnung \\
\hline typische Zöliakie & klassische Zöliakie \\
\hline $\begin{array}{l}\text { atypische Zöliakie } \\
\text { overte Zöliakie }\end{array}$ & symptomatische Zöliakie \\
\hline subklinische Zöliakie & subklinische Zöliakie \\
\hline $\begin{array}{l}\text { asymptomatische Zöliakie } \\
\text { silente Zöliakie }\end{array}$ & \\
\hline refraktäre Zöliakie & refraktäre Zöliakie \\
\hline latente Zölialie & potenzielle Zöliakie \\
\hline potenzielle Zöliakie & \\
\hline
\end{tabular}

als Synonyma zu verstehen. Die typische bzw. klassische Zöliakie als gluteninduzierte Enteropathie manifestiert sich mit den Krankheitszeichen der Malabsorption wie Gewichtsverlust, Steatorrhö und Eiweißmangelödemen. Die volle Ausprägung des Krankheitsbilds beim Kleinkind, welches immer noch mit der Zöliakie gleichgesetzt wird, umfasst ein aufgetriebenes Abdomen, voluminöse übelriechende dyspeptische Diarrhön, Muskelhypotrophie, Anorexie und eine Veränderung des Verhaltens. Als typische Hinweise im Kindesalter gelten zudem Eisenmangel, Wesensveränderungen, z.B. Weinerlichkeit, oder eine Wachstumsretardierung („klassische Zöliakie“) [18 - 20]. Die Symptome beginnen meist zwischen dem 1. und 3. Lebensjahr.

Heute hat sich das Erscheinungsbild der Zöliakie jedoch so verändert, dass diese typische Form des Kleinkindes nicht mehr die ist, die am häufigsten beobachtet wird. Die meisten Betroffenen mit symptomatischer Zöliakie leiden unter abdominellen Beschwerden wie Dyspepsie, Flatulenz oder Wechsel der Stuhlgewohnheiten. Auch Schlaflosigkeit, Müdigkeit, Depressionen oder eine Obstipation können Symptome sein. Gelegentlich sind aber auch laborchemische Veränderungen, z. B. eine (leichte) Transaminasenerhöhung oder eine Schilddrüsenfunktionsstörung die einzigen Indikatoren. Die Zahl der Personen, die aufgrund gastrointestinaler Symptome diagnostiziert werden, geht zurück, wohingegen die Zahl der beim Screening von Risikogruppen erkannten Fälle zunimmt [21] ( $\bullet$ Tab. K-3).

Die veraltete Bezeichnung der „atypische Zöliakie“ ergab sich zwangsläufig aus den durch den Begriff „klassische Zöliakie“ beschriebenen Symptomen. So wurden unter der Bezeichnung „atypische Zöliakie“ bei Betroffenen Symptome bzw. Konstellationen wie erhöhte Transaminasen, neurologisch-psychiatrische Veränderungen (z. B. Migräne, Epilepsie, Depression) oder Hautveränderungen einschließlich der Dermatitis herpetiformis Duhring beschrieben. Es wird stattdessen empfohlen den Begriff der symptomatischen Zöliakie zu verwenden. Manchmal sind diese Symptome sehr dezent, sodass der falsche Begriff der „asymptomatischen Zöliakie verwandet wird [22-24]. Unzweifelhaft hat sich das klinische Bild der Zöliakie in den letzten Dekaden verändert, sodass andere Symptome und moderate chronische Mangelzustände (z. B. Anämie, Osteopathie; $\bullet$ Tab. K-4) dominieren. Von verschiedenen Experten wird deshalb auch empfohlen den Begriff „typische Zöliakie“ nicht mehr zu verwenden [25].

\section{Subklinische Verlaufsform}

Betroffene mit „asymptomatischer Zöliakie“, d.h. Betroffene mit zöliakiespezifischer Serologie und typischen Veränderungen in den Dünndarmbiopsien (mind. MARSH 2), weisen auch bei sorg-

\begin{tabular}{|c|c|c|c|c|c|}
\hline & $\begin{array}{l}\text { Malabsorptions- } \\
\text { syndrom }\end{array}$ & $\begin{array}{l}\text { unspezifische } \\
\text { Symptome }\end{array}$ & Zöliakie spezif. AK & HLA & $\begin{array}{l}\text { Marsh } \\
20.3\end{array}$ \\
\hline & & & tTG-AK & DQ2 & \\
\hline & & & & DQ8 & \\
\hline klassische & + & $+1-$ & + & + & + \\
\hline symptomatische & - & + & + & + & + \\
\hline subklinische & - & - & + & + & + \\
\hline $\begin{array}{l}\text { refraktäre } \\
\text { (nur Erwachsene) }\end{array}$ & + & $+1-$ & + & + & + \\
\hline potenzielle & - & - & + & + & - \\
\hline
\end{tabular}

${ }^{1}$ Angelehnt an Ludvigsson et al. Gut 2013 [17]. 
Tab. K-3

\begin{tabular}{|c|c|c|}
\hline & Zöliakie & Weizensensitivität \\
\hline $\begin{array}{l}\text { Zeitraum zwischen } \\
\text { Glutenexposition } \\
\text { und Symptomen }\end{array}$ & Wochen bis Jahre ${ }^{1}$ & Stunden bis Tage \\
\hline Pathogenese & $\begin{array}{l}\text { angeborene und adap- } \\
\text { tive Immunantworten }\end{array}$ & $\begin{array}{l}\text { wahrscheinlich angebore- } \\
\text { ne Immunität gegen z. B. } \\
\text { ATIs; Vermehrung der IEL } \\
\text { möglich (nicht so stark wie } \\
\text { bei klassischer Zöliakie) }\end{array}$ \\
\hline HLA & HLA DQ2 / DQ8 in 99\% & nicht bekannt \\
\hline Antikörper & tTG-Antikörper positiv & $\begin{array}{l}\text { Gliadin-Antikörper (IgA } \\
\text { oder lgG) möglich }\end{array}$ \\
\hline $\begin{array}{l}\text { Dünndarmhistolo- } \\
\text { gie (unter Normal- } \\
\text { kost) }\end{array}$ & MARSH $2-4$ & MARSH $0-1$ \\
\hline Komplikationen & $\begin{array}{l}\text { Komorbiditäten, lang- } \\
\text { fristige Komplikationen } \\
\text { (Lymphomrisiko) }\end{array}$ & noch unklar \\
\hline
\end{tabular}

Einzelne Zöliakiebetroffene können bereits nach Stunden auf Diätfehler mit Durchfall und Bauchschmerzen reagieren.

\begin{tabular}{l} 
Tab. K-4 \\
intestinale Symptome \\
Motilitätsstörungen, von der Diarrhoe bis hin zur Obstipation \\
Übelkeit und Erbrechen, Flatulenz, chronische Bauchschmerzen \\
aufgeblähtes Abdomen \\
extraintestinale Symptome \\
Gewichtsverlust \\
\hline Wachstumsstörung beim Kind \\
\hline Anämie \\
\hline Osteomalazie/Osteoporose, Zahnschmelzveränderungen \\
\hline periphere Neuropathie/Polyneuropathie \\
Tetanie/Muskelschwäche \\
\hline Nachtblindheit \\
\hline Hämatome \\
\hline Ödeme \\
\hline rezidivierende orale Aphten \\
\hline
\end{tabular}

fältiger Anamneseerhebung und körperlicher Untersuchung sowie orientierender Labordiagnostik keine Auffälligkeiten auf. Nach Einleitung einer glutenfreien Diät (GFD) sind in der Regel keine positiven Veränderungen zu beobachten. Von verschiedenen Gruppen wurde für diese Situation auch der Begriff „silente Zöliakie“ gebraucht; dieser erscheint entbehrlich und die Bezeichnung „subklinische Form“ ist zu bevorzugen. Personen mit asymptomatischer Zöliakie werden meist im Rahmen populationsbasierter Screeningprogramme, bei der Testung Verwandter ersten Grades oder bei gezielter Suche nach möglichen Ursachen von Komorbiditäten (siehe auch ๑ Tab. K-5) identifiziert.

Verschiedene Studien haben bei Personen mit „asymptomatischer Zöliakie“ eine verminderte Lebensqualität oder andere Minorsymptome, insbesondere extraintestinale Manifestationen (z.B. Fatigue-Syndrome) [26], nachgewiesen. Diese können sich nach Einleitung einer glutenfreien Diät bessern. Korrekterweise sollte deshalb in diesen Situationen die Bezeichnung „subklinische Zöliakie“ benutzt werden. Andere Studien zur Lebensqualität von Personen mit asymptomatischer Zöliakie weisen diese Einschränkungen nicht nach, was die Empfehlung zur Durchführung bzw. Akzeptanz einer glutenfreien Diät erschwert [27 - 31].

\section{Tab. K-5}

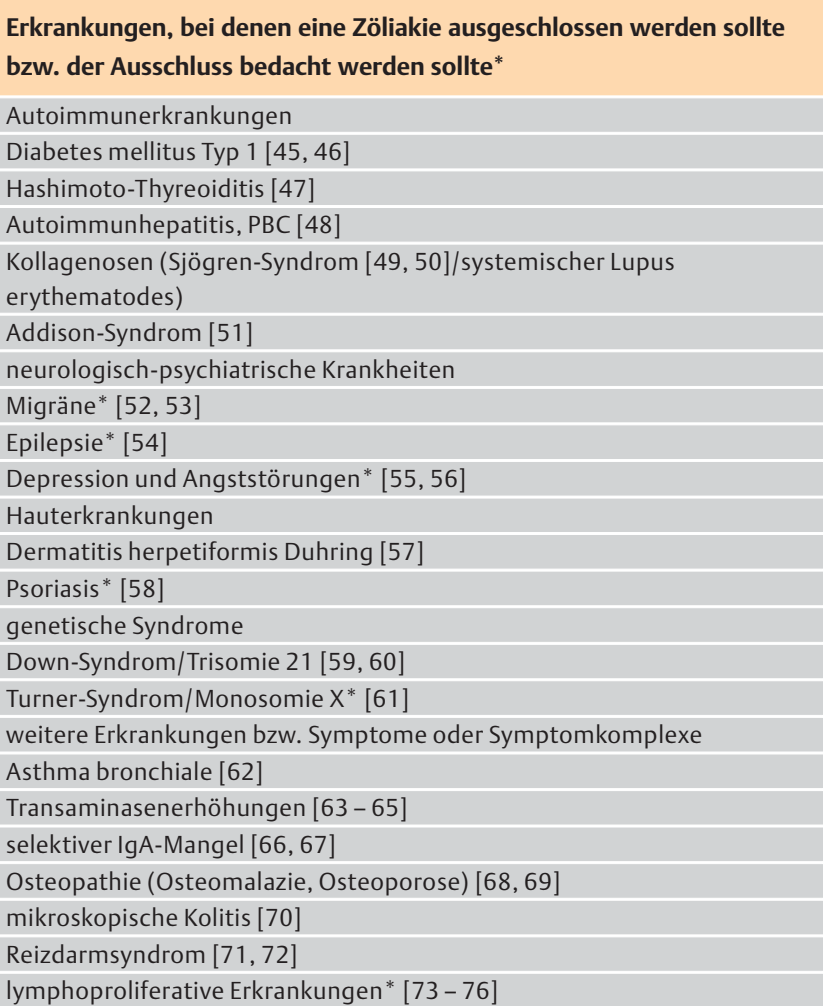

Wahrscheinlich entstehen die Widersprüche durch die Untersuchung verschiedener Patientenkollektive; von Patienten, die entweder gar keine Symptome und normale Laborwerte aufweisen („asymptomatische Zöliakie“) und Patienten, die nur bei sehr sorgfältiger Untersuchungen bzw. Erhebung spezieller Laborwerte krankhafte Veränderungen aufweisen oder nach Einleitung einer GFD eine subjektive Verbesserung ihrer Gesamtsituation verspüren („subklinische Zöliakie“). Typische Beispiele wären Personen mit Wohlbefinden, die lediglich leicht erhöhte Transaminasen aufweisen oder bei denen in einer Mineralsalzdichtebestimmung des Skeletts pathologische Werte auffallen.

\section{Refraktäre Zöliakie}

Eine refraktäre Zöliakie liegt vor, wenn bei Nachweis einer neuen oder persistierenden Zottenatrophie, trotz strikter glutenfreier Diät über 12 Monate, intestinale oder extraintestinale Symptome persistieren oder wieder auftreten. Zur genauen Charakterisierung und Beschreibung des Krankheitsbilds wird auf den Abschnitt 5 „Refraktäre Zöliakie“ verwiesen.

\section{Latente Zöliakie}

In der Literatur existieren teilweise kontroverse Diskussionen zur „latenten Zöliakie“. Von einigen Arbeitsgruppen wird als „latente Zöliakie“ die Konstellation mit positiver zöliakiespezifischer Serologie und aktuell normaler Dünndarmmukosa unter Normalkost, aber Nachweis einer pathologischen Dünndarmhistologie in der Vergangenheit verstanden. Andere verstehen hierunter eine nicht diagnostizierte Zöliakie oder ein Zöliakiepotenzial bei Personen mit anderen Autoimmunerkrankungen. Insgesamt erscheint die Bezeichnung nicht zielführend und sollte deshalb nicht mehr verwandet werden. 


\section{Potenzielle Zöliakie}

Die Bezeichnung „potenzielle Zöliakie“ sollte für Personen verwandet werden, die eine positive, zöliakiespezifische Antikörperkonstellation im Serum aufweisen, bei denen aber die histologische Beurteilung der Dünndarmmukosa einen unauffälligen Befund ergeben hat. Andere Arbeitsgruppen bezeichnen mit dem Begriff „Patienten mit potenzieller Zöliakie“ Personen, die eine positive Serologie haben und bei denen im Duodenum eine erhöhte Anzahl von intraepithelialen Lymphozyten (IEL) (MARSH 1) nachgewiesen werden kann [33] - einer histologischen Konstellation mit geringer Spezifität (siehe Kapitel Pathologie).

Einer aktuellen Untersuchung nach wiesen immerhin knapp 20\% aller Personen mit zöliakiespezifischer Serologie keine Veränderungen im Duodenum auf. Die potenzielle Zöliakie wäre somit eine relativ häufige klinische Konstellation [3]. Jedoch sind derartige Studien problematisch, da die Rate falsch negativer oder falsch positiver Serologien u. a. von der Art des eingesetzten Tests und der Wertung grenzwertiger Titer abhängt.

\section{Weizenallergie}

Genauso wie die Zöliakie ist die Weizenallergie eine immunologische Reaktion gegen Weizenproteine; im Unterschied zur Zöliakie treten hier IgE-vermittelte und/oder T-Zell-vermittelte Reaktionen gegen verschiedene Weizenproteine, u.a. w-5-Gliadin [35], y-Gliadin, Amylase-Trypsin-Inhibitoren (ATIs), Thioredoxin oder Lipid-Transfer-Protein auf. Die Symptome der Weizenallergie können in Mund, Nase, Augen und Rachen (Schwellung, Jucken oder Kratzgefühl), der Haut (atopisches Ekzem, Urticaria), der Lunge (Atemnot, Asthma, Bäckerasthma) oder dem Gastrointestinaltrakt (Krämpfe, Übelkeit, Erbrechen, Blähungen, Diarrhö) auftreten. Die gastrointestinalen Formen der Weizenallergie sind klinisch nicht eindeutig von einer Zöliakie zu unterscheiden. Eine Sonderform ist die eosinophile Ösophagitis, bei der auch Weizen ein Auslöser sein kann. Endoskopisch und histologisch findet sich bei Weizenallergie ähnlich wie bei anderen Nahrungsmittelallergien ein breites Spektrum, das von Normalbefunden, über eosinophile Infiltrate, einer Vermehrung der intraepithelianen Lymphozyten (MARSH 1), nodulärer Hyperplasie mit vermehrten Lymphfollikeln bis zu den eher seltenen Formen, vor allem im Kindesalter, mit Ulzerationen oder Zottenschaden reicht.

\section{Nichtzöliakie-Nichtweizenallergie-Weizensensitivität}

Die Nichtzöliakie-Nichtweizenallergie-Weizensensitivität ist eine Intoleranz gegenüber Weizenbestandteilen. Das klinische Bild kann der Zöliakie ähnlich sein. Möglicherweise sind nicht das im Weizen enthaltene Gluten, sondern die mit glutenhaltigen Produkten assoziierten Amylase-Trypsin-Inhibitoren (ATIs), die zu einer Aktivierung des angeborenen Immunsystem über Toll-like-4-Rezeptoren führen, ursächlich [35]. Möglicherweise besitzen aber auch sog. FODMAPs eine wichtige Bedeutung. Hier handelt es sich um nicht resorbierbare „Fermentierbare Oligo-, Di- und Monosaccharide und (and) Polyole“. Diese natürlicherweise in Nahrungsmitteln vorkommenden Kohlenhydrate könnten auch bei Personen mit Nichtzöliakie-Nichtweizenallergie-Weizensensitivität für die Beschwerden verantwortlich zu machen sein. In einer jüngst publizierten placebokontrollierten Cross-over-Belastungsstudie bei Personen, die auch Reizdarmkriterien erfüllten, konnte kein pathologischer Effekt für Gluten, wohl aber ein günstiger Effekt bei Reduktion der FODMAPs nachgewiesen werden [37].

Sicher ist, dass es sich bei diesem unscharf definierten Krankheitsbild nicht um eine allergische oder autoimmune Erkrankung handelt, bei der der Konsum von weizenhaltigen Produkten Symptome ähnlich jenen der Zöliakie verursachen kann. Zu den gastrointestinalen Symptomen zählen Blähungen, abdominelle Beschwerden, Schmerzen oder Durchfälle; es können aber auch zahlreiche extraintestinale Symptome einschließlich Kopfschmerzen und Migräne, Lethargie und Müdigkeit, Aufmerksamkeitsdefizitstörungen und Hyperaktivität, Muskelbeschwerden sowie Knochen- und Gelenksschmerzen auftreten [4, 38, 39]. Betroffene sollten eine glutenfreie Diät ähnlich wie Zöliakiebetroffene einhalten; aufgrund der wahrscheinlich zentralen Rolle der angeborenen Immunität gegen ATIs ist es jedoch plausibel, dass hier eine weniger strikte glutenfreie Diät möglich ist. Studien hierzu gibt es jedoch noch nicht ( $\bullet$ Tab. K-3).

\section{Empfehlung 1.2.: Formen der Zöliakie}

Es gibt kein klinisches Bild (z. B. Adipositas, Obstipation etc.), das per se eine Zöliakie ausschließt.

[starker Konsens]

\section{Kommentar}

Das klinische Bild der Zöliakie ist durch unterschiedliche mehr oder weniger stark ausgeprägte Symptome gekennzeichnet (siehe - Tab. K-4).

Zum Teil sind Betroffene beschwerdefrei; d. h. es liegt eine subklinische Zöliakie vor. Vor diesem Hintergrund gibt es kein Leitsymptom oder keinen Symptomenkomplex, der dem behandelnden Arzt nahe legt, an eine Zöliakie zu denken. Vielmehr sind primär die differenzialdiagnostischen Überlegungen breit zu führen und somit relativ häufig eine Zöliakie auszuschließen (siehe dazu Kapitel 2, Diagnostik). Häufig wird mit einer Zöliakie ein Gewichtsverlust bzw. Untergewicht assoziiert. Systematische Studien belegen jedoch, dass bei Diagnosestellung $28 \%$ übergewichtig und $11 \%$ sogar adipös sein können [40]. D.h. Übergewicht schließt eine Zöliakie nicht aus. Bei Frauen mit Zöliakie ist häufiger eine Amenorrhö zu beobachten; bez. der Fertilität und der Abortrate gibt es kontroverse Befunde. So beschreiben Choi und Mitarbeiter eine verminderte Fertilität [42], während Tata und Mitarbeiter zwar ein höheres Alter der Mütter bei Geburten, aber insgesamt keine verminderte Fertilität oder erhöhte Abortrate nachweisen [42]. Insgesamt gibt es verschiedene Hinweise, dass bei schwangeren Frauen mit Normalkost ein höheres Gesundheitsrisiko besteht als bei Schwangeren, die eine GFD einhalten. Zu diesen Risiken gehören eine intrauterine Wachstumsretardierung, Untergewicht, Frühgeburtlichkeit und eine höhere Kaiserschnittrate [43]. Keine Risikoerhöhung liegt bei einer Zöliakie des Vaters vor [44].

Unabhängig davon gibt es Komorbiditäten, die gehäuft bei einer Zöliakie auftreten bzw. aufgrund derer Untersuchungen zum Nachweis oder Ausschluss einer Zöliakie durchgeführt bzw. erwogen werden sollen ( $\bullet$ Tab. K-5).

Kritisch angemerkt sei aber an dieser Stelle auch, dass die Summe der Häufigkeiten dieser Komorbiditäten bei konsequenter Umsetzung zum „Screenen“ großer Bevölkerungsgruppen führen würde. Dieses ist in der aktuellen Situation nicht umsetzbar, sodass eine intensivierte „Case-finding-strategy“ wie sie von Catassi et al. beschrieben wurde sinnvoll erscheint [77].

Unabhängig von dieser Einschränkung ist allgemein bekannt, dass bei klassischen Autoimmunerkrankungen wie dem Diabetes mellitus Typ 1, einer Autoimmunthyreoiditis [47] - oder Autoimmunhepatitis [48] das Risiko für eine begleitende Zöliakie signifikant erhöht ist (zur Übersicht siehe Denham 2013 [78]). Insbe- 
sondere ist die Assoziation zwischen der Zöliakie und Personen mit Typ-1-Diabetes-mellitus gut bekannt $[45,46]$. In einer aktuellen Übersicht wird die Zöliakieprävalenz bei pädiatrischen und adulten Typ-1-Diabetikern zwischen 4,4 und $11 \%$ angegeben [79]. Auch ist die Prävalenz von Kollagenosen [80] oder neurologisch-psychiatrischen Erkrankungen (zur Übersicht siehe Cooke Brain 1966 [81]) einschließlich Depression und Angststörungen [55] bei Personen mit Zöliakie erhöht. Eine aktuelle Prävalenzstudie beschreibt für Zöliakiebetroffene ein 3,8-fach erhöhtes Risiko (95\% Vertrauensintervall: 1,8-8,1) an einer Migräne zu erkranken [53]. Eine weitere große epidemiologische Studie, unter Einbeziehung von fast 29000 Zöliakiepatienten und 143000 Kontrollen, beschreibt ein erhöhtes Risiko für die Manifestation einer Epilepsie (Risiko 1,4 [1, 7]) [54].

Auch bei einer Reihe von genetisch-determinierten Syndromen (Down-Syndrom, Turner-Syndrom) ist die Prävalenz der Zöliakie deutlich erhöht [59-61].

Erhöhte Transaminasen sind häufige klinische Befunde, die auch bei Zöliakiebetroffenen zu beobachten sind. Vor diesem Hintergrund sollte in der differenzialdiagnostischen Abklärung erhöhter Transaminasen eine Zöliakiediagnostik durchgeführt werden [63]. Nach Einleitung einer GFD kommt es häufig zu einer Normalisierung der Transaminasen [64]. Selten kann eine Zöliakie mit einer schweren, vital bedrohlichen Lebererkrankung einhergehen [65]. Der IgA-Mangel ist das häufigste Immundefektsyndrom in Deutschland und in der Gesamtbevölkerung mit einer Prävalenz von 1:400 bis 1:800 nachzuweisen. Bei Zöliakiebetroffenen ist der IgA-Mangel deutlich häufiger (ca. 2 - $3 \%$ ) [66, 67]; somit sind Personen mit nachgewiesenem IgA-Mangel auf das gleichzeitige Vorhandensein einer Zöliakie zu untersuchen (siehe dazu Kapitel 2, Diagnostik).

Wenn auch einzelne Untersuchungen für Patienten mit Reizdarmsyndrom (RDS) kein erhöhtes Risiko für eine Zöliakie aufweisen [82], zeigt eine aktuelle Metaanalyse bei Personen mit RDS-Symptomen ein insgesamt etwa 4-fach erhöhtes Risiko für eine Zöliakie auf [71]. Auch weisen Zöliakiebetroffene vor Diagnosestellung ein signifikant höheres Risiko auf, die Diagnose „Reizdarmsyndrom“ zu erhalten bzw. RDS-spezifische Untersuchungen zu erhalten [72]. Weiterhin ist ein Screening von RDSPatienten auf Zöliakie unter Kosten-Nutzen-Aspekten sinnvoll [83]. Eine epidemiologische Studie weist bei Personen mit mikroskopischer Kolitis [70] in ca. 5\% der Fälle auf eine begleitende Zöliakie hin.

Verschiedene Studien beschreiben ein erhöhtes Risiko für lymphoproliferative Erkrankungen bei Personen mit Zöliakie [7376]. Dabei nimmt das Erkrankungsrisiko über die Zeit nach Diagnosestellung ab. Diese Abnahme ist wahrscheinlich auf die glutenfreie Diät zurückzuführen (siehe dazu auch Kapitel 5, refraktäre Zöliakie). Das Lymphomrisiko bleibt allerdings höher als in der Normalbevölkerung [84]; insbesondere bei Personen, bei denen eine Persistenz der Zottenatrophie nachgewiesen wird [25].

Zur Assoziation der Zöliakie mit chronisch-entzündlichen Darmerkrankungen (Morbus Crohn, Colitis ulcerosa) [85], kolorektalen Karzinomen [86], Fibromyalgiesyndrom [87, 88], nicht insulinpflichtigem Diabetes mellitus und dem metabolischem Syndrom [88] sind kontroverse Ergebnisse beschrieben worden.

\section{Empfehlung 1.3.: Dermatitis herpetiformis Duhring}

Die Dermatitis herpetiformis Duhring ist eine Sonderform der Zöliakie, die sich an der Haut manifestiert. Betroffenen Personen soll eine gastroenterologische Mitbetreuung angeboten werden.

[starker Konsens, starke Empfehlung]

\section{Kommentar}

Die Dermatitis herpetiformis Duhring (auch Morbus Duhring) ist eine blasenbildende Autoimmundermatose mit subepidermaler Blasenbildung. Die Erkrankung bietet ein vielfältiges Bild mit herpesähnlich gruppierten Bläschen. Rötungen, Ekzeme und Quaddeln können weitere Veränderungen sein; die Patienten leiden häufig unter starkem brennendem Juckreiz. Meist ist die Haut an Ellbogen und Knie, aber auch die Kopfhaut, die Haut an der Stirn, an Schultern, am Gesäß und im oberen Brustbereich betroffen. Männer sind rund 1,5-mal häufiger betroffen als Frauen. Die Erkrankung tritt v.a. im mittleren Lebensalter auf. Ursächlich scheint die Ablagerung von Komplexen der epidermalen Transglutaminase (eTG) und gegen eTG gerichtetem IgA an der Basalmembran beteiligt zu sein, die zu einer Aktivierung von Komplementfaktoren und einer damit verbundenen Spalt- und Blasenbildung führt $[89,90]$. Bei fast jedem Patienten mit einer Dermatitis herpetiformis Duhring liegt eine meist subklinische Zöliakie als Primärerkrankung zugrunde [57]. Zum Ausschluss einer Malabsorption bzw. anderer Mangelzustände und Komorbiditäten, soll betroffenen Personen eine gastroenterologische Mitbetreuung angeboten werden. Eine Ernährungsberatung mit dem Ziel einer glutenfreien Diät ist auch zur Behandlung der kutanen Primärläsionen sinnvoll.

Neben der Dermatitis herpetiformis Duhring ist bei Zöliakiebetroffenen vor und nach Diagnosestellung das Risiko für die Entwicklung einer Psoriasis um den Faktor 1,7 (95\% Vertrauensintervall: $1,54-1,92)$ erhöht [58].

\section{Kapitel 2: Diagnostik (Arbeitsgruppe 1) \\ $\nabla$}

\section{Empfehlung 2.1.: Klinischer Verdacht}

Bei klinischem Verdacht auf Zöliakie sollen primär die GewebsTransglutaminase-IgA-Antikörper (tTG-IgA-Ak) oder die Endomysium-IgA-Antikörper (EmA-IgA-Ak), sowie das Gesamt-IgA im Serum untersucht werden. Es genügt in der Regel ein spezifischer Antikörpertest.

[starker Konsens, starke Empfehlung]

\section{Kommentar}

Bei der Verdachtsdiagnose einer Zöliakie sind primär serologische Untersuchungen indiziert. Ausreichend hohe Spezifität und Sensitivität bei der Diagnostik der Zöliakie besitzen die GewebsTransglutaminase-IgA-Antikörper (tTG-IgA-Ak) (ELISA) und die Endomysium-IgA-Antikörper (EmA-IgA-Ak) (indirekte Immunfluoreszenz) [13, 91, 92]. Nach der jüngsten Übersicht von Giersiepen et al. liegen die Werte für die vielen auf dem Markt erhältlichen Tests für tTG-IgA-Ak zwischen 74 und 100\% (Sensitivität) und 78 und $100 \%$ (Spezifität). Für die EmA-IgA-Ak liegt die Sensitivität zwischen 83 und $100 \%$ und die Spezifität zwischen 95 und $100 \%$ [91]. 
Die Endomysiumantikörper besitzen auch nach neueren Untersuchungen eine hohe Spezifität und Sensitivität. Es besteht eine Assoziation zwischen der Titerhöhe und dem Grad der Zottenatrophie [93]. In manchen Studien wurden die EmA-IgA-Ak als Bestätigungstest für die Fälle eingesetzt, die zuvor durch ein Screening mit positiven tTG-IgA-Ak entdeckt wurden [94]. Bei der Interpretation der Immunfluoreszenz ist jedoch eine ausreichende Erfahrung des Untersuchers notwendig. Daher sollte die Bestimmung der EmA-IgA-Ak nur durch Labore erfolgen, die diese Antikörper regelmäßig bestimmen und an Ringversuchen teilnehmen (siehe Empfehlung 2.5.). In den neuen europäischen Leitlinien werden die EmA-IgA-Ak als Referenzantikörper bezeichnet, vorausgesetzt, das Labor besitzt eine entsprechende Expertise [13].

Diese Empfehlung gilt für alle Altersgruppen. Bei Kindern unter 2 Jahren sollen primär die gleichen Antikörper (tTG-IgA-Ak, EmA-IgA-Ak) und das Gesamt-IgA bestimmt werden wie bei älteren Kindern bzw. Erwachsenen. Obwohl in vielen Leitlinien für Kinder unter 2 Jahren für die Antikörperbestimmungen gesonderte Empfehlungen ausgesprochen wurden, gab und gibt es dafür keine ausreichende Evidenz. Neuere Studien zeigen eine ähnlich gute Sensitivität und Spezifität für tTG-IgA-Antikörper und EmA-IgA-Antikörper für diese Altersgruppe wie bei älteren Kindern und Erwachsenen [95, 96].

Der vom Labor übermittelte Antikörperbefund sollte nicht nur die Bewertung positiv oder negativ, sondern die genaue Konzentration, das untersuchte Immunglobulin (IgA oder IgG), den Grenzwert und den Hersteller enthalten.

Eine Bestimmung des Gesamt-IgA ist zum Ausschluss eines IgAMangels notwendig, weil bei Vorliegen eines IgA-Mangels Endomysium- und Transglutaminase-IgA-Antikörper nicht nachweisbar sein können (siehe Empfehlung 2.3.).

\section{Empfehlung 2.2.: IgG-dGP-Antikörper}

Die Bestimmung von Antikörpern gegen deamidierte Gliadinpeptide (dGP) kann zurzeit für die Primärdiagnostik nicht empfohlen werden.

[starker Konsens, Empfehlung offen]

\section{Kommentar}

Eine zusätzliche Bestimmung der Antikörper gegen deamidierte Gliadinpeptide (dGP) bringt gegenüber den EmA-IgA-Ak und den tTG-IgA-Ak keinen gesonderten Nutzen. Lediglich bei einem IgAMangel kann die Bestimmung von dGP-IgG-Antikörpern sinnvoll sein (siehe Empfehlung 2.3.). Die diagnostische Signifikanz der IgG-Antikörper gegen deamidierte Gliadinpeptide kann zurzeit nicht abschließend bewertet werden. Es gibt Studien, in denen sie eine sehr niedrige Spezifität aufweisen, auch wenn ihre Sensitivität und Spezifität besser ist als die der Antikörper gegen natives Gliadin. Letztere Antikörper sollten nicht mehr bestimmt werden (siehe Empfehlung 2.4.). Olen et al. beurteilten die kombinierte Bestimmung von tTG-IgA-Ak und dGP-IgG-Ak als nicht sinnvoll [9]. Sie untersuchten 537 Kinder (davon 278 mit Zöliakie) und ermittelten für die dGP-IgG-Ak eine Spezifität von $26 \%$ und einem positiven prädiktiven Wert (PPV) von $51 \%$. Je nach getesteter Population, Selektion und Testvariante fanden sich in anderen Studien eine höhere Sensitivität (65-98\%) und Spezifität (50-100\%) [97-100]. Sie erreichen aber nicht die Werte der tTG-IgA-Ak oder EMA-IgA-Ak [92]. Zudem hängen Sensitivität und Spezifität der dGP-IgG-Ak stark vom verwendeten Antigen ab und sind von Test zu Test unterschiedlich. Die Hersteller geben i. d. R. keine Peptidsequenz der verwendeten deamidierten Gliadinpeptide an. Für eine abschließende Beurteilung sind weitere Studien notwendig. Die dGP-IgA-Ak sind entbehrlich und sollen in keinem Fall bestimmt werden.

\section{Empfehlung 2.3.: Diagnostik bei IgA-Mangel}

Bei erniedrigtem Serum-Gesamt-IgA (unterhalb des Referenzbereichs des Labors bezogen auf das Alter) sollen zusätzlich IgG-Antikörper gegen Gewebs-Transglutaminase (tTG) oder IgG-Antikörper gegen deamidierte Gliadinpeptide (dGP) bestimmt werden.

[starker Konsens, starke Empfehlung]

\section{Kommentar}

Bei der Diagnostik der Zöliakie soll stets ein IgA-Mangel ausgeschlossen werden, da in diesem Fall die tTG-IgA-Ak oder EmAIgA-Ak trotz Vorliegens einer aktiven Zöliakie negativ ausfallen können. Der selektive IgA-Mangel hat in der Gesamtbevölkerung eine Häufigkeit von ca. 0,2\%, bei Personen mit Zöliakie dagegen von $2-3 \%$ [100]. Es gibt keine eindeutigen Studien, inwieweit die IgG-Antikörper nur bei einem nicht nachweisbaren SerumIgA (absoluter IgA-Mangel) oder auch dann bestimmt werden sollten, wenn das IgA erniedrigt, aber nachweisbar ist. Es scheint sinnvoll zu sein, die IgG-Antikörper bereits bei einem, gemessen an den Referenzwerten für das Alter, erniedrigten IgA zu bestimmen [101].

\section{Empfehlung 2.4.: Nicht geeignete Testansätze}

Die folgenden Tests sind zur Diagnostik der Zöliakie nicht geeignet und sollen nicht verwendet werden: Antikörper gegen natives Gliadin, Speichel- und Stuhltests.

[starker Konsens, starke Empfehlung]

Für die Diagnostik werden Blut-Schnelltests nicht empfohlen. Sofern sie durchgeführt worden sind, sollen sie durch die empfohlene serologische Diagnostik (Empfehlung 2.1.) bestätigt werden.

[starker Konsens, starke Empfehlung]

\section{Kommentar}

Die Sensitivität und Spezifität der Antikörper gegen natives Gliadin für die Diagnostik der Zöliakie sind unzureichend [92]. Das gilt auch für Stuhlantikörpertests, die in einer repräsentativen Studie lediglich eine Sensitivität von 10\% erreichten [10]. Während die Schnelltests (Point-of-Care) für tTG-IgA-Ak deutlich besser abschneiden, sind diese Tests nicht quantitativ und haben eine geringere Sensitivität und Spezifität als die ELISAs. Schnelltests sind in keinem Fall ein Ersatz für quantitative serologische Tests oder für eine Biopsie. Die Testergebnisse werden darüber hinaus i.d.R. nicht fachgerecht unter Berücksichtigung der Klinik, des Alters und der Ernährung des Betroffenen beurteilt. In den Übersichtsarbeiten von Leffer et al. und Giersiepen et al. werden Schnelltests ausdrücklich nicht empfohlen [91, 92].

\section{Empfehlung 2.5.: Qualitätssicherung}

Zur Qualitätssicherung sollen Labore, die Antikörper bestimmen, an externen Qualitätskontrollen (Ringversuchen) teilnehmen.

[starker Konsens, starke Empfehlung] 


\section{Kommentar}

Die Bestimmung zöliakiespezifischer Antikörper soll nur in Laboren erfolgen, die zur Sicherung der Qualität regelmäßig an Ringversuchen mit externen Qualitätskontrollen teilnehmen. Die Qualifikationsnachweise sollen einsehbar sein. Dies ist wichtig, da es auf dem Markt eine sehr große Zahl an Tests mit unterschiedlichen Antigenen und unterschiedlicher Qualität gibt (dies betrifft vor allem die tTG- und die dGP-Antikörper). Die Interpretation der Immunfluoreszenz bei der Bestimmung der EmA-IgAAk ist abhängig von der Erfahrung des Untersuchers und von der Regelmäßigkeit, mit der diese Antikörper in dem entsprechenden Labor bestimmt werden. Die Forderung nach einer externen Qualitätskontrolle ist in diesem Fall besonders wichtig.

\section{Empfehlung 2.6.}

Die Diagnostik soll unter einer glutenhaltigen Ernährung erfolgen. Wenn die Person jedoch bereits eine glutenfreie Kost begonnen hat, soll eine Glutenbelastung erfolgen (siehe Empfehlungen 2.7. und 2.8.).

[starker Konsens, starke Empfehlung]

\section{Empfehlung 2.7.: Glutenbelastung}

Die Antikörper sollen bei Kindern und Erwachsenen vor und unter einer Glutenbelastung bestimmt werden. Bei ausgeprägten Beschwerden soll zeitnah eine Biopsie erfolgen. Bei weniger ausgeprägten Beschwerden oder Beschwerdefreiheit sollen die Antikörper frühestens nach 4 spätestens nach 12 Wochen bestimmt werden.

Wenn diese Kontrolle keinen Antikörperanstieg ergibt, soll eine Normalkost empfohlen werden.

[starker Konsens, starke Empfehlung]

\section{Empfehlung 2.8.: Glutenbelastung bei Kindern}

Bei Kinder und Jugendlichen (bis 18 Jahre) sollen unter einer Glutenbelastung die Antikörper alle 6 Monate für 2 Jahre bestimmt werden. Wenn nach 2 Jahren die Antikörper negativ geblieben sind und Symptome fehlen, gilt die Glutenbelastung in der Regel als negativ.

Sicherheitshalber sollte nach 5 und 10 Jahren eine nochmalige Antikörperbestimmung erfolgen.

Bei Erwachsenen sollte keine systematische Nachbeobachtung erfolgen.

[starker Konsens, starke Empfehlung]

\section{Kommentar}

Zum Zeitpunkt der Antikörperuntersuchung muss eine ausreichende Glutenzufuhr sichergestellt sein, weil die Antikörper unter einer glutenfreien Diät bereits negativ geworden sein können. Der Zeitraum, in dem die Antikörper unter einer glutenfreien oder stark glutenreduzierten Diät negativ werden, ist sehr unterschiedlich, er kann Wochen aber auch viele Monate, in einigen Fällen sogar Jahre betragen und hängt von verschiedenen Faktoren ab (initiale Höhe der Antikörper, Grad der Zottenatrophie, genetische Disposition, Diätadhärenz, Sensitivität gegenüber Spuren von Gluten). Esch et al. untersuchten das Verhalten zöliakiespezifischer Antikörper bei Kindern und Jugendlichen mit serologisch und histologisch gesicherter Zöliakie. Sie fanden noch 2 Jahre nach Beginn einer glutenfreien Diät bei $12 \%$ der untersuchten Kinder positive EmA- oder tTG-Antikörper [103]. Dringend abgeraten werden muss daher von einer versuchsweisen glutenfreien Kost vor einer Diagnostik. Ein weiterer wichtiger Grund für diese Empfehlung ist, dass auch bei einem klinischen Ansprechen auf eine glutenfreie Diät die Differenzierung einer Zöliakie von einer Nichtzöliakie-Nichtweizenallergie-Weizensensitivität (siehe Empfehlungen 2.22. und 2.23.) nicht mehr möglich ist.

Wenn Personen bereits eine glutenfreie Diät ohne vorherige Diagnostik begonnen haben, sollte eine Glutenbelastung erfolgen. Wenn die glutenfreie Diät nur kurz durchgeführt wurde (unter 4 Wochen), sind die zöliakiespezifischen Antikörper möglicherweise noch positiv. Negative Antikörper hingegen schließen in diesem Fall eine Zöliakie nicht aus. Eine Glutenbelastung kann auch auf Wunsch von Personen erfolgen, bei denen in der Vergangenheit die Diagnose Zöliakie gestellt wurde und Zweifel an dieser Diagnose bestehen. Auch hier sollte die Glutenbelastung in Absprache mit dem betreuenden Gastroenterologen bzw. Kindergastroenterologen erfolgen. Bei diesen Personen besteht auch die Indikation für eine HLA-Typisierung (siehe Empfehlung 2.14.). Bei Negativität für HLA-DQ2 und -DQ8 ist eine Zöliakie weitgehend ausgeschlossen. Die Betroffenen können eine glutenfreie Diät beenden. Antikörperbestimmungen sind in diesem Fall nicht notwendig.

Es gibt keine sicheren evidenzbasierten Daten für die Dauer der Glutenbelastung und die tägliche Menge an Gluten, die vor einer zuverlässigen Antikörpertestung konsumiert werden sollte, da die immunologische Reaktion auf Gluten bei Personen mit Zöliakie individuell sehr unterschiedlich sein kann. Die o.g. Empfehlungen sind daher ein Kompromiss, mit dem möglichst viele Betroffene erfasst werden können.

Lange Zeit wurde eine Glutenbelastung mit $15 \mathrm{~g}$ Gluten pro Tag (bei Kindern entsprechend adaptiert) über 8-12 Wochen bzw. bis zum Auftreten von Beschwerden vor einer Antikörperdiagnostik empfohlen. Mindestens 2 Mahlzeiten pro Tag sollten Gluten enthalten. Eine jüngste Studie an 20 erwachsenen Zöliakiebetroffenen in (serologischer) Remission konnte jedoch zeigen, dass mit deutlich weniger Gluten ( 3 Gramm pro Tag) bereits nach 4 Wochen $55 \%$ der Betroffenen positive tTG-IgA-Antikörper entwickelt hatten [104].

Die durchschnittliche Nahrung eines Erwachsenen enthält 10-20 g Gluten pro Tag (in einigen Ländern bis zu 40 g). Der Glutengehalt einer Weizenbrotscheibe beträgt etwa 6 - 7\% des Gesamtgewichts. In 6 Scheiben Brot sind etwa 15 Gramm Gluten enthalten. Dieser Wert kann je nach Dicke der Scheibe schwanken.

Empfehlung 2.9.: Diagnostik bei Personen mit erhöhtem Risiko

Personen mit einem erhöhten Risiko (siehe Spezifizierung in - Tab. K-5) für eine Zöliakie soll eine Antikörperbestimmung (siehe Empfehlung 2.1.) angeboten werden.

[starker Konsens, starke Empfehlung]

\section{Kommentar}

Personen mit einem erhöhten Risiko für eine Zöliakie sind insbesondere Verwandte 1. Grades eines Zöliakiebetroffenen (Risiko 10-15\%), Personen mit Diabetes mellitus Typ 1 (Risiko bis zu $9 \%$ ) und Autoimmunthyreoiditis (Risiko bis zu 10\%) und Trisomie 21 [105, 106]. Bei negativen Autoantikörpern kann eine HLA-Typisierung zum Ausschluss einer Zöliakie angeboten werden (siehe Empfehlung 2.14.). Auch Verwandte 2. und höheren 
Grades haben ein etwas erhöhtes Risiko für eine Zöliakie. Bei entsprechenden Symptomen soll die Indikation für eine Diagnostik großzügig gestellt werden. Vor Durchführung einer Diagnostik sollen die Betroffenen über die Implikationen eines positiven, als auch eines negativen Testergebnisses aufgeklärt werden.

\section{Empfehlung 2.10.}

Bei Kindern und Jugendlichen mit Diabetes mellitus Typ 1 sollen bei Diagnosestellung des Diabetes und dann alle 1 - 2 Jahre bis zum 18. Lebensjahr die zöliakiespezifischen Antikörper untersucht werden.

[starker Konsens, starke Empfehlung]

\section{Empfehlung 2.11.}

Erwachsene mit Diabetes mellitus Typ 1 sollten mind. einmal serologisch auf Zöliakie untersucht werden, falls dies in Kindes- und Jugendalter nicht erfolgt ist.

[starker Konsens, Empfehlung]

\section{Kommentar}

Die Prävalenz der Zöliakie bei Personen mit Diabetes mellitus Typ 1 beträgt bis zu 9\% [107]. Die meisten dieser Betroffenen haben keine klassische Zöliakie, viele sind a- oder oligosymptomatisch. Es gibt widersprüchliche Studienergebnisse darüber, ob diese Personen von einer glutenfreien Diät bez. der Einstellung und der Folgen ihres Diabetes mellitus Typ 1 mittel- oder langfristig profitieren. Jüngste Studien legen allerdings nahe, dass sowohl die Insulineinstellung verbessert, wird als auch Spätfolgen wie Arteriosklerose oder Niereninsuffizienz mit einer strikt glutenfreien Diät gemildert werden $[12,108]$. Eine Empfehlung muss auch die langfristigen Folgen einer unerkannten Zöliakie berücksichtigen. In jedem Fall ist das Vorgehen nach Erhalt des Antikörperbefundes individuell mit dem Betroffenen und ggf. mit den Eltern zu besprechen.

Es konnte gezeigt werden, dass eine glutenfreie Ernährung bei Kindern mit Zöliakie und Diabetes mellitus Typ 1 kurzfristig gastrointestinale Symptome und schwere Hypoglykämien reduzierte, während der Insulinbedarf signifikant anstieg [109].

In einer Fallkontrollstudie bei erwachsenen Personen mit Diabetes mellitus Typ 1 wurden diejenigen mit neuentdeckter Zöliakie (Fälle) und diejenigen ohne Zöliakie (Kontrollen) verglichen. Bei Personen mit Diabetes mellitus Typ 1 und bislang unentdeckter Zöliakie fanden sich ein höherer Wert für $\mathrm{HbA}_{1 \mathrm{c}}(8,2$ vs. 7,5\%, $\mathrm{p}=0,05)$ und eine statistisch signifikant höhere Prävalenz mikrovaskulärer Veränderungen (Retinopathie, Nephropathie) als in der Kontrollgruppe [108].

\section{Empfehlung 2.12.}

Bei Personen mit erhöhtem Risiko für eine Zöliakie soll bei deutlich positiver Serologie ( $>3$-fach oberen Grenzwert) eine histologische Untersuchung der Dünndarmschleimhaut erfolgen, um die Diagnose zu sichern. Bei geringer erhöhten Antikörpertitern (<3-fach oberer Grenzwert) und Symptomfreiheit sollte nach 3-6 Monaten zunächst eine serologische Kontrolle erfolgen.

[starker Konsens, starke Empfehlung]

\section{Kommentar}

Der Grund für diese Empfehlung ist, dass bei asymptomatischen Personen mit erhöhtem Risiko für eine Zöliakie, durch z. B. Virusinfektion, transient tTG-IgA-Ak getriggert werden können, ohne dass histologisch eine Zöliakie nachgewiesen werden kann. Bei einem Teil dieser Personen verschwinden diese Antikörper im Verlauf, ohne dass die Betroffenen eine Zöliakie entwickeln [110]. Sollten die Antikörperkonzentrationen wiederholt erhöht, aber unterhalb des 3-fachen oberen Grenzwerts liegen, kann eine Biopsie erwogen werden. Bei leicht positiven tTG-Antikörpern kann ggf. die zusätzliche Bestimmung der EmA-IgA-Antikörper sinnvoll sein.

\section{Empfehlung 2.13.}

Den erstgradigen Verwandten (Eltern, Kindern, Geschwistern) von Zöliakiebetroffenen soll eine Antikörperdiagnostik angeboten werden, auch wenn sie keine typischen Symptome haben. Bei Kindern und Jugendlichen kann diese Diagnostik alle 1 - 2 Jahre und soll beim Auftreten von mit Zöliakie assoziierten Symptomen (siehe $\bullet$ Tab. K-4) wiederholt werden.

Bei Erwachsenen sollte diese Testung einmal erfolgen, weitere Male nur bei mit Zöliakie assoziierten Symptomen.

[Konsens, starke Empfehlung]

\section{Kommentar}

Die Prävalenz der Zöliakie bei Verwandten 1. Grades beträgt zwischen 10 und 15\%. Rubio-Tapia et al. testeten 344 erstgradige Verwandte von Zöliakiebetroffenen und konnten bei $11 \%$ von ihnen eine Zöliakie serologisch und histologisch nachweisen. Etwa die Hälfte dieser Personen hatte eine nach der veralteten Nomenklatur als asymptomatische Zöliakie zu bezeichnende Form [111]. Auch andere Studien ergaben ähnliche Ergebnisse. Viele der primär scheinbar asymptomatischen Personen erfahren nach Beginn einer glutenfreien Diät eine klinische Besserung (subklinische Zöliakie). Kinos et al. fanden bez. der Diätadhärenz, der klinischen Besserung und der Zufriedenheit mit der Diagnose keinen wesentlichen Unterschied zwischen pädiatrischen Zöliakiebetroffenen, die aufgrund von Symptomen oder die durch ein Screening diagnostiziert worden sind [112]. Aus diesem Grund wird die Empfehlung ausgesprochen, auch asymptomatische Verwandte 1. Grades zu testen. Die Empfehlung, bei Kindern auch bei initial negativer Serologie diese im Verlauf zu wiederholen, gründet sich auf Studien, die bei Verwandten eine Serokonversion bei wiederholten Testungen nachweisen konnten [105]. Die Serokonversionsrate dieser Risikogruppe scheint bei Kindern deutlich höher als bei erwachsenen Verwandten zu sein [113], weshalb auch altersabhängige Empfehlungen ausgesprochen wurden.

\section{Empfehlung 2.14 .}

Eine HLA-Typisierung (Bestimmung von DQ2 bzw. DQ8) zum weitgehenden Ausschluss einer Zöliakie kann bei folgenden Personen empfohlen werden:

- Personen/Patienten mit erhöhtem Risiko für eine Zöliakie

- Patienten mit diskrepanten Befunden

- Patienten mit fraglicher Zöliakiediagnose, die längere Zeit ( $>2$ Monate) eine glutenfreie Diät eingehalten haben und bei denen eine Glutenbelastung erwogen wird.

[starker Konsens, Empfehlung offen] 


\section{Kommentar}

25 - 35\% der Bevölkerung sind positiv für HLA-DQ2 oder -DQ8. Daher hat ein Nachweis von HLA-DQ2 oder -DQ8 nur einen niedrigen positiven Vorhersagewert. Eine Negativität für HLA-DQ2 und -DQ8 hingegen schließt eine Zöliakie weitgehend (zu etwa $95-100 \%$ ) aus. Die Bestimmung des HLA-Genotyps kann daher zum Ausschluss einer Zöliakie sinnvoll sein.

In Europa sind ca. 85-90\% der Zöliakiebetroffenen positiv für HLA-DQ2 und ca. 10 - 15\% für HLA-DQ8 [114]. 5 - 6\% der Betroffenen tragen nur ein „halbes“ HLA-Heterodimer, d. h. entweder eine Alpha- oder Beta-Kette des HLA-Heterodimers [114, 115]. In den beiden letztgenannten Studien gab es zudem nur wenige Betroffene (3 bzw. 0,4\%) bei denen weder HLA-DQ2, -DQ8 noch ein Allel für eine einzelne Alpha- oder Beta-Kette nachweisbar waren. Die neuen ESPGHAN-Leitlinien [13] empfehlen primär eine HLA-Typisierung bei Personen mit einem erhöhten Zöliakierisiko. Da aber ein hoher Prozentsatz der erstgradigen Verwandten positiv für die HLA-Risikoallele ist, limitiert dies den Prozentsatz von Personen, bei denen eine Zöliakie ausgeschlossen werden kann. In der Studie von Rubio-Tapia et al. waren z.B. $73 \%$ der erstgradigen Verwandten von Zöliakiebetroffenen positiv für HLA-DQ2 [111]. Allerdings haben Personen mit erhöhtem Risiko für Zöliakie auch häufiger falsch-positive Ergebnisse bei der Messung von Antikörpern gegen tTG, sodass ein negativer Befund für HLA-DQ2 oder -DQ8 hier weitere Antikörperbestimmungen überflüssig machen kann [116]. Da die Interpretation der genetischen Befunde im Einzelfall schwierig sein kann, sollte die Beurteilung durch mit der Genetik der Zöliakie vertraute Gastroenterologen erfolgen.

Diskrepante Befunde ergeben sich vor allem bei sich widersprechenden serologischen und histologischen Ergebnissen.

\section{Empfehlung 2.15.}

Bei Kindern mit klinischen Symptomen und Zeichen der Malabsorption kann unter den folgenden Umständen der Verzicht auf eine Biopsie erwogen und die Diagnose Zöliakie ohne eine histologische Sicherung gestellt werden:

- tTG-IgA-Ak Titer > 10-fachem des oberen Grenzwerk UND

- positiver EmA-IgA-Ak aus einer zweiten unabhängigen Blutprobe UND

- Nachweis von HLA-DQ2 oder -DQ8 UND

- Verschwinden der Symptome unter einer glutenfreien Diät.

Die Entscheidung zum Verzicht auf eine Biopsie soll durch einen Kindergastroenterologen in Absprache mit den Sorgeberechtigten getroffen werden.

[starker Konsens, Empfehlung offen]

\section{Kommentar}

Diese Empfehlung lehnt sich an die neuen ESPGHAN-Leitlinien an [13] und stützt sich auf Studien [117-119], die hohe Spezifitäten (>95\%) für dieses Vorgehen beschreiben. Zu beachten bei dieser Empfehlung ist vor allem, dass sie nur für Kinder mit klinischen Zeichen einer Malabsorption bzw. Symptomen einer Malabsorption (d.h. Zeichen einer klassischen Zöliakie) gilt. Kurppa et al. haben diese Kriterien auch bei 3031 Personen (25\% unter 18 Jahren) mit einem erhöhten Zöliakierisiko, v. a. bei Verwandten 1. Grades, untersucht. Histologisch konnte eine Zöliakie bei 94\% (75/80) der Personen mit stark erhöhten tTG-IgA-Ak (> 100 U) und positiven EmA-IgA-Ak nachgewiesen werden [1209. Diese Personengruppe erfüllt allerdings nicht die klinischen Kriterien für eine klassische Zöliakie. Bei der Entscheidung zur Diag- nose einer Zöliakie ohne Entnahme einer Biopsie, die stets durch einen Kindergastroenterologen gemeinsam mit den Sorgeberechtigten erfolgen sollte, muss berücksichtigt werden, dass die Diagnose eine lebenslange glutenfreie Diät mit allen damit verbundenen Einschränkungen notwendig macht.

Auch bei Erwachsenen gibt es Studien, die unter bestimmten Umständen einen Verzicht auf die Dünndarmbiopsie rechtfertigen $[121,122]$. Die in einzelnen Studien erreichten sehr hohen positiven Vorhersagewerte wurden jedoch immer unter der Annahme sehr hoher Prävalenzen und damit für vorselektierte Personengruppen errechnet [123]. Überwiegend gilt daher die Empfehlung, bei Erwachsenen die Diagnose Zöliakie histologisch zu bestätigen [14].

\section{Empfehlung 2.16.}

Die Diagnose Zöliakie kann sicher gestellt werden bei:

p positiver Serologie UND

positiver Histologie (d. h. MARSH 2 oder 3) UND

- serologischer Besserung unter glutenfreier Diät.

[starker Konsens, starke Empfehlung]

\section{Kommentar}

Für die Diagnose einer Zöliakie gibt es keinen einzelnen beweisenden Test. Die Diagnose einer Zöliakie basiert auf Anamnese, der klinischen Untersuchung, der Antikörperbestimmung und der histologischen Untersuchung von Dünndarmbiopsien [13, 14, 124]. Dazu kommt ggf. eine HLA-Typisierung. Das Kriterium einer serologischen Besserung setzt voraus, dass die Betroffenen langfristig weiterbetreut und serologisch überwacht werden. Bei fehlenden Symptomen (subklinischen Zöliakie) hängt die Sicherheit der Diagnose von der Eindeutigkeit der Serologie (Antikörpertiter > 3-fach über dem oberen Grenzwert) und der Histologie (MARSH 3) ab. Es kann eine subklinische Zöliakie bestehen, bei der erst nach Beginn einer GFD eine Besserung des Allgemeinbefindens bemerkt wird.

Negative zöliakiespezifische IgA-Antikörper bei einer IgA-kompetenten Person bzw. negative zöliakiespezifische IgG-Antikörper bei einer IgA-defizienten Person unter langfristiger glutenhaltiger Diät schließen hingegen eine Zöliakie zum Zeitpunkt der Untersuchung weitgehend aus. Es ist aber nicht ausgeschlossen, dass sich eine Zöliakie im Verlauf entwickeln kann.

\section{Empfehlung 2.17.}

Bei diskrepanten Befunden zwischen Serologie und Histologie soll die Validität der Diagnostik überprüft und die Diagnostik ggf. wiederholt oder erweitert werden.

[starker Konsens, starke Empfehlung]

\section{Kommentar}

Am häufigsten sind Diskrepanzen zwischen positiven Antikörpern und negativer Histologie (d. h. MARSH 0 oder 1, siehe AG 3). Ein mögliches Vorgehen besteht hier in der Untersuchung eines zusätzlichen Antikörpers, z. B. der EmA-IgA-Ak bei positiven tTG-IgA-Ak, aber negativer Histologie [94]. Bei negativer Histologie muss überprüft werden, ob die Biopsien entsprechend der Empfehlung 4.3. in ausreichender Anzahl und unter Einschluss des Bulbus duodeni entnommen worden sind. Ggf. muss die Histologie wiederholt oder ein Referenzpathologe konsultiert werden. Entsprechend Empfehlung 2.14. kann eine HLA-Typisierung sinnvoll sein. Bei positiven Autoantikörpern, negativer Histologie 
(MARSH 0 oder MARSH 1) und Positivität für HLA-DQ2 oder -DQ8 kann es sich in $10-15 \%$ der Fälle um eine potenzielle Zöliakie handeln $[14,17]$. Diese Personen sollen weiter überwacht werden, da sich im Verlauf eine Zottenatrophie entwickeln kann [125].

\section{Empfehlung 2.18.}

Bei der initialen Diagnostik können folgende weitere Laborwerte bestimmt werden: Blutbild, Vitamin $\mathrm{B}_{12}$, Folsäure, Ferritin, Transaminasen, Calcium, Nüchternglucose, Vitamin-DSpiegel (25-OH-Cholecalciferol), alkalische Phosphatase, Zink, Thyreoidea-stimulierendes-Hormon (TSH).

Weitere Autoantikörper sollen nur bei einem klinischen Verdacht bestimmt werden.

[Konsens, Empfehlung offen]

\section{Kommentar}

Personen mit unbehandelter Zöliakie haben gegenüber Personen ohne Zöliakie ein erhöhtes Risiko für einen Mangel an Mikronährstoffen (Vitaminen und Spurenelementen) und für eine Anämie. Es gibt viele Studien, die bei Diagnosestellung einer Zöliakie eine erhöhte Prävalenz für einen Mangel an Eisen, Folsäure, Vitamin- $B_{12}$ und anderen Vitaminen und Spurenelementen gezeigt haben $[125,126]$. Das erhöhte Risiko für eine Osteoporose ist wahrscheinlich v.a. die Folge eines Vitamin-D-Mangels. Die Prävalenz der Osteoporose steigt mit dem Alter und damit der Zeitdauer der Glutenbelastung an [128]. Ebenso korreliert das Ausmaß des Knochendichteschwunds mit dem Schweregrad der Zottenatrophie [129]. Es gibt für eine allgemein akzeptierte Empfehlung zur Untersuchung bestimmter Serumspiegel von Vitaminen und Spurenelementen bei Diagnosestellung einer Zöliakie und im Verlauf wenig Evidenz. Trotzdem scheint es sinnvoll zu sein, initial zusätzlich folgende Laborparameter zu bestimmen: Blutbild, Ferritin, Thyreoidea-stimulierendes-Hormon (TSH), Folsäure, Vitamin $\mathrm{B}_{12}$ und Vitamin D (25-OH-Cholecalciferol). Bei Verdacht auf eine Osteoporose sollten weitere Parameter des Knochenstoffwechsels untersucht werden.

Eine Autoimmunthyreoiditis findet sich bei etwa 4 - 10\% der Personen mit einer Zöliakie. Eine initiale Bestimmung des TSH ist daher sinnvoll. Die Bestimmung schilddrüsenspezifischer Antikörper hingegen hat bei Kindern mit Zöliakie einen geringen PPV für die Entwicklung einer Autoimmunthyreoiditis [130]. Unter einer glutenfreien Diät scheint hier eine regelmäßige Evaluation auf eine Autoimmunthyreoditis nicht notwendig. In einer prospektiven Studie über 2 Jahre an 545 Kindern mit Zöliakie unter GFD und 622 Kontrollen zeigte sich kein Unterschied in der Prävalenz der Autoimmunthyreoiditis zwischen Zöliakiepatienten unter einer Diät und Kontrollen [131].

Die Entscheidung über die Untersuchung zusätzlicher Laborparameter muss der behandelnde Arzt unter Berücksichtigung der Anamnese, Klinik und des körperlichen Befundes individuell treffen.

\section{Empfehlung 2.19.}

Die Kapselendoskopie soll zur Primärdiagnostik nicht eingesetzt werden. Sie ist speziellen Fragestellungen vorbehalten. [starker Konsens, starke Empfehlung]

\section{Kommentar}

Die Kapselendoskopie soll nicht zur Primärdiagnostik eingesetzt werden, da sie keine Entnahme von Biopsien ermöglicht. Bei speziellen Fragestellungen und bei Personen, bei denen aus medizinischen Gründen eine Endoskopie nicht möglich ist, kann sie jedoch sinnvoll sein $[132,133]$. In einer Metaanalyse wurde eine Sensitivität von 89 \% und eine Spezifität von 95 \% für die Diagnose einer Zöliakie mittels Kapselendoskopie errechnet [134].

\section{Empfehlung 2.20.}

Eine Glutenbelastung zur Bestätigung der Diagnose einer Zöliakie ist i.d.R. nicht notwendig. Sie sollte unter folgenden Umständen durchgeführt werden:

- Zweifel an der initialen Diagnose

- negative zöliakiespezifische Antikörper oder untypische Konstellationen in der initialen Diagnostik

- auf Wunsch des Betroffenen/der Sorgeberechtigten

[starker Konsens, Empfehlung]

\section{Kommentar}

Die Empfehlung, auf eine routinemäßige Glutenbelastung zur Diagnosesicherung zu verzichten, betrifft ausdrücklich auch Kinder, bei denen die Diagnose Zöliakie vor Vollendung des 2. Lebensjahrs gestellt wurde [135]. Bei diesen war bislang eine bestätigende Glutenbelastung vor Beginn des Schulbesuchs empfohlen worden. Voraussetzung für den Verzicht ist aber, dass die Diagnose entsprechend den Kriterien dieser Leitlinie gestellt wurde. Unter den unter 2.20 aufgeführten Umständen sollte allerdings eine Glutenbelastung durchgeführt werden. Die Entscheidung für eine Glutenbelastung und deren ärztliche Begleitung sollte bei Kindern immer durch einen Kindergastroenterologen in Absprache mit den Sorgeberechtigten des Kindes erfolgen (Durchführung siehe Empfehlungen 2.7. und 2.8.).

\section{Empfehlung 2.21.}

Nach Ausschluss einer Zöliakie sollte bei Verdacht auf eine Weizenallergie folgende Diagnostik erfolgen:

a) Führen eines Beschwerdetagebuchts

b) Bestimmung von spezifischem IgE gegen Weizen

c) Haut-Prick-Test mit Weizen

[starker Konsens, Empfehlung]

\section{Kommentar}

Weizen gehört zu den stark allergenen Nahrungsmitteln und löst von allen Getreidesorten am häufigsten eine Allergie aus. Kleinkinder, bei denen eine Weizenallergie diagnostiziert wird, entwickeln häufig im Schulalter eine Toleranz gegenüber Weizen [35]. Wenn allerdings hohe IgE-Antikörper gegen Weizen nachweisbar sind, kann die Weizenallergie persistieren. Positive spezifische IgE AK oder ein positiver Haut-Prick-Test auf Weizen erhöht die Wahrscheinlichkeit, dass die Beschwerden Folge einer Allergie sind, beweist für sich alleine aber nicht die Diagnose Weizenallergie. Umgekehrt schließen negative Tests nicht die Diagnose einer Weizenallergie aus. Die Weizenallergie ist von der Zöliakie streng zu unterscheiden. Eine Zöliakie sollte vor Beginn der Weizenelimination immer durch eine negative Zöliakieserologie ausgeschlossen worden sein. Der Goldstandard für die Diagnostik von Nahrungsmittelallergien ist die Besserung oder das Verschwinden der Beschwerden unter einer strikten Allergenkarenz und eine positive, doppelblinde, placebokontrollierte, orale Nahrungsmittelprovoka- 
tion [136]. Bei anamnestisch eindeutig schwerer Sofort- oder lebensbedrohlicher Reaktion und positivem spezifischen IgE sollte auf eine orale Provokation verzichtet werden.

Empfehlung 2.22.

Bei einer weizenabhängigen Klinik und negativer Serologie (für zöliakiespezifische Antikörper), normaler Dünndarmhistologie, negativem spezifischem IgE (Weizen) und negativem Prick-Test (Weizen) kann nach sorgfältigem Ausschluss anderer Diagnosen der Verdacht auf eine Nichtzöliakie-Nichtweizenallergie-Weizensensitivität gestellt werden. [Konsens, Empfehlung offen]

\section{Kommentar}

Die Nichtzöliakie-Nichtweizenallergie-Weizensensitivität (im Folgenden kurz Weizensensitivität) ist bislang nur unzureichend definiert und umfasst alle klinischen, oft zöliakieähnlichen Beschwerden, die durch Weizen ausgelöst werden, ohne dass eine Zöliakie oder eine Weizenallergie vorliegen [17, 137]. Die Weizensensitivität ist eine wichtige Differenzialdiagnose zur Zöliakie. Alle Befunde deuten auf eine angeborene Immunität (Sofortreaktion insbesondere von myeloiden Entzündungszellen z.B. auf Zellwandbestandteile, DNA oder RNA von Bakterien oder Viren) hin. Es wurde bewusst der Begriff Weizensensitivität statt Glutensensitivität (im englischen Sprachraum auch non-coeliac gluten sensitivity, abgekürzt NCGS) gewählt, da nach jüngsten Befunden nicht das Gluten, sondern andere Bestandteile des Weizens und anderer glutenhaltiger Getreide, die Alpha-Amylase-Trypsin-Inhibitoren (ATIs), für die klinische Reaktion (angeborene Immunität) verantwortlich zu sein scheinen [36].

Es gibt noch keinen diagnostischen Test, der eine Weizensensitivität nachweist, weshalb der Ausschluss einer Zöliakie und einer Weizenallergie notwendig sind. Die Weizensensitivität weist im Gegensatz zur Zöliakie keine relevante Assoziation mit bestimmten HLA-Typen auf. Aufgrund der Klinik können die Zöliakie und die Weizensensitivität nicht unterschieden werden [138]. Überlappungen bestehen auch zum Reizdarmsyndrom. Histologisch findet sich oft eine eosinophile Infiltration der Dünndarmmukosa, aber keine Zottenatrophie, weshalb auch Symptome der Malabsorption selten sind [138]. Die weizenabhängige Klinik soll durch ein Beschwerdetagebuch dokumentiert und ggf. durch eine Reexposition erneut provoziert werden. Die Unterscheidung der Weizensensitivität von der Zöliakie und der Weizenallergie ist wichtig, weil sich die Diätempfehlungen und die Prognose unterscheiden (dosisabhängige Klinik bei der Weizensensitivität). Bei ca. 20\% der Personen, bei denen eine Weizenelimination zu einer Besserung der Beschwerden führt, kann eine Unverträglichkeit gegen die sonst unschädlichen FODMAPs (fermentierbare Oligo-, Di-, Monosaccharide und Polyole), primär aus Hülsenfrüchten sowie bestimmten Obst-, Gemüse- und Getreidearten inkl. Weizen, vorliegen [37].

\section{Empfehlung 2.23.}

Bei Kindern und Jugendlichen sollte die Nichtzöliakie-Nichtweizenallergie-Weizensensitivität durch eine doppelblinde, placebokontrollierte Belastung bewiesen oder ausgeschlossen werden, um negative psychosoziale und nutritive Folgen einer strikt glutenfreien Diät zu vermeiden.

[starker Konsens, Empfehlung]*

* Bei der Abstimmung enthielten sich mehrere Nicht-Pädiater.

\section{Kommentar}

Die Diagnostik der Nichtzöliakie-Nichtweizenallergie-Weizensensitivität (im Folgenden kurz Weizensensitivität) sollte in Analogie zur Diagnostik von Nahrungsmittelallergien als Elimination und Provokation durchgeführt werden [136]. Gefordert sind 1. eine Besserung bzw. ein Verschwinden der Symptome unter Weizen-(Roggen-, Gerste-)Karenz und 2. ein reproduzierbares Auftreten der Symptome unter erneuter Belastung. Die Belastung kann zunächst offen oder „single-blind“ durchgeführt werden, wenn anamnestisch keine Hinweise auf eine schwere Sofortreaktion bzw. eine Weizenallergie bestehen. Verläuft die offene Provokation negativ, d.h. treten keine Symptome auf, dann kann eine Weizensensitivität ausgeschlossen werden. Treten Symptome auf, muss durch eine doppelblinde, placebokontrollierte, orale Weizenprovokation die Diagnose bestätigt werden. Die Provokation kann ambulant erfolgen; die Beschwerden sollen in einem Tagebuch dokumentiert werden. Bei der Weizensensitivität sind die Symptome meist innerhalb von Stunden zu erwarten, weshalb z.B. nach zwei Belastungstagen eine Wash-out-Phase von einigen Tagen folgen kann. Entscheidend ist die Blindung, so dürfen sich Aussehen und Geschmack von Verum und Placebo kaum unterscheiden. Dafür sollten Gebäck oder Brot in einer Diätküche zubereitet werden.

\section{Kapitel 3: Therapie (Arbeitsgruppe 3) \\ $\boldsymbol{\nabla}$}

\section{Empfehlung 3.1.}

Indikationen für Diät

Symptomatische Personen (Kinder, Jugendliche und Erwachsene) mit gesicherter Zöliakie sollen unabhängig von möglichen Begleiterkrankungen (z. B. Typ-1-Diabetes, Trisomie 21) mit einer glutenfreien Diät (GFD) behandelt werden.

[starker Konsens, starke Empfehlung]

\section{Kommentar}

Therapieziele einer glutenfreien Diät (GFD) bei symptomatischen Personen mit Zöliakie sind die Besserung oder das Verschwinden gastrointestinaler und extraintestinaler Beschwerden bzw. Komplikationen, Risikoreduktion von Mikro- und Makronährstoffmangel mit ihren Folgen (z. B. Anämie, Osteopenie, Osteoporose, bei Kindern vermindertes Wachstum und verzögerte Pubertät) und von Langzeitkomplikationen (insbesondere Malignome) und Verbesserung der Lebensqualität. Die klinischen Symptome von Personen mit Zöliakie sind vielfältig und altersabhängig. Sie sind meistens Folge der Enteropathie (Zottenatrophie) mit Reduktion der resorptiven Oberfläche, Verminderung der Disaccharidaseaktivität, Inflammation und Störung der von der Darmschleimhaut sezernierten gastrointestinalen Hormone. Eine Normalisierung der Dünndarmarchitektur ist daher eine wichtige Voraussetzung für das Erreichen von Symptomfreiheit und Risikoreduktion für Nährstoffdefizienz und Langzeitkomplikationen. Eine Normalisierung der intraepithelialen Inflammation wird dabei manchmal erst nach Jahren einer GFD oder überhaupt nicht erreicht [139]. Das Ausmaß der Zottenschädigung korreliert hoch signifikant mit gastrointestinalen Symptomen, psychischen Beschwerden, Hämoglobinwerten, Eisen- und Vitamin- $\mathrm{B}_{12}$-Status [140]. Besteht bei Kindern bereits eine Malnutrition, bessert oder normalisiert sich der Ernährungszustand unter einer GFD meist innerhalb weniger Wochen bis Monate [141]. Eine vermin- 
derte Wachstumsgeschwindigkeit normalisiert sich bereits in den ersten 6 Monaten nach Beginn der Diät, häufig ist ein Aufholwachstum mit vorübergehend erhöhter Wachstumsgeschwindigkeit zu verzeichnen [141]. Eine frühe Diagnose und striktes Einhalten der GFD sind wichtige Faktoren für die Endgröße [142]. So kann in Einzelfällen bei erst im späteren Kindes- oder Jugendalter diagnostizierter, aber schon länger bestehender Zöliakie, die genetisch zu erwartende Ziellänge nicht erreicht werden [143].

\section{Empfehlung 3.2. Indikationen für Diät}

Asymptomatische Kinder und Jugendliche mit gesicherter Zöliakie sollen unabhängig von möglichen Begleiterkrankungen (z. B. Typ-1-Diabetes, Trisomie 21) mit einer GFD behandelt werden.

[starker Konsens, starke Empfehlung]

\section{Empfehlung 3.3. Indikationen für Diät}

Erwachsene mit gesicherter, aber subklinischer Zöliakie sollen unabhängig von möglichen Begleiterkrankungen (z. B. Typ-1Diabetes, Schilddrüsenerkrankung) über die Möglichkeit einer GFD informiert werden. Die Vor- und Nachteile sollen mit dem Betroffenen diskutiert werden.

[starker Konsens, starke Empfehlung]

\section{Kommentar}

Subklinische Zöliakiebetroffene (zur Definition siehe dazu Kapitel 1) werden in der Regel durch Screening mittels serologischer Tests identifiziert. Sie gehören häufig einer Risikogruppe an, z.B. Diabetes mellitus Typ 1 oder Verwandte von Personen mit Zöliakie. Asymptomatische Kinder mit Typ-1-Diabetes sind vor Beginn einer GFD im Schnitt kleiner und haben im Vergleich zu gesunden Kontrollen ein erhöhtes Risiko für eine Osteopenie und erhöhte Parathormonwerte [144]. Sonst beschwerdefreie Kinder mit Kleinwuchs als einzigem Zeichen der Zöliakie weisen nach Einführung einer glutenfreien Diät eine verbesserte Wachstumsgeschwindigkeit auf [145]. Frauen mit Ulrich-Turner-Syndrom und subklinischer Zöliakie erreichen unter Wachstumshormontherapie eine geringere Endgröße im Vergleich zu Frauen mit Ulrich-Turner-Syndrom ohne positive Zöliakieserologie [146]. Die Auswirkungen auf die metabolische Kontrolle ( $\mathrm{HbA}_{1 \mathrm{c}}$, Hypoglykämien, Insulinbedarf) einer GFD bei subklinischen Zöliakiebetroffenen mit Typ-1-Diabetes wurde in verschiedenen prospektiven pädiatrischen Fallkontrollstudien mit z.T. widersprüchlichen Ergebnissen untersucht. Zusammenfassend ergaben sich keine statistisch signifikanten Auswirkungen auf die drei untersuchten Parameter nach Einleitung der GFD im Vergleich zu den Kontrollen [145]. Langzeitdaten bez. kardiovaskulärer oder renaler Komplikationen liegen nicht vor. Zusammenfassend gibt es umfangreiche Daten, dass sich auch bei Fehlen von klinischen Symptomen eine unbehandelte Zöliakie bei Kindern und Jugendlichen mit und ohne begleitende Erkrankung ungünstig auf Wachstum und Knochenqualität auswirken kann. Die Vorteile einer GFD bei asymptomatischen Erwachsenen sind weniger ausführlich untersucht worden. Bei Schwangeren kann eine nicht erkannte bzw. nicht behandelte Zöliakie das Risiko für Frühgeburtlichkeit und untergewichtige Neugeborene („small for gestational age“) sowie für Aborte und Totgeburten erhöhen [147, 148]. Es gibt aber auch eine Arbeit, die keine vermehrte Abortrate ausweist [42]. Die Fertilität scheint nicht nur bei Frauen, sondern auch bei Männern eingeschränkt zu sein [149]. Bei den zugrunde liegenden epidemiologischen oder Fallkontrollstudien wurde jedoch nicht immer streng zwischen Personen mit und ohne gastrointestinalen Symptomen unterschieden. Bisher gibt es wenige Daten von durch Screening diagnostizierten erwachsenen subklinischen Zöliakiebetroffenen zur Osteopenie/Osteoporose oder anderen Risiken einer nicht behandelten Zöliakie. Allerdings gibt es Hinweise dafür, dass bei subklinischen Personen mit Zottenatrophie eine erhöhte Gefahr für Osteoporose besteht, welche eine GFD rechtfertigt [150]. In jedem Fall müssen asymptomatische Erwachsene mit diagnostizierter Zöliakie über potenzielle negative Auswirkungen einer unbehandelten Zöliakie auf ihre Gesundheit aufgeklärt werden.

\section{Empfehlung 3.4. Durchfïhrung der Diät}

Die glutenfreie Diät (GFD) soll bei gesicherter Diagnose Zöliakie lebenslang eingehalten werden. [starker Konsens, starke Empfehlung]

\section{Empfehlung 3.5. Durchführung der Diät}

Hafer und daraus hergestellte Produkte ohne Kontamination mit glutenhaltigem Getreide sollen von einer GFD nicht ausgeschlossen werden, wenn unter dem Verzehr keine Beschwerden oder Symptome auftreten.

[starker Konsens, starke Empfehlung]

\section{Kommentar}

Solange keine Alternative zur GFD als wirksame und sichere Behandlung der Zöliakie besteht, soll eine GFD lebenslang und strikt eingehalten werden. Da die Erkrankung als lebenslang gilt, führt die Beendigung der GFD früher oder später zu einem Rezidiv. Bei den wenigen Fallberichten von sogenannter transienter Zöliakie wurde die initiale Diagnose oft zu einem Zeitpunkt gestellt, als eine Testung auf zöliakiespezifische Antikörper noch nicht möglich war $[150,151]$. Auch ist unklar, ob die Toleranzentwicklung bei den wenigen beschriebenen Patienten anhaltend blieb.

Glutenhaltiges Getreide (d.h. Weizen, Dinkel, Grünkern, Roggen, Gerste, Triticale, Khorasan-Weizen [Kamut ${ }^{\circledR}$ ], Emmer, Einkorn) sowie daraus hergestellte Erzeugnisse müssen nach der Allergenkennzeichnungspflicht (EU-Verordnung Nr.1169/2011; Kennzeichnungspflicht für Stoffe oder Erzeugnisse, die Allergien oder Unverträglichkeiten auslösen) ausgezeichnet werden. Von der Allergenkennzeichnungspflicht ausgenommen sind: Glukosesirupe, einschließlich Dextrose und Maltodextrine auf Weizenbasis, Glukosesirupe auf Gerstenbasis und Getreide zur Herstellung von Destillaten oder Ethylalkohol für Spirituosen und andere alkoholische Getränke.

Folgende glutenfreien Getreide sind erlaubt: Hirse, Mais, Reis. Folgende glutenfreien Mehlpflanzen, die z.T. als „Pseudogetreide“ bezeichnet werden, sind erlaubt: Buchweizen, Quinoa, Maniok, Amaranth, Kartoffeln u.a.. Das Hauptrisiko bei dem Verzehr von glutenfreiem Getreide, von Mehlpflanzen und anderen Lebensmitteln ist eine Kontamination im Herstellungs-, Verarbeitungs- und Lagerungsprozess. In einer kanadischen Studie lag der Glutengehalt über dem zugelassenen Wert von $20 \mathrm{mg} / \mathrm{kg}$ (bis zu $7995 \mathrm{mg} / \mathrm{kg}$ ) bei 9,5\% (61 von 649) der getesteten Lebensmittel, die nur von Natur aus glutenfreie Getreide oder Mehlpflanzen enthielten, aber nicht mit dem glutenfreien Siegel gekennzeichnet waren, und nur bei 3 von 269 (1\%) der als glutenfrei deklarierten Produkte [152]. 
Der Begriff „glutenfrei“ impliziert eine komplette Elimination von Gluten, was praktisch kaum möglich ist. Der international anerkannte Codex Alimentarius definiert „glutenfreie“ Nahrungsmittel, wenn der Glutengehalt unter 20 p. p. m. (mg/kg) liegt. Die noch tolerierte Glutenmenge pro Tag, die nach Dosisfindungsstudien nicht oder nur sehr selten zu Schleimhautschäden führt, liegt bei weniger als $10 \mathrm{mg}$ pro Tag bei Erwachsenen, Beschwerdefreiheit vorausgesetzt $[153,154]$. Einige wenige Personen scheinen jedoch bereits bei diesen geringen Tagesmengen Beschwerden zu entwickeln. Auf Nahrungsmittel umgesetzt entsprechen $10 \mathrm{mg}$ etwa 10 Brotbröseln oder einem Drittel eines Croutons oder einem Teil einer Nudel. Für Kinder und Jugendliche wurden keine in Studien etablierten Grenzwerte festgelegt. Es gibt große interindividuelle Unterschiede in der Toleranz kleinster Glutenmengen. Persistieren trotz vermeintlich kompletter GFD die Beschwerden und die Mukosaläsionen, sollte eine erneute Diätberatung mit tatsächlich gut kontrollierter GFD frei von Lebensmitteln mit möglicher Kontamination mit Gluten versucht werden, ehe eine refraktäre Zöliakie diagnostiziert wird [155].

Haferflocken haben nutritive Vorteile durch ihren hohen Gehalt an Faserstoffen und B-Vitaminen, bei niedrigem glykämischen Index. In der Kleinkinderkost haben sie in Deutschland einen hohen Stellenwert. Haferflocken verbessern eine GFD geschmacklich, erhöhen das Sättigungsgefühl, die Variabilität der GFD und damit die Lebensqualität. Sortenreine Haferflocken ohne Glutenkontamination werden von der überwiegenden Mehrzahl von Zöliakiebetroffenen ohne nachteilige Auswirkungen auf die Dünndarmschleimhaut vertragen.

Die Toxizität von Hafer bzw. seinem Prolamin Avenin wurde in den letzten Jahren ausführlich in vivo und in vitro untersucht. Insgesamt ist der Prolamingehalt im Hafer deutlich geringer im Vergleich zum Weizen, Roggen und Gerste. Es wurden aber innerhalb der Aveninfraktion einzelne Epitope identifiziert, die von T-Lymphozyten weniger Zöliakiebetroffener erkannt wurden [156]. Ob diese mit einer vermehrten intestinalen Entzündung korrelieren können, ist unklar. Haferflocken haben jedoch ein hohes Risiko während des Herstellungsprozesses mit Gluten kontaminiert worden zu sein $[157,158]$. Daher sollten nicht als glutenfrei gekennzeichnete Haferflocken und ihre Produkte weder von Erwachsenen noch von Kindern mit Zöliakie verzehrt werden. Inzwischen sind auch in Deutschland produzierte Haferflocken verfügbar, deren Glutengehalt unter 5 ppm liegt [159].

Verschiedene systematische Übersichtsarbeiten von randomisierten kontrollierten Studien und offene Kohortenstudien bei Kindern und Erwachsenen zur Verträglichkeit von Haferflocken bei Zöliakiebetroffenen liegen vor [160-162]. Anschließend wurden weitere Patientenstudien publiziert, die die Verträglichkeit von Hafer bei Zöliakie belegen [159, 163]. Nicht alle Studien wurden mit sortenreinen Haferflocken ohne Glutenkontamination durchgeführt.

Betroffene sind darauf hinzuweisen, dass eine klinische Unverträglichkeit von sortenreinen Haferflocken ohne Glutenkontamination nicht mit einer immunologischen Schädigung gleichzusetzen ist. Beschwerden wie Bauchschmerzen, Blähungen und weichere Stühle sind oft transient und durch den erhöhten Fasergehalt zu erklären. Diätfehler müssen ausgeschlossen werden. Bei Wunsch nach weiterem Haferverzehr trotz Persistenz der Beschwerden sollten Dünndarmbiopsien durchgeführt werden. Kinder und Erwachsene mit Zöliakie, die Haferprodukte in ihrer Kost wünschen, sollten wie alle Betroffene mit Zöliakie regelmäßig überwacht werden. Routinemäßige Rebiopsien sind nach dem jetzigen Kenntnisstand bei Beschwerdefreiheit nicht notwendig.

\section{Empfehlung 3.6. Durchführung der Diät}

Eine laktosereduzierte Diät soll nur dann empfohlen werden, wenn Symptome nach Genuss von laktosehaltigen Nahrungsmitteln auftreten. Die enteropathieassoziierte Laktoseunverträglichkeit ist in der Regel transient.

[starker Konsens, starke Empfehlung]

\section{Kommentar}

Eine Zottenschädigung im Dünndarm führt in der Regel zu einer verminderten Aktivität der in den Mikrovilli lokalisierten Disaccharidasen. Die Laktaseaktvität ist im Vergleich zur Saccharase- und Isomaltaseaktivität störanfälliger. So kann bei unbehandelter Zöliakie und in den ersten Wochen bis Monaten nach Beginn der GFD eine dosisabhängige Laktoseunverträglichkeit auftreten, die ähnliche Symptome wie die Zöliakie verursachen kann (Blähungen, Durchfall). Eine vorübergehende Reduktion von Milchprodukten, oder ein Wechsel auf laktosefreie Produkte empfiehlt sich nur bei symptomatischen Personen. Joghurt und Hartkäse werden meistens vertragen. Falls die Laktoseunverträglichkeit bestehen bleibt, kann eine genetisch bedingte Laktasedefizienz (sog. adulte Form) vorliegen, die durch einen $\mathrm{H}_{2}$-Atemtest belegt oder durch einen genetischen Test ausgeschlossen werden kann $[164,165]$.

\section{Empfehlung 3.7. Durchfïhrung der Diät}

Bei Malnutrition oder klinisch relevantem Mangel an Mikronährstoffen sollte eine adäquate Nährstoffzufuhr und/oder eine Substitution mit Vitaminen oder Spurenelementen durchgeführt werden.

[starker Konsens, Empfehlung]

\section{Kommentar}

Erwachsene und Kinder mit unbehandelter Zöliakie weisen häufiger einen Mangel an Mikronährstoffen im Vergleich zu altersund geschlechtsgleichen Personen ohne Zöliakie auf. Gut dokumentiert sind ein Mangel an Eisen, Folsäure, der Vitamine $A, B_{12}$, $\mathrm{B}_{6}$ und D, Kupfer, Zink und Carnitin [166]. Am besten untersucht ist der Eisenmangel, der durch Malabsorption und okkulte Blutverluste entsteht. Zöliakiebetroffene mit Eisenmangelanämie haben einen höhergradigen Zottenschaden als Betroffene mit Durchfällen [167]. Bei bisher unbekannter oder nicht behandelter Zöliakie ist die Eisenmangelanämie typischerweise refraktär auf orale Eisengaben. Bei Eisenmangelanämie ist neben der strengen GFD in jedem Fall eine Eisensubstitution empfehlenswert, da eine alleinige GFD die Anämie erst nach 6-12 Monaten korrigiert [168]. Bisher liegen keine randomisierten kontrollierten Studien dazu vor, ob eine i.v. Eisengabe einer oralen Gabe überlegen ist, um z.B. das Zeitintervall bis zur Normalisierung der Schleimhaut oder anderer gestörter Funktionen wie Wachstum oder Immunfunktionen zu verkürzen.

Bis zu 75\% der Zöliakiebetroffenen weisen bei Diagnose eine Osteopenie oder Osteoporose, verminderte Vitamin D oder erhöhte Parathormonspiegel auf [169]. Das Ausmaß der Knochendichteverminderung bei Erstdiagnose korreliert mit dem Ausmaß des Zottenschadens [129]. Das Frakturrisiko von Zöliakiebetroffenen liegt ca. $40 \%$ über dem alters- und geschlechtsgleicher gesunder Kontrollen [169]. Vitamin D und Calcium sollten bei verminder- 
ter Knochendichte oder pathologisch erhöhtem Parathormonspiegeln zusätzlich zur GFD substituiert werden. Dies gilt besonders bei verminderter Zufuhr von Milchprodukten (z. B. bei primärem oder sekundärem Laktasemangel) [170]. Unterstützend kann den Betroffenen ein Muskelaufbautraining empfohlen werden [171]. Trotz dieser Maßnahmen normalisiert sich die Knochendichte nicht bei allen Personen unter GFD [170]. Bezüglich weitergehender Informationen sei auf die AWMF S3-Leitlinie „Prophylaxe, Diagnostik und Therapie der Osteoporose bei Erwachsenen“ des Dachverbands Osteologie (DVO) verwiesen [172].

Bei klinisch evidentem bzw. nachweislichem Mangel anderer Mikronährstoffe sollte großzügig oral supplementiert werden. Dies gilt besonders für Kinder mit Wachstumsverzögerung und Erwachsenen mit Untergewicht. Der Bedarf während des Aufholwachstums nach Beginn der GFD kann oft nicht durch eine normale Ernährung gedeckt werden, da die Resorption noch unvollständig ist. Wie auch bei anderen Medikamenten dürfen nur glutenfreie Arzneimittelzubereitungen zur Anwendung kommen (siehe Positivliste der Deutschen Zöliakie-Gesellschaft).

\section{Empfehlung 3.8. Durchführung der Diät}

Eine Ernährungsberatung durch eine Ernährungsfachkraft soll zu Beginn einer GFD durchgeführt und kann im Verlauf wiederholt werden.

[starker Konsens, starke Empfehlung]

\section{Empfehlung 3.9.}

Auf die Möglichkeit der Unterstützung durch eine Selbsthilfegruppe soll hingewiesen werden.

[starker Konsens, starke Empfehlung]

\section{Empfehlung 3.10.}

Eine psychologische Beratung kann in bestimmten Situationen empfohlen werden.

[starker Konsens, Empfehlung offen]

\section{Kommentar}

Eine ausführliche Ernährungsberatung des Betroffenen bzw. der Eltern oder des Lebenspartners durch eine mit der Zöliakie vertraute Ernährungsfachkraft sollte bei Diagnose und bei Bedarf im Verlauf erfolgen. Die GFD erfordert eine umfassende Beratung, insbesondere da Gluten sehr oft in Lebensmitteln versteckt und nicht sofort erkennbar ist. Ernährungsprotokolle von Kindern und Erwachsenen unter GFD und Messungen von Vitaminen und Spurenelementen wiesen häufig eine unzureichende Zufuhr bzw. einen Mangel an Mikronährstoffen auf [173 - 176]. Praktische Hilfe bei Durchführung der GFD für Personen mit Zöliakie wird von der Deutschen Zöliakie-Gesellschaft (DZG) in Stuttgart (Deutsche Zöliakie-Gesellschaft e.V., Kupferstraße 36. 70565 Stuttgart, Telefon 0711/ 459981-0, FAX 0711/459981-50, Email info@dzg-online.de, Internet: (www.dzg-online.de) sowie von der Österreichischen (www.zoeliakie.or.at) und Schweizerischen (www.zoeliakie.ch) Zöliakie-Gesellschaft gegeben. Auch Schulungen, Kochkurse und Treffen in Selbsthilfegruppen mit einem Erfahrungsaustausch von Betroffenen leisten einen wichtigen Beitrag dafür, dass Patienten umfassende Kenntnisse einer GFD erwerben und die Diät einhalten. Die Adhärenz zu einer
GFD ist besonders bei jugendlichen Zöliakiebetroffenen nach Transition in die Erwachsenenmedizin unbefriedigend [177]. In einigen Fällen kann eine psychologische Unterstützung mit Schulungsprogrammen bei der Akzeptanz der GFD helfen [178].

\section{Empfehlung 3.11. Monitoring unter der Diät}

Personen mit Zöliakie unter GFD sollen regelmäßig ärztlich untersucht und der Ernährungsstatus erhoben werden. Die Untersuchung schließt eine Befragung zu Symptomen und zur Einhaltung der Diät, eine körperliche Untersuchung mit Erhebung des BMI und die Bestimmung von zöliakiespezifischen Antikörpern ein. Bei Kindern und Jugendlichen sollen zusätzlich Längenperzentile und die Pubertätsstadien bestimmt werden.

[starker Konsens, starke Empfehlung]

\section{Empfehlung 3.12. Monitoring unter der Diät}

Eine zusätzliche Labordiagnostik kann individuell durchgeführt werden.

[starker Konsens, Empfehlung offen]

\section{Empfehlung 3.13. Monitoring unter der Diät}

Bei klinischen Zeichen oder Symptomen, erhöhten zöliakiespezifischen Antikörpern oder diätassoziierter Malnutrition sollte die Diagnostik individuell erweitert werden und/oder eine erneute Ernährungsberatung erfolgen.

[starker Konsens, Empfehlung]

\section{Kommentar}

Personen mit Zöliakie sollen in regelmäßigen Abständen bez. klinischer Symptome und des Ernährungsstatus ärztlich überwacht werden. Ferner sollten Zöliakiebetroffene auf Komorbiditäten (z. B. Schilddrüsenerkrankungen) oder mögliche Komplikationen untersucht werden. Die Adhärenz zur GFD muss erfragt werden. Bei Kindern sollen die Kontrolluntersuchungen bis zur Beendigung des Wachstums mindestens einmal pro Jahr stattfinden und eine Dokumentation der Gewichts-, Längen- und Pubertätsentwicklung einschließen. Auch bei Erwachsenen scheinen jährliche Kontrollen die Adhärenz zur Diät zu erhöhen. Eine Seropositivität war unter einem solchen Überwachungsprogramm nur bei $1 \%$ der Betroffenen zu beobachten [179]. Allerdings gibt es keine klaren Daten zum Umfang des Monitorings, weshalb die Empfehlungen in verschiedenen Leitlinien variieren [180]. Bevor eine bessere Evidenz vorliegt, scheinen Kontrollen im Jahresabstand sinnvoll [14]. Erneute Biopsien oder eine Knochendichtemessung sind bei beschwerdefreien Betroffenen und normalisierten Laborparametern im Verlauf nicht notwendig. Eine Knochendichtemessung soll aber, unabhängig vom Alter, bei Fraktur mit inadäquatem Trauma in der Anamnese oder anderen Hinweisen auf eine Osteoporose (Knochenschmerzen, Hinweisen auf konventioneller Röntgenaufnahme) durchgeführt werden. Auch bei asymptomatischen Personen kann eine Kontrolle von Blutbild, Ferritin, TSH, evtl. Vitamin D sinnvoll sein.

Das Monitoring schließt Laborbestimmungen wie zöliakiespezifische Antikörper (bevorzugt tTG-IgA-Ak) zur Erfassung der Diätadhärenz ein. Sollten bei der initialen Diagnose EmA-IgA-Ak bestimmt worden sein, sind diese im Verlauf zu kontrollieren. Bei Verdacht auf Mangelzustände, sind Untersuchungen zum Blut- 
bild, Eisenstatus, zu Parametern zur Erfassung einer Thyreoiditis und eines Vitamin-D-Mangels sinnvoll. Die bei Diagnosestellung pathologischen Laborwerte sollen im Verlauf auf eine Normalisierung hin überprüft werden. Abweichungen des Body-Mass-Index (BMI) über die 90. bzw. unter die 10. Perzentile und weiterhin positive tTg-Antikörper (bzw. EmA-IgA-Antikörper) sollten in jedem Alter Anlass für eine erneute Ernährungsberatung und/ oder weiterführende Diagnostik sein.

Unter einer GFD sollten - in Abhängigkeit von der Ausgangskonzentration - die tTG-Antikörper im ELISA innerhalb von 6 Monaten deutlich (mehr als um den Faktor 2) abfallen und nach spätestens 2 Jahren im Normalbereich sein [128, 181]. Werden die Antikörper mit einem Radioimmunoassay (RIA) gemessen, ist länger mit positiven Ergebnissen zu rechnen [182]. Weiterhin positive Werte oder ein erneuter Anstieg weisen auf bewusste oder unbewusste Diätfehler hin. Negative tTG-Antikörper (bzw. EmA-IgA-Ak) sind dagegen keine Garantie für das Einhalten der Diät oder für eine ausgeheilte Schleimhaut. Daher ersetzt die Serologie nicht das Erfragen nach gelegentlichen oder regelmäßigen Diätfehlern. Die zusätzliche Bestimmung anderer zöliakiespezifischer Antikörper (dGP-Ak) liefert keine weiteren Informationen und ist in der Überwachung entbehrlich [13]. Bei anhaltenden oder wiederauftretenden Symptomen sollte, auch bei negativer Serologie, nach Ausschluss anderer möglicher Ursachen eine erneute Endoskopie mit multiplen Biopsien aus der Pars descendens und dem Bulbus duodeni erwogen werden.

\section{Empfehlung 3.14. Andere Therapieoptionen}

Alternative Therapien anstelle der GFD zur Behandlung der Zöliakie sollen außerhalb klinischer Studien nicht durchgeführt werden.

[starker Konsens, starke Empfehlung]

\section{Kommentar}

Momentan gibt es keine Alternative zur Einhaltung einer lebenslangen, glutenfreien Diät, obwohl neue Therapiemöglichkeiten von Zöliakiebetroffenen erwünscht sind. In einer Befragung in England waren bis zu $40 \%$ der Betroffenen mit der Problematik der Einhaltung einer strikt glutenfreien Diät unzufrieden. Alle Befragten waren an neuen Therapieformen interessiert. Bei einer Befragung galt besonderes Interesse der Impfung gegen Zöliakie (42\%), gefolgt von Anti-Zonulin (35\%) und Peptidasen (23\%), während als letzte Option der genmanipulierte Weizen gewünscht wurde [183].

Der Einsatz von oralen Endopeptidasen, glutenbindenden Polymeren, tTG-Inhibitoren, HLA-DQ blockierenden Peptiden oder verschiedenen Biologica (z. B. Anti-IL-15 oder zonulinblockierendes Peptid,) sowie eine Impfung mit immunreaktiven Gliadinpeptiden wird aktuell in zahlreichen Forschungsansätzen, hauptsächlich in vitro, aber z.T. auch in ersten klinischen Studien getestet. In verschiedenen Übersichtsarbeiten werden Stand der Entwicklung, Vorteile und Risiken der Interventionsmöglichkeiten diskutiert [184-186]. Die neuen Therapieformen müssen sich bez. Effektivität und Sicherheit an einer GFD als Referenztherapie messen. Dieses Ziel wird besonders für Medikamente schwer erreichbar sein. Bestimmte Medikamente wie Peptidasen oder Polymere zur Glutenbindung werden eher ergänzend zur Diät eingesetzt werden, um z. B. bei Restaurantbesuchen nicht durch Glutenkontamination in der Zubereitung der Speisen geschädigt zu werden. Bei Drucklegung der Leitlinien war keine der o.g. Therapiemöglichkeiten zugelassen. Daher kann derzeit außer der GFD keine andere Therapie empfohlen werden.

\section{Empfehlung 3.15. Prävention der Zöliakie}

Medikamente zur Primärprävention einer Zöliakie sollen nicht empfohlen werden.

[starker Konsens, starke Empfehlung]

\section{Empfehlung 3.16. Prävention der Zöliakie}

Ernährung im Säuglingsalter: Gluten sollte in kleinen Mengen in die Beikost von Säuglingen eingeführt werden, jedoch nicht vor der 17. und nicht nach der 26. Woche. Es wird empfohlen, dass die Mutter in der Zeit der Gluteneinführung noch stillt. [starker Konsens, Empfehlung]

\section{Kommentar}

Die Zöliakie ist eine stark genetisch determinierte Erkrankung, die fast ausschließlich Personen mit den HLA-Risikogenen DQ2 und/oder DQ8 betrifft. In Deutschland sind das ca. 30\% der Allgemeinbevölkerung, von denen aber weniger als $5 \%$ eine Zöliakie entwickeln. Die Zunahme der Inzidenz in den letzten Jahren weist auf Umweltfaktoren (z. B. Infektionen, Ernährung, psychosoziale Faktoren) als Risiko- oder Schutzfaktoren für die mit einer Zöliakie assoziierten Autoimmunität oder die Zöliakie selbst hin. Bis auf den Einfluss frühkindlicher Ernährung konnten bisher keine weiteren Faktoren identifiziert werden. Generell gilt, dass jede präventive Intervention sicher sein muss, wenn sie bei $95 \%$ der genetisch prädisponierten Personen, die letztlich keine Zöliakie entwickeln, zur Anwendung kommt. Außerdem ist die Zöliakie eine i.d.R. gut und nebenwirkungsfrei behandelbare Erkrankung mit exzellenter Prognose. Damit verbieten sich z. B. Studien oder der Einsatz von immunsuppressiven oder anderen potenziell toxischen Medikamenten zu ihrer Prävention.

Epidemiologische Studien weisen auf den Einfluss der frühkindlichen Ernährung auf das Risiko einer Zöliakiemanifestation im Kindesalter hin, die in einer systematischen Übersichtsarbeit kürzlich zusammengefasst wurden [187]. Studien zum Einfluss des Stillens sind widersprüchlich. So ist unklar, ob Stillen zum Zeitpunkt der Gluteneinführung das Risiko für eine Zöliakie vermindern kann [188]. Eine sehr frühe (vor Beginn des 4. Lebensmonats) und eine späte (nach dem 7. Lebensmonat) Einführung von glutenhaltiger Beikost war mit einem erhöhten Risiko für eine Zöliakie assoziiert [189]. Große Glutenmengen bei Einführung scheinen ebenfalls eine Risikoerhöhung darzustellen [190]. Untersuchungen zweier Geburtskohorten von 1993 und 1997 aus Schweden bestätigen, dass es nach dem jetzigen Kenntnisstand empfehlenswert erscheint, Gluten ab dem 5. Monat und nicht später als dem 7. Monat in kleinen Mengen einzuführen [191]. Diese Hypothese wird zurzeit in einer von der EU geförderten randomisierten, doppelblinden Interventionsstudie bei Kindern überprüft, die den Risikogenotyp aufweisen und aus Familien stammen, bei denen mindestens ein Familienmitglied 1. Grades an Zöliakie erkrankt ist (www.preventcd.de) [192]. Mit den ersten Ergebnissen ist 2014 zu rechnen. 


\section{Empfehlung 3.17.}

Bei Verdacht auf Weizenunverträglichkeit soll eine GFD zu diagnostischen oder therapeutischen Zwecken erst nach Ausschluss einer Zöliakie begonnen werden.

[starker Konsens, starke Empfehlung]

\section{Kommentar}

Die Zöliakie ist eine Erkrankung mit oder ohne Symptome, die nach klaren diagnostischen Kriterien sicher zu diagnostizieren oder auszuschließen ist [13]. Einer Unverträglichkeit von Gluten oder Weizen, die sich mit verschiedenen gastrointestinalen oder extraintestinalen Beschwerden oder einer eosinophilen Ösophagitis oder Gastroenteropathie manifestieren kann, kann eine IgE-vermittelte Weizenallergie (positives weizenspezifisches IgE im Serum oder positiver Haut-Prick-Test mit Weizen) zugrunde liegen [193, 194]. Nahrungsmittelallergien, denen nicht IgE-vermittelte immunologische z.T. zellvermittelte Mechanismen zugrunde liegen, sind für Weizen und anderen Nahrungsmittel wie Milch und Soja seit langem bekannt. Der sog. Atopiepatchtest könnte einen Platz in der Diagnostik haben, er ist jedoch nicht standardisiert [193]. Mangels Biomarkern kann die Diagnose einer IgE-negativen Weizenallergie nur durch Allergenelimination und doppelblinde Weizenbelastung nachgewiesen oder ausgeschlossen werden [136]. Personen mit Weizenallergie können eine Vermehrung der intraepithelialen Lymphozyten in Duodenalbiopsien (entsprechend MARSH 1) aufweisen.

Für die sogenannte Nichtzöliakie-Nichtweizenallergie-Weizensensitivität („non-coeliac gluten sensitivity“) sind weder die Pathomechanismen noch die diagnostischen Kriterien bisher klar definiert. Weizenproteine außerhalb der Glutenfraktion scheinen eine Rolle zu spielen [36]. Oft handelt es sich um eine Selbstdiagnose, d. h. die Betroffenen erfahren eine Besserung ihrer Beschwerden unter einer GFD. Eine doppelblinde Belastung wird von den Betroffenen häufig abgelehnt oder scheitert aus logistischen Gründen. Da die Diagnose einer Zöliakie unter einer GFD nicht mehr möglich sein kann (Verschwinden der zöliakiespezifischen Antikörper, Normalisierung der Schleimhaut), sollte vor Beginn einer GFD bei V.a. Weizensensitivität als Minimum an Diagnostik die Bestimmung von Gesamt-IgA und AntitTG-IgA AK durchgeführt werden. Wenn die Antikörper unter Normalkost negativ sind, ist eine Zöliakie unwahrscheinlich und Duodenalbiopsien sind vor Beginn der GFD nicht zwingend notwendig.

\section{Kapitel 4: Pathologie (Arbeitsgruppe 4)} $\nabla$

\section{Empfehlung 4.1.}

Zur Primärdiagnostik der Zöliakie sollen bei Kindern, Jugendlichen und Erwachsenen Dünndarmbiopsate untersucht werden, sofern nicht die in Empfehlung 2.15. genannte Befundkonstellation vorliegt.

[starker Konsens, starke Empfehlung]

\section{Kommentar}

Die Diagnose der Zöliakie setzt sich aus mehreren Komponenten zusammen:

- Klinische Symptomatik

- Serologische Befunde

- Histologische Befunde

Die Ösophagogastroduodenoskopie mit Entnahme duodenaler Schleimhautbiopsien ist wesentlicher Bestandteil der Primärdiagnostik der Zöliakie bei Kindern, Jugendlichen und Erwachsenen. Die histologische Untersuchung kann dabei primär die Verdachtsdiagnose stellen und die serologische Testung nach sich ziehen, den serologischen Verdacht auf eine Zöliakie bestätigen, oder auch zum Ausschluss bzw. Nachweis möglicher anderer Differenzialdiagnosen dienen $[13,195]$.

Nur unter bestimmten Umständen, die in Empfehlung 2.15. näher erläutert werden, kann ein Verzicht auf die histologische Sicherung der Diagnose durch duodenale Biopsien bei Kindern erwogen werden.

Die Evaluation der Biopsien soll nach den in Empfehlung 4.4. genannten Kriterien erfolgen. Für die optimale Beurteilbarkeit ist die orthograde Einbettung der Biopsate essenziell, da die Zotten-/Kryptenarchitektur sowie das Zotten-/Kryptenverhältnis nur bei orthograder Schnittrichtung beurteilt werden kann [13, $195-198]$.

\section{Empfehlung 4.2.}

Eine erneute Entnahme von Dünndarmbiopsien und ihre histologische Beurteilung sollte zur Verlaufsdiagnostik einer Zöliakie dann durchgeführt werden, wenn trotz strikter GFD kein klinisches Ansprechen zu beobachten ist. [starker Konsens, Empfehlung]

\section{Kommentar}

Fehlendes oder unzureichendes klinisches Ansprechen auf empfohlene glutenfreie Diät wird bei bis zu 30\% der Personen mit diagnostizierter Zöliakie beobachtet $[198,199]$. Wenn ein Diätfehler, die häufigste Ursache der Beschwerdepersistenz [198], ausgeschlossen ist und die Primärdiagnose der Zöliakie überprüft wurde, stellt die erneute Biopsieentnahme aus dem Dünndarm die entscheidende Methode zur Ursachenabklärung der Beschwerdepersistenz dar [200-202]. Der Nachweis einer regelhaften Zottenarchitektur in der Kontrollbiopsie weist auf die Möglichkeit alternativer und/oder additiver Erkrankungen als Ursache der Beschwerden (u. a. Laktoseintoleranz, Pankreasinsuffizienz, mikroskopische Kolitis, für eine Zusammenfassung siehe Rubio-Tapia AJG 2013 [14]) hin. Ein Fortbestehen der Zottenatrophie sollte Anlass zur Überprüfung der Primärdiagnose durch Ausschlussdiagnostik auf zöliakieunabhängige, zottendestruierende Erkrankungen (u. a. Lambliasis, autoimmune Enteropathie, kollagene Sprue) geben. Nach Abarbeitung dieses Algorithmus mit Überprüfung der Primärdiagnose und dem Ausschluss von Zweiterkrankungen ist die Diagnose einer refraktären Zöliakie in Erwägung zu ziehen (siehe Kapitel 5.) [200, 202].

\section{Empfehlung 4.3.}

Für die histologische Diagnostik der Zöliakie sollen mind. 6 Biopsien aus verschiedenen Abschnitten des Duodenums einschließlich Bulbus duodeni und mittlerem und distalem Duodenum (jeweils 2) entnommen werden. [starker Konsens, starke Empfehlung] 


\section{Kommentar}

Die Analyse multipler Biopsien aus verschiedenen Abschnitten des Duodenums ist für eine korrekte Diagnosestellung erforderlich, da die charakteristischen histologischen Veränderungen der Zöliakie (siehe Empfehlung 4.4.) sehr fleckförmig auftreten und in unterschiedlichem Ausmaß vorhanden sein können [4, 13, 195]. Über die Verteilung der Läsionen gibt es kontroverse Beobachtungen [203-205]. Daher wird empfohlen, Biopsate aus dem mittleren und distalen Duodenum sowie aus dem Bulbus duodeni zu entnehmen. In Studien konnte festgestellt werden, dass die höchste Sensitivität bei einer Anzahl von mind. 4-6 Biopsien aus verschiedenen Abschnitten des Duodenums erreicht werden konnte [206 - 208].

\section{Empfehlung 4.4.}

Im Rahmen der histologischen Diagnostik soll die Zotten-/ Kryptenarchitektur nach der Marsh-Oberhuber-Klassifikation und das entzündliche Infiltrat im Schleimhautstroma beurteilt werden. Die Zahl der intraepithelialen Lymphozyten (IEL) soll in Bezug auf 100 Epithelien angegeben werden. Bei einem Schwellenwert von mehr als > 25 IEL pro 100 Enterozyten ist von einer erhöhten Zahl intraepithelialer Lymphozyten auszugehen. Zusätzlich soll die Zotten- und Kryptenarchitektur beurteilt werden.

[starker Konsens, starke Empfehlung]

\section{Kommentar}

Charakteristische histologische Veränderungen der Zöliakie sind:

- partielle oder totale Zottenatrophie,

- Kryptenhyperplasie,

V Veränderungen des Zotten-/Kryptenverhältnisses,

- vermehrte Mitosen in den Krypten,

- vermehrte intraepitheliale Lymphozyten (IEL)

- vermehrte Mitosen in den intraepithelialen Lymphozyten und

- ein vermehrtes Infiltrat aus Plasmazellen, Lymphozyten, eosinophilen und basophilen Granulozyten in der Lamina propria.

Dabei kann ein hoch variables Spektrum histologischer Veränderungen, von der normalen Zotten-/Kryptenarchitektur mit erhöhter IEL-Anzahl bis hin zur kompletten Zottenatrophie, vorhanden sein. Für die Beschreibung dieser Veränderungen sind verschiedene Klassifikationen etabliert [209, 210]. Die MarshOberhuber-Klassifikation [209] hat sich in der Praxis bewährt (siehe $\odot$ Tab. K-6). Sie unterscheidet zwischen infiltrativen, hyperplastischen und atrophischen Läsionen.

Der histologische Bericht soll Aussagen zur Orientierung der Biopsien, zur Zottenarchitektur, dem Zotten-/Kryptenverhältnis, der Anzahl intraepithelialer Lymphozyten und zum entzündlichen Infiltrat der Lamina propria enthalten. Die Veränderungen sollen entsprechend der modifizierten Marsh-Oberhuber-Klassifikation graduiert werden.
Eine Anzahl von mehr als 25 IEL/100 Epithelien ist suggestiv für eine infiltrative Läsion [210 - 213], insbesondere wenn die intraepitheliale Lymphozytendichte ein fehlendes Decrescendo zur Zottenspitze aufweist; der ursprüngliche Grenzwert von mehr als 40 IEL/100 Epithelien in der nicht modifizierten Marsh-Oberhuber-Klassifikation [209] erscheint zu hoch. Hierbei sei jedoch darauf hingewiesen, dass jedweder Grenzwert arbiträr ist und dass insbesondere eine erhöhte Anzahl intrapithelialer Lymphozyten, aber auch die anderen beschriebenen Veränderungen nicht pathognomonisch für eine Zöliakie sind. Als mögliche Differenzialdiagnosen (insbesondere bei infiltrativen Läsionen, MARSH 1) kommen u.a. in Betracht (Übersicht in Rubio-Tapia et al. AJG 2013 [14]):

- virale Enteritiden

- Kuhmilchallergie

- Nahrungsmittelallergien,

- Immundefizienzen

- Giardiasis

- bakterielle Überwucherung.

Daher sollten sämtliche genannten histologischen Veränderungen immer im Kontext der klinischen und serologischen Befunde interpretiert werden.

Immunhistologische Zusatzuntersuchungen (CD3, CD8) können in Grenzfällen hilfreich sein, um intraepitheliale Lymphozyten zu erkennen und in ihrer Verteilung zu beurteilen. Es sei jedoch darauf hingewiesen, dass sich der Grenzwert von 25 IEL/100 Epithelien auf die Quantifizierung der IEL im HE-Schnitt bezieht.

\section{Empfehlung 4.5.}

Bei Hinweisen auf das Vorliegen einer refraktären Zöliakie soll mithilfe immunhistologischer und molekularpathologischer Zusatzuntersuchungen an Dünndarmbiopsien zwischen einer refraktären Zöliakie Typ I und Typ II unterschieden werden. [starker Konsens, starke Empfehlung]

\section{Kommentar}

Die refraktäre Zöliakie ist eine seltene Erkrankung, die bei ca. 1 $2 \%$ aller Zöliakiebetroffenen auftritt [214-216], allerdings für $10-18 \%$ der „therapie-resistenten“ Zöliakiefälle verantwortlich ist [198, 199]. Die Einteilung der refraktären Zöliakie in Typ I und Typ II erfolgt anhand der Charakterisierung der infiltrierenden T- Zellen [217-219], für die ergänzende immunhistologische und molekulare Analysen angewendet werden müssen. Während beim Typ I der refraktären Zöliakie im Allgemeinen keine T-Zell-Klonalität vorliegt und die gleichen Oberfächenantigene (CD3 / CD8) wie bei der unkomplizierten Zöliakie nachgewiesen werden, lässt sich beim Typ II der refraktären Zöliakie mithilfe der PCR gestützten T-Zell-Rezeptor-Analyse eine T-ZellKlonalität sowie immunhistologisch ein Verlust der Oberflächenantigene (CD3 / CD8) in mehr als 50\% der intraepithelialen T-Zellen nachweisen [202, 219]. Immunhistologie und molekulare Pa-

Tab. K-6 Modifizierte Marsh-Oberhuber-Klassifikation mit modifiziertem Grenzwert für die Anzahl intraepithelialer Lymphozyten (IEL).

\begin{tabular}{|c|c|c|c|c|c|c|}
\hline & Typ 0 & Typ 1 & Typ 2 & Typ 3a & Typ 3b & Typ 3c \\
\hline IEL/100Epithelien & $<25$ & $>25$ & $>25$ & $>25$ & $>25$ & $>25$ \\
\hline Krypten & normal & normal & Hyperplasie & Hyperplasie & Hyperplasie & Hyperplasie \\
\hline Zotten & normal & normal & normal & $\begin{array}{l}\text { geringe bis mäßi- } \\
\text { ge Atrophie }\end{array}$ & subtotale Atrophie & totale Atrophie \\
\hline
\end{tabular}


thologie ergänzen sich in ihrer Aussagekraft. T-Zellklonalität und aberranter Immunphänotyp weisen auf eine neoplastische Transformation der T-Lymphozyten hin, sind für sich allein genommen jedoch nicht spezifisch für die refraktäre Zöliakie und können auch - in der Regel transient - bei unkomplizierter Zöliakie unter Glutenbelastung beobachtet werden [220]. Die Kombination aus positivem Klonalitätsbefund und aberranter Antigenexpression hat hingegen eine hohe Spezifität und hohen prädiktiven Wert hinsichtlich der Entwicklung eines enteropathieassoziierten Lymphoms [220]. Es ist davon auszugehen, dass sich ein EATL aus einem aberranten T-Zell-Klon bei refraktärer Zöliakie Typ II entwickelt. Die Grenzen des Übergangs eines solchen T-Zell-Klons in ein beginnendes Lymphoma in situ werden kontrovers diskutiert, die EATL-Diagnose setzt aber weitere, allgemeine Tumorkriterien, vor allem das Vorliegen zytologischer Atypien voraus.

\section{Kapitel 5: Refraktäre Zöliakie, ulzerative Jejunitis und enteropathieassoziiertes T-Zelllymphom (EATL); (Arbeitsgruppe 5) \\ $\nabla$}

Die refraktäre Zöliakie (RCD) zählt mit einer kumulativen Inzidenz von ca. 1,5\% bei Personen mit einer Zöliakie zu den seltenen Erkrankungen [216]. Zumeist sind analog zur unkomplizierten Zöliakie Frauen betroffen [221]. Der Erkrankungsgipfel liegt bei ca. 50 Jahren, wobei auch ein Auftreten unter 30 Jahren beschrieben ist [221]. Verlässliche europäische oder deutsche Daten existieren hierzu nicht. In der Abklärung von Personen mit Symptomen einer RCD ergeben sich häufig andere Ursachen für die Zottenatrophie wie z. B. anhaltende Diätfehler, sodass nach diesen initial gezielt gesucht werden muss [198].

Ein initial nach Diagnose einer Zöliakie erhöhtes Malignomrisiko für diverse Karzinome scheint sich im Laufe der Beobachtungszeit und einer mutmaßlichen GFD dem der Normalbevölkerung anzupassen [25, 74]. Die Normalisierung des Malignomrisikos trifft nicht für Non-Hodgkin-Lymphome und hier vor allem nicht für das enteropathieassoziierte T-Zelllymphom (EATL) (3,5 - 15fach erhöht) zu. Jedoch scheint auch hier eine Verbesserung der Schleimhautmorphologie und damit die Einhaltung einer GFD mit einer Reduktion des Lymphomrisikos einherzugehen [25, $74,222]$. Das initial von Holmes et al. beschriebene massiv erhöhte Risiko (bis zu 70-fach) konnte in den großen populationsbasierten Studien nicht nachvollzogen werden [74, 223].

\section{Empfehlung 5.1.}

Bei Auftreten bzw. Wiederauftreten folgender Symptome sollte an das Vorliegen einer Komplikation einer Zöliakie (refraktäre Zöliakie [RCD], enteropathieassoziiertes T-Zell-Lymphom [EATL], ulzerative Jejunitis [UJ], Adenokarzinom des Dünndarms) gedacht werden:

- persistierende oder wiederaufgetretene Diarrhö (länger als 4 Wochen anhaltend)

- unklarer Gewichtsverlust

- unklare Temperaturerhöhungen

- Leistungsminderung, Müdigkeit

- ungeklärter Nachtschweiß

[starker Konsens, Empfehlung]

\section{Kommentar}

Eine refraktäre Zöliakie (RCD) kann sich primär im Rahmen der Erstdiagnose einer Zöliakie manifestieren oder nach einer Periode initialer Besserung der diagnostizierten Zöliakie unter einer glutenfreien Diät [201].

Die Symptome, die auf eine Komplikation einer Zöliakie (refraktäre Zöliakie [RCD], enteropathieassoziiertes T-Zell-Lymphom (EATL), ulzerative Jejunitis (UJ), Adenokarzinom des Dünndarms) hinweisen können, sind unspezifisch und können z. B. auch im Rahmen von Diätfehlern auftreten [198, 224]. Letztere sind in jedem Fall mittels einer Diätberatung durch eine geschulte Diätassistentin auszuschließen [202]. Weitere Symptome wie eine Anämie, ein Wechsel der Stuhlgewohnheiten (Diarrhö, Obstipation oder im Wechsel), abdominelle Schmerzen oder Vitaminmangelzustände können ebenfalls im Rahmen einer Komplikation auftreten, sind jedoch noch weniger spezifisch.

Das parallele Auftreten von mehr als einem Symptom erhöht die Wahrscheinlichkeit für eine Komplikation der Zöliakie.

EATLs können sich auch ohne weitere Symptomatik durch ein akutes Abdomen oder eine gastrointestinale Blutung manifestieren [225].

\section{Empfehlung 5.2.}

Folgende Befundkonstellation sollte bei der Diagnose einer refraktären Zöliakie vorliegen:

- initial unter Normalkost erhöhte Gewebs-Transglutaminase-IgA-Antikörper (tTG-IgA-Ak) oder Endomysium-IgAAntikörper (EmA-IgA-Ak) Titer

- im Verlauf unter glutenfreier Diät Normalisierung der tTGIgA Ak bzw. EmA-IgA-Ak

- konsequente glutenfreie Diät durch suffiziente Diätberatung bestätigt (Diätassistent)

- persistierende oder erneut aufgetretene Zottenatrophie $>12$ Monate trotz strikter glutenfreier Diät und parallel klinische Symptome

[starker Konsens, Empfehlung]

\section{Kommentar}

Zur Abgrenzung einer RCD von anderen nicht mit der Zöliakie assoziierten Enteropathiesyndromen, sollten bei der Primärdiagnose der Zöliakie die in Empfehlung 2.16. dargelegten Diagnosekriterien vorgelegen haben. Diese Angaben können bei bereits lange zurückliegender Diagnose oder initial nicht lege artis durchgeführter Diagnostik fehlen. Dann ist die RCD als Komplikation einer zugrunde liegenden Zöliakie nicht zu beweisen. Dies ist insbesondere bei initial fehlenden tTG-IgA-Ak der Fall. Eine Testung auf HLA-DQ2 und HLA-DQ8 kann eine zugrunde liegende Zöliakie nicht ausschließen, sondern nur unwahrscheinlich machen (hoher NPV). Zu Definitionszwecken einigte man sich auf eine Dauer von 12 Monaten, die eine RCD nach Ausschluss von wissentlichen Diätfehlern vorliegen muss, um als gesichert zu gelten [201]. Im Einzelfall kann jedoch auch bei kürzer persistierender Zottenatrophie und schwerwiegenden Symptomen mit der Notwendigkeit einer klinischen Intervention von einer RCD ausgegangen und eine Therapie nach entsprechender Diagnostik eingeleitet werden [226]. Sollten klassische zöliakiedefinierende Kriterien wie tTG-Ak oder eine histologische oder klinische Besserung unter einer glutenfreien Diät fehlen, ist die Abgrenzung einer RCD zu nicht zöliakieassoziierten Enteropathiesyndromen schwierig. Eine diagnostische Hilfestellung zur Abgrenzung zu nicht zöliakieassoziierten Enteropathiesyndromen kann der 
Nachweis einer Klonalität im Rahmen einer Klonalitätsanalyse des T-Zellrezeptor-Gens geben, da die Präsenz einer Klonalität aus Duodenalbiopsien eine hohe Spezifität für eine RCD Typ II aufweist [227, 228]. Eine Klonalität des T-Zellrezeptor-Gens wird bei Enteropathiesyndromen ohne vorliegende Zöliakie nicht beschrieben, ist jedoch nicht prinzipiell ausgeschlossen [227]. Ebenso findet sich ein Antigenverlust von CD8 kaum bei Enteropathiesyndromen ohne zugrunde liegender Zöliakie [227]. Häufigste Fehldiagnosen zur RCD Typ I stellen in den Arbeiten von Abdulkarim et al. und Leffler et al. unbeabsichtigte Diätfehler dar. Daher sind Diätfehler in jedem Fall auch mittels einer Diätberatung durch eine geschulte Diätassistentin auszuschließen [198, 199].

\section{Empfehlung 5.3 .}

Folgende Laborparameter sollen bei (V.a.) RCD bestimmt werden:
A) Ferritin
B) Differenzialblutbild
C) Laktatdehydrogenase (LDH)
D) Beta-2-Mikroglobulin
E) Albumin
[starker Konsens, starke Empfehlung]

\section{Kommentar}

Im Rahmen der Diagnostik einer RCD müssen zum einen Komplikationen, die im Rahmen einer Malabsorption auftreten können, zum anderen eine ulzerative Jejunitis oder ein enteropathieassoziiertes T-Zell-Lymphom weitestgehend ausgeschlossen werden. Im Rahmen der Malabsorptionsdiagnostik sollten primär zum Ausschluss eines latenten Eisenmangels bzw. einer Knochenmarksinfiltration durch ein EATL-Ferritin und ein Differenzialblutbild bestimmt werden. In der weitergehenden Diagnostik können Parameter wie sie auch bei der Primärdiagnostik der Zöliakie empfohlen werden, z. B. Vitamin $B_{12}$, Zink, INR und Vitamin D (25-Hydroxy-Cholecalciferol) (siehe Empfehlung 2.18.), untersucht werden.

Die Differenzialdiagnostik zu einem sich entwickelnden Lymphom bzw. Diätfehlern bei unkomplizierter Zöliakie umfasst die Bestimmung von Proliferationsmarkern (LDH, Beta-2-Mikroglobulin) wie sie auch zur Lymphomdiagnostik empfohlen werden. Zwar existieren keine Studien über einen direkten Vergleich von LDH und Beta-2-Mikroglobulin zur Diskriminierung von RCD I, RCD II und einem EATL, jedoch sind beide Parameter Bestandteil verschiedener Scores zu Prognoseabschätzung und Therapieplanung bei Non-Hodgkin-Lymphomen (LDH: z. B. im internationalen Prognoseindex [IPI]) [229, 230]. Albumin kann als Verlaufsparameter für den Ernährungszustand bestimmt werden und scheint einen prognostischen Wert bei Entwicklung eines EATL aufzuweisen [230].

\section{Empfehlung 5.4.}

Folgende Untersuchungen sollen initial bei dem klinischen Verdacht auf das Vorliegen einer refraktären Zöliakie durchgeführt werden:

- tiefe Duodenalbiopsien inkl. Immunhistologie (CD8, T-Zellrezeptor- $\beta$ ) und Molekularpathologie (T-Zellrezeptor-Klonalitätsanalyse)
- Schnittbildgebung (Frage: Lymphknotenvergrößerung), ggf. Dünndarmendoskopie (Frage: Ulzerationen)

- Koloskopie (inkl. Biopsien aus dem terminalen Ileum)

[starker Konsens, starke Empfehlung]

\section{Kommentar}

Die Diagnose einer RCD basiert primär auf dem Vorliegen einer Dünndarmzottenabflachung (MARSH 3). Das alleinige Vorliegen einer MARSH-1 oder MARSH-2-Veränderung reicht zur Diagnose nicht aus, da v.a. MARSH-1-Befunde bei Personen ohne Beschwerden in bis zu $24 \%$ der Fälle nach 2 Jahren glutenfreier Diät vorkommen [231]. Spätestens bei der Rebiopsie zur Evaluation nach Diätberatung sollte eine Immunhistologie mit Färbung von CD8 und T-Zellrezeptor- $\beta$ erfolgen. Eine Differenzierung zwischen einer RCD I und RCD II basiert auf Immunhistologie bzw. FACS-Analyse isolierter duodenaler intraepithelialer Lymphozyten (IELs) und dem Nachweis einer Population klonaler IELs (Klonalitätsanalyse des T-Zellrezeptor-Gens aus Duodenalbiopsien) [215, 227, 227]. Ob die FACS-Analyse isolierter duodenaler IELs zu einer signifikant besseren Diskriminierung zwischen RCD I und RCD II führt, ist umstritten. Ein direkter Vergleich wurde bisher nicht geführt. Aktuell wird eine RCD II definiert durch das Vorliegen von mehr als $20 \%$ sog. aberranter IELs (u.a. CD3 und CD8-negativ) in der FACS-Analyse und dem parallelen Nachweis einer T-Zellrezeptor-Klonalität [232]. Alternativ zur FACS-Analyse kann die Diagnose auf Basis einer immunhistologischen Vermehrung CD3- und CD8-negativer IELs auf mehr als 50\% etabliert werden [227]. Die vermutlich bessere Diagnostik der FACS-Analyse könnte u. a. darauf beruhen, dass der Nachweis einer intrazytoplasmatischen Lokalisation des CD3-Markers bei der RCD II immunhistologisch nicht immer eindeutig gelingt [232].

Zur kompletten Ausbreitungsdiagnostik gehören eine Koloskopie mit Intubation des terminalen Ileums und Stufenbiopsien zur weiteren Differenzialdiagnostik. In Einzelfällen können Ulzerationen, die bei RCD II eine ulzerative Jejunitis definieren, lediglich in der Koloskopie mit Ileoskopie nachgewiesen werden [233]. Eine Schnittbildgebung, bevorzugt eine Dünndarm-MRT, kann neben einer Abschätzung der Dünndarmwandschichtung vergrößerte abdominelle Lymphknoten, eine Milzatrophie oder andere extraintestinale Pathologien nachweisen. Diese sind häufiger mit einer RCD II oder einem EATL assoziiert als mit einer RCD I oder der unkomplizierten Zöliakie [234]. Im Falle der Detektion einer der genannten Befunde sollte eine weitere intensivierte endoskopische Abklärung mit dem Ziel der Materialgewinnung erfolgen, da sich hier Manifestationen eines EATL oder einer UJ ergeben können [233, 235].

Eine Prognoseabschätzung sollte aufgrund der o.g. Befunde durchgeführt werden. Negative prognostische Faktoren sind die Diagnose einer RCD II, der Nachweis von Dünndarmulzerationen (dann definitionsgemäß ulzerative Jejunitis) und das Ausmaß der Ausbreitung der aberranten IELs [217, 232]. 


\section{Empfehlung 5.5 .}

Bei refraktärer Zöliakie Typ II soll folgende spezifische Diagnostik durchgeführt werden:

- Enteroskopie (Ballonenteroskopie) und Entnahme von Stufenbiopsien

- Videokapselendoskopie

- bei vergrößerten abdominellen Lymphknoten, Entnahme bzw. Probebiopsie der vergrößerten Lymphknoten

- ggf. bei unklarem Befund Laparotomie/Laparoskopie/intraop. Enteroskopie

[starker Konsens, starke Empfehlung]

\section{Kommentar}

Bei Nachweis einer RCD II sollte eine Dünndarmbildgebung zur Abgrenzung einer ulzerativen Jejunitis durchgeführt werden, da die ulzerative Jejunitis eine schlechtere Prognose aufweist als eine RCD II [217]. Hierzu bieten sich Kapselendoskopie oder Enteroskopie an. Die Enteroskopie weist den Vorteil einer möglichen histologischen Sicherung auf, die Kapselendoskopie gewährt jedoch eine umfassendere Einsicht [233, 236, 237]. Die Kapselendoskopie erbringt bei klarer RCD I keine oder nur eine sehr geringe Rate an neuen Erkenntnissen, die zu einer Therapieänderung führen [233, 238]. Da die Einnahme von nicht steroidalen Antirheumatika (NSAR) oder Acetylsalicylsäure (ASS) eine ulzerative Jejunitis vortäuschen kann, müssen diese ca. 4 Wochen vor der Durchführung der Kapselendoskopie abgesetzt werden [238]. Kapselendoskopie und radiologische Schnittbildgebung ergänzen sich, da durch eine zuerst durchgeführte Schnittbildgebung evtl. Stenosen, die eine Kontraindikation zur Anwendung der Kapselendoskopie darstellen, detektiert werden können [233, 239]. In Einzelfällen können eine Laparotomie zur Durchführung einer intraoperativen Intestinoskopie bzw. eine Laparoskopie mit Entnahme von vergrößerten Lymphknoten oder deren Biopsie notwendig werden [233]. Der alleinige Nachweis vergrößerter abdomineller Lymphknoten hat eine geringe diagnostische Wertigkeit, da dies sowohl bei der unbehandelten Zöliakie, der RCD I wie RCD II vorkommen kann [233, 240].

Zur 18-FDG-PET gibt es bisher lediglich die Studie eines einzelnen Zentrums, die eine etwas höhere Sensitivität zur Detektion eines EATL im Vergleich zur konventionellen Computertomografie zeigte [241].

\section{Empfehlung 5.6.}

Bei vorliegender therapiebedürftiger Symptomatik bei RCD I können folgende Therapeutika zum Einsatz kommen:

- Budesonid

- Azathioprin

oligopeptidbasierte Sonden-/Trinknahrung

- Calcineurininhibitor

- Anti-TNF-alpha-Antikörper

[starker Konsens, Empfehlung offen]

\section{Kommentar}

In Abhängigkeit von der Symptomatik und der Diagnose (RCD I versus RCD II) erfolgt die Therapie stufenweise. Prinzipiell sollte immer neben einer evtl. immunsuppressiven Therapie (RCD I) oder antineoplastischen Therapie (RCD II) die Verbesserung der Ernährungssituation angegangen werden. Hierzu können orale (ggf. auch über Anlage einer Ernährungssonde) oder parenterale Formen der Zusatzernährung zum Einsatz kommen. Bei der RCD I scheint eine Oligopeptiddiät einen eigenständigen therapeutischen Wert für die Verbesserung der Grunderkrankung zu haben [242]. Zwei retrospektive Arbeiten belegen den Wert einer Budesonidgabe bei beiden RCD-Entitäten [243, 244]. Gerade auch bei älteren oder multimorbiden Personen mit einer RCD II, die sich nicht für eine intensivere antineoplastische Therapie qualifizieren, scheint Budesonid eine wirksame und relativ nebenwirkungsarme Alternative darzustellen. Entocort ${ }^{\circledR}$ hat hier die bessere Bioverfügbarkeit im oberen Dünndarm im Vergleich zu anderen Budesonidpräparaten [19].

Zur Therapie der RCD I kommen primär Azathioprin bzw. Thioguanin zum Einsatz [245, 246]. Sie können auch mit lokal wirksamen oder systemischen Steroiden kombiniert werden. Eine immunsuppressive Therapie mit Azathioprin sollte hingegen bei der RCD II in keinem Fall begonnen werden. In einer der wenigen prospektiven Studien unter Azathioprin kam es bei RCD II zu einem raschen Progress zu einem EATL [245]. In Rezidivfällen bei RCD I oder bei primärer Unwirksamkeit von Azathioprin/Thioguanin gibt es neben einer prospektiven Studie zu Cyclosporin nur Einzelbeschreibungen zu Tacrolimus und Infliximab [247, 248]. Lediglich eine retrospektive Einzelfallsammlung zeigte in ca. $50 \%$ der Patienten mit einer RCD I unter Mesalazin ein klinisches und histologisches Ansprechen. In der Studie erhielten allerdings mehr als die Hälfte der Personen parallel Budesonid, sodass eine Aussage zur alleinigen Effektivität von Mesalazin bisher nicht gegeben werden kann [249].

\section{Empfehlung 5.7.}

Personen mit nachgewiesener refraktärer Zöliakie (sowohl Typ I und II) sollen bei einem dafür ausgewiesenen Experten in einem dafür ausgewiesenen Zentrum vorgestellt werden. [starker Konsens, starke Empfehlung]

\section{Kommentar}

Da die refraktäre Zöliakie eine seltene Erkrankung darstellt, die Abgrenzung zu Diätfehlern schwierig ist und sowohl diagnostisch als auch therapeutisch eine Herausforderung darstellt, empfiehlt sich eine Vorstellung der Betroffenen in einem hierfür ausgewiesenen Zentrum. Kontaktadressen können hierfür z. B. über die Deutsche Zöliakie-Gesellschaft (DZG) erfragt werden.

\section{Empfehlung 5.8 .}

Bei vorliegender therapiebedürftiger Symptomatik bei RCD II können folgende Therapeutika zum Einsatz kommen:

A) Budesonid

B) Cladribin

C) Chemotherapie nach CHOP-Schema

D) autologe Stammzelltransplantation (SCT) nach Chemotherapie

[starker Konsens, Empfehlung offen]

\section{Kommentar}

Auch bei der RCD II sollte in Abhängigkeit von Alter und Multimorbidität vorgegangen werden. Bei wenig symptomatischen Personen und stabiler Erkrankung unter histologischen und bildgebenden Kontrollen kann die Therapie initial auf eine Ernährungstherapie und Budesonidtherapie beschränkt werden (siehe Empfehlung 5.6.). Eine darüber hinausgehende immunsuppressive Therapie sollte bei der RCD II in keinem Fall begonnen werden. Im Gegensatz zur RCD I scheint bei der RCD II eine frühere Thera- 
pieintensivierung („step-up“) notwendig, wobei hierzu keine vergleichenden Daten existieren. Letztlich sollte eine Mangelernährung aufgrund einer fortschreitenden Malabsorption und Entwicklung eines EATL nicht abgewartet werden. Ziel der Therapie bei der RCD II ist es, mittels antiproliferativer Medikamente bei möglichst geringer Nebenwirkung die Zahl der aberranten TZellen zu reduzieren bzw. diese zu eliminieren. Zu Cladribin existieren zwei Studien aus derselben Arbeitsgruppe, die eine gute Effektivität bei relativ geringer Nebenwirkungsrate belegen [250, 251]. Gerade bei Personen mit einem BMI kleiner als $18,5 \mathrm{~kg} / \mathrm{m}^{2}$, die sich für eine autologe SCT nicht eignen, kann die Therapie mit Cladribin eine wirksame Alternative darstellen [252]. Alternative Therapiestrategien, zu denen nur Einzelfallberichte existieren, gibt es zu Alemtuzumab $[253,254]$. Betroffene jünger als 65 Jahre mit einer schweren Zottenatrophie und ausgeprägter Infiltration der Dünndarmschleimhaut durch aberrante T-Zellen, sowie Personen, die auf eine Cladribin-Therapie nicht angesprochen haben oder rezidivieren, können von einer autologen SCT profitieren [255]. Leider führt auch diese intensive Therapie nur zu einem 4-Jahres-Überleben von ca. 66\% [255]. Einzelfallbeschreibungen existieren zu dem CHOP-Schema. Diese sollte nur Personen, die auf eine Cladribin-Therapie nicht angesprochen haben und die für eine autologe SCT nicht infrage kommen, angeboten werden [256].

\section{Empfehlung 5.9.}

Folgende Befunde sollten zur Diagnose einer ulzerativen Jejunitis (UJ) vorliegen:

A) nachgewiesene Dünndarmulzerationen

B) immunhistochemisch Antigenverlust/ Klonalität aus Dünndarmbiopsien

C) Pathologie: Einholung einer Zweitmeinung

[starker Konsens, Empfehlung]

\section{Kommentar}

Die Diagnose einer ulzerativen Jejunitis (UJ) bedeutet für die Betroffenen eine im Vergleich zur RCD II schlechtere Prognose mit höherem Risiko, ein EATL zu entwickeln [217]. Definitionsgemäß findet sich dieselbe Histologie wie bei einer RCD II (Zottenatrophie, Antigenverlust von CD8, intrazytoplasmatisch CD3), sowie eine klonale Population der intraepithelialen Lymphozyten. Im Unterschied zur RCD II zeigen sich jedoch, gelegentlich verstreut über den gesamten Dünndarm, Ulzerationen. Ein EATL muss sorgfältig mittels Koloskopie (mit Intubation des terminalen Ileum zum Ausschluss eines umschriebenen Tumors mit entsprechender Histologie im Sinne eines EATL), Dünndarm-MRT und Kapselendoskopie ausgeschlossen werden. Des Weiteren dürfen zur Diagnosestellung keine NSAR eingenommen worden sein, da sonst die Diagnose einer UJ falsch gestellt werden kann [238]. Als Mindestabstand zwischen der Einnahme von NSAR und einer Endoskopie scheinen 4 Wochen ausreichend. Aufgrund der Seltenheit der UJ wird die Einholung einer Zweitmeinung zur Pathologie bei einem ausgewiesenen Experten empfohlen. Bei entsprechender Expertise einer Abteilung kann eine Zweitmeinung auch innerhalb desselben Instituts eingeholt werden.

Empfehlung 5.10.

Folgende Therapien können bei UJ zum Einsatz kommen:

A) Budesonid

B) Ernährungstherapie
B) Cladribin
D) Chemotherapie nach CHOP-Schema
E) autologe Stammzelltransplantation nach Hochdosisthera- pie
[starker Konsens, Empfehlung offen]

\section{Kommentar}

Prinzipiell kommen bei der UJ dieselben Therapieprinzipien zum Einsatz wie bei der RCD II (siehe Empfehlung 5.8.). Eine intensive Diagnostik inkl. einer Enteroskopie mit Stufenbiopsien zum Ausschluss eines manifesten EATL sollte der Therapie vorausgehen. Ähnlich der RCD II kann die Therapie wenig symptomatischer UJ-Patienten initial auf eine Ernährungs- bzw. eine Budesonidtherapie beschränkt bleiben.

\section{Empfehlung 5.11.}

Folgende Untersuchungen sollen zur Primärdiagnose eines EATL durchgeführt werden:

A) histologische Beurteilung zum Nachweis eines hochmalignen T-Zelllymphoms

B) Schnittbildgebung (CT, MRT)

C) Endoskopie (Ösophagogastroduodenoskopie (ÖGD), Ileokoloskopie, Dünndarmendoskopie)

D) Knochenmarkpunktion

[starker Konsens, starke Empfehlung]

\section{Kommentar}

Die Diagnose eines EATL wird histologisch unter Berücksichtigung einer vorbestehenden Zöliakie gestellt. In Abgrenzung hierzu wurde bereits 1998 durch Chott et al. erstmals eine Variante des EATL beschrieben, welche keine Assoziation mit einer Zöliakie aufweist und morphologisch durch eher kleine bis mittelgroße Lymphomzellen charakterisiert ist [257]. Diese Entdeckung wurde erst 2008 durch die Weltgesundheitsorganisation (WHO) aufgenommen und EATL Typ II benannt (WHO 2008). Weitere Arbeiten v. a. aus Asien konnten diese Entität näher charakterisieren und abgrenzen, wobei auch hier die Assoziation mit einer Zöliakie fehlte [258]. Blastäre Zellen mit hoher Wachstumsfraktion finden sich beim EATL Typ II nicht. Die mit Zöliakie assoziierten EATL sind in der Regel CD3 +, CD5-, CD7 +, CD8-/+, CD4-, CD103 +, T-Zellrezeptor $ß+/$ - und weisen damit das gleiche Immunprofil wie die aberranten IELs bei RCD II auf. EATL Typ II sind dagegen zumeist CD3 +, CD4-, CD8 +, CD56 + und T-Zellrezeptor $ß+($ WHO 2008). Bei Verdacht auf ein EATL sollte eine Mitbeurteilung durch eine Referenzpathologie erfolgen. Da die Lymphomzellen schon frühzeitig in die Haut und Meningen disseminieren können, sollten je nach klinischer Indikation entsprechende Proben zur histopathologischen und evtl. molekularpathologischen Aufarbeitung gewonnen werden [20].

Bei entsprechendem Verdacht bzw. bereits gestellter Diagnose eines EATL steht ein Staging mit Schnittbildgebung, ÖGD und Koloskopie mit Biopsien aus dem Duodenum und möglichst terminalem Ileum an. In einer prospektiven Untersuchung an Personen mit einem manifesten histologisch bewiesenem EATL konnte eine PET-Computertomografie in 8/8 Patienten Abnormitäten aufdecken, eine konventionelle Computertomografie in immerhin 7/8 Fällen [241].

Eine Knochenmarkbiopsie soll in jedem Fall durchgeführt werden. Eine Knochenmarksinfiltration, die in immerhin ca. $20 \%$ der Fälle vorkommt, kann bei einem umschriebenen intestinalen Befund das therapeutische Vorgehen beeinflussen [230, 259]. 


\section{Empfehlung 5.12.}

Folgende Therapien können beim EATL zum Einsatz kommen:

A) Budesonid

B) Ernährungstherapie

C) primäre Resektion eines umschriebenen Tumors

D) Chemotherapie nach CHOP-Schema

E) autologe Stammzelltransplantation nach Hochdosischemotherapie

[starker Konsens, Empfehlung offen]

\section{Kommentar}

Ähnlich zum therapeutischen Prozedere bei RCD II und UJ ist bei EATL die Therapie entsprechend der Klinik und dem Allgemeinzustand des Betroffenen anzupassen, sodass in manchen Fällen auch alleine Budesonid und eine Optimierung der Ernährungssituation eingesetzt werden können (siehe Empfehlung 5.6. und 5.8.).

Bei drohenden Komplikationen wie Perforation oder Blutung erfolgt die primäre Resektion eines umschriebenen Tumors [225, 230]. Kann eine Resektion durchgeführt werden, trägt dieses Vorgehen laut einer multivariaten retrospektiven Analyse zu einer verbesserten Prognose bei [230].

Eine systemische Chemotherapie nach dem CHOP-Schema oder analogen Protokollen ist die am häufigsten eingesetzte Therapie, wobei lediglich eine prospektive Studie diese Fragestellung einarmig untersuchte [225]. Hier wurde ein mittleres Überleben von 28 Monaten erreicht.

Zur autologen SCT nach Hochdosistherapie wurden in den letzten Jahren widersprüchliche Daten publiziert. Eine Gruppe um Lennart publizierte ein 5-Jahres-Gesamtüberleben von $60 \%$ unter einer autologen SCT nach Ifosfamid und MTX, während die Amsterdamer Gruppe um Mulder et al. mit einer Hochdosistherapie unterschiedlicher Regime lediglich bei einem von vier Patienten eine Langzeitremission erzielen konnte [259]. $\mathrm{Zu}$ einer evtl. notwendigen Zweitlinientherapie existiert bisher lediglich eine kleine Fallserie von Raderer et al. mit sechs Patienten. Regime, die zu einer Remission führten, waren Kombinationen mit Fludarabin/Cyclophosphamid und Ifosfamid/Carboplatin/Etoposid [260].

Zusammenfassend sollte in Abhängigkeit des Eastern Cooperative Oncology Group Performance Status (ECOG) bei EATL ein Stufenschema zum Einsatz kommen. Dieses umfasst eine autologe SCT bei Personen, die sich dazu qualifizieren und CHOP ohne Stammzelltherapie bei älteren bzw. Patienten mit schlechterem ECOG.

Aufgrund dieser begrenzten Datenlage sollten Personen mit einem EATL möglichst in laufende Studien eingebracht werden (http://www.lymphome.de). Hier wird zum Erstellungszeitpunkt des Manuskriptes u.a. eine allogene SCT geprüft. Daten hierzu existieren nur bei Patienten mit nodalen T-Zelllymphomen [261].

\section{Institute}

Klinik für Innere Medizin IV, Universitätsklinikum der Friedrich-SchillerUniversität Jena

2 Institut für Pathologie, Universitätsklinikum Carl Gustav Carus an der Technischen Universität Dresden

3 Deutsche Zöliakie-Gesellschaft e. V. (DZG), Stuttgart

${ }^{4}$ Institut für Ernährungsmedizin, Universität Hohenheim, Stuttgart

Institut für Pathologie, Charité, Universitätsmedizin Berlin

${ }^{6}$ Medizinische Klinik für Gastroenterologie, Infektiologie und Rheumatologie, Charité, Universitätsmedizin Berlin

Medizinische Klinik II, Gastroenterologie, Onkologie, Klinikum Aschaffenburg

8 Dr. von Hauner Kinderspital, Klinikum der Universität München Campus Innenstadt, Ludwig-Maximilians-Universität München

9 Klinik und Poliklinik für Kinder und Jugendmedizin, Universitätsklinikum Carl Gustav Carus, Technische Universität Dresden, Dresden

${ }^{10}$ Arbeitsgemeinschaft der Wissenschaftlichen Medizinischen Fachgesellschaften e. V. (AWMF), Philipps-Universität, Marburg

${ }^{11}$ Medizinische Klinik II, Abteilung für Gastroenterologie, Universitätsklinikum Gießen und Marburg, Standort Gießen

12 Institut für Translationale Immunologie, Universitätsmedizin Mainz, Johannes-Gutenberg-Universität Mainz

\begin{tabular}{|c|c|c|c|c|c|c|}
\hline AG & Funktion & Anrede & Titel & Name & Welche Konflikte? & mit wem? \\
\hline \multirow[t]{3}{*}{ Diagnostik } & \multirow[t]{3}{*}{ AG-Leiter } & \multirow[t]{3}{*}{ Herrn } & \multirow[t]{3}{*}{ Dr. med. } & \multirow[t]{3}{*}{ Laßß } & Honorare & Phodia, Nutricia \\
\hline & & & & & Finanzielle Zuwendungen & Nifor \\
\hline & & & & & Mitgliedschaft & DGVS, DGKJ, GPGE \\
\hline \multirow[t]{4}{*}{ Diagnostik } & \multirow[t]{4}{*}{ AG-Leiter } & \multirow[t]{4}{*}{ Herrn } & \multirow[t]{4}{*}{ Prof. Dr. Dr. } & \multirow[t]{4}{*}{ Schuppan } & Berater- und Gutachtertätigkeit & $\begin{array}{l}\text { Abbott, Aegerion, Boehringer-Ingel- } \\
\text { heim, Conatus, Echosense, } \\
\text { Eli Lilly, Furui, Gilead, Pfizer, Sanofi- } \\
\text { Aventis, Silence Therapeutics, Stomedix, } \\
\text { Takeda }\end{array}$ \\
\hline & & & & & Honorare & $\begin{array}{l}\text { Boehringer-Ingelheim, Falk, Furui, Ganz- } \\
\text { immun, Sanofi-Aventis, Schär }\end{array}$ \\
\hline & & & & & Finanzielle Zuwendungen & Boehringer-Ingelheim \\
\hline & & & & & Eigentümerinteresse & Eurospital \\
\hline klinisches Bild & AG-Leiter & Frau & Prof. Dr. med. & Roeb & Honorare & GILEAD, BMS, MERZ, Falk \\
\hline \multirow[t]{4}{*}{ klinisches Bild } & \multirow[t]{4}{*}{ AG-Leiter } & \multirow[t]{4}{*}{ Herrn } & \multirow[t]{4}{*}{ Prof. Dr. med. } & \multirow[t]{4}{*}{ Stallmach } & Berater- und Gutachtertätigkeit & MSD, AbbVie, Astellas \\
\hline & & & & & Honorare & $\begin{array}{l}\text { MSD, AbbVie, Falk Foundation, Astellas, } \\
\text { Bayer }\end{array}$ \\
\hline & & & & & Finanzielle Zuwendungen & Pentax, Abbott \\
\hline & & & & & Mitgliedschaft & DGVS \\
\hline \multirow[t]{2}{*}{ Pathologie } & \multirow[t]{2}{*}{ AG-Leiter } & \multirow[t]{2}{*}{ Frau } & \multirow[t]{2}{*}{ PD Dr. med. } & \multirow[t]{2}{*}{ Aust } & Honorare & Pfizer, Dr. Falk Foundation \\
\hline & & & & & Mitgliedschaft & $\begin{array}{l}\text { Deutsche Gesellschaft für Pathologie, } \\
\text { Deutsche Krebsgesellschaft }\end{array}$ \\
\hline
\end{tabular}


Interessenkonflikte (Fortsetzung)

\begin{tabular}{|c|c|c|c|c|c|c|}
\hline AG & Funktion & Anrede & Titel & Name & Welche Konflikte? & mit wem? \\
\hline \multirow[t]{4}{*}{ Pathologie } & \multirow[t]{4}{*}{ AG-Leiter } & \multirow[t]{4}{*}{ Herrn } & \multirow[t]{4}{*}{ Prof. Dr. med. } & \multirow[t]{4}{*}{ Gaßler } & Honorare & $\begin{array}{l}\text { Referent bei START 6, Referent 19. interd. } \\
\text { Workshop G-I-Tumore }\end{array}$ \\
\hline & & & & & Finanzielle Zuwendungen & DFG, Krebshilfe \\
\hline & & & & & Eigentümerinteresse & Patient zur Verwendung der ACSL5 \\
\hline & & & & & Mitgliedschaft & Mandatsträger DGP \\
\hline \multirow{3}{*}{$\begin{array}{l}\text { refraktäre Zölia- } \\
\text { kie }\end{array}$} & \multirow[t]{3}{*}{ AG-Leiter } & \multirow[t]{3}{*}{ Herrn } & \multirow[t]{3}{*}{ PD Dr. med. } & \multirow[t]{3}{*}{ Daum } & Berater- und Gutachtertätigkeit & Shire \\
\hline & & & & & Finanzielle Zuwendungen & Fa. Schar \\
\hline & & & & & Mitgliedschaft & wissenschaftl. Beirat DZG \\
\hline \multirow{3}{*}{$\begin{array}{l}\text { refraktäre Zölia- } \\
\text { kie }\end{array}$} & \multirow[t]{3}{*}{ AG-Leiter } & \multirow[t]{3}{*}{ Herrn } & \multirow[t]{3}{*}{ Prof. Dr. med. } & \multirow[t]{3}{*}{ Fischbach } & Berater- und Gutachtertätigkeit & Fresenius Biotech, Norgine, Pfizer \\
\hline & & & & & Honorare & $\begin{array}{l}\text { Abbott, Aptalis, Falk, Merck Serono, Mor- } \\
\text { gine, Novartis, Nycomed, Phizer, Roche, } \\
\text { Sanofi-Aventis, Shire }\end{array}$ \\
\hline & & & & & Mitgliedschaft & DGVS \\
\hline \multirow[t]{5}{*}{ Therapie } & \multirow[t]{5}{*}{ AG-Leiter } & \multirow[t]{5}{*}{ Herrn } & \multirow[t]{5}{*}{ Prof. Dr. med. } & \multirow[t]{5}{*}{ Bischoff } & Berater- und Gutachtertätigkeit & Danone, Coridien \\
\hline & & & & & Honorare & $?$ \\
\hline & & & & & Finanzielle Zuwendungen & IBIS \\
\hline & & & & & Geschäftsanteile & Aktien (<1QQ.QQQ EUR) \\
\hline & & & & & Mitgliedschaft & DGEM, DGVS, DGMIN, ESPEN, EMCBM \\
\hline \multirow[t]{4}{*}{ Therapie } & \multirow[t]{4}{*}{ AG-Leiter } & Frau & Prof. Dr. med. & Koletzko & Berater- und Gutachtertätigkeit & Abbott, Danone, Janssen, Merck, MSD \\
\hline & & & & & Honorare & $\begin{array}{l}\text { Abbott, Danone, Eruoimmuns, Hipp, Im- } \\
\text { mundiagnostik, Menarinie, MSD, Schär, } \\
\text { Nestle, ThermoFischer }\end{array}$ \\
\hline & & & & & Finanzielle Zuwendungen & $\begin{array}{l}\text { Mead Johnson Euroimmun, Eurospital } \\
\text { Immundiagnostik, Schär, Nestle, Ther- } \\
\text { moFischer, Inova, R-Biopharm }\end{array}$ \\
\hline & & & & & Mitgliedschaft & $\begin{array}{l}\text { Council-Member der ESPGHAN, Vertreter } \\
\text { im Scientific Com der UEG der ESPFHAN }\end{array}$ \\
\hline Diagnostik & AG-Mitglied & Herrn & Prof. Dr. med. & Allgayer & keine & \\
\hline Diagnostik & AG-Mitglied & Frau & Dr. med. & Baas & Honorare & Nestle \\
\hline & & & & & Persönl. Beziehungen & $\begin{array}{l}\text { Ehemann, Dr. Baas Vorstandsvors. Tech- } \\
\text { niker Krankenkasse }\end{array}$ \\
\hline & & & & & Mitgliedschaft & DGEM \\
\hline Diagnostik & AG-Mitglied & Herrn & Prof. Dr. med. & Mothes & Eigentümerinteresse & $\begin{array}{l}\text { Erfinder im Patent "Peptide u. Verf. zur } \\
\text { Diagnostik von Zöliakie und Dermatitis" }\end{array}$ \\
\hline Diagnostik & AG-Mitglied & Frau & & Schäfer & keine & \\
\hline Diagnostik & AG-Mitglied & Herrn & Prof. Dr. med. & Zimmer & keine & \\
\hline klinisches Bild & AG-Mitglied & Frau & & Eiswirth & Mitgliedschaft & Sprecherin Jugendausschuss DZG \\
\hline klinisches Bild & AG-Mitglied & Herrn & PD Dr. med. & Häuser & Polit., akadem. Wissen. Persönl. & Dozent bzw. Lehrtheurapeut \\
\hline klinisches Bild & AG-Mitglied & Herrn & Prof. Dr. med. & Holtmeier & Berater- und Gutachtertätigkeit & Schär GmbH \\
\hline & & & & & Honorare & Schär GmbH \\
\hline & & & & & Mitgliedschaft & wissenschaftl. Beirat DZG \\
\hline klinisches Bild & AG-Mitglied & Herrn & Prof. Dr. med. & Keller & Honorare & $\begin{array}{l}\text { Abbott, Danone, Falk, Essex, Hipp, } \\
\text { Hestle, P.... }\end{array}$ \\
\hline & & & & & Finanzielle Zuwendungen & Infektophern, Euromisum \\
\hline & & & & & Mitgliedschaft & DPGE, ESRGHAN, DGVS, DGKJ, BVKJ \\
\hline klinisches Bild & AG-Mitglied & Herrn & Prof. Dr. med. & Lembcke & Persönl. Beziehungen & $\begin{array}{l}\text { Bruder (Geschäftsführer EVER Pharma } \\
\text { Jena GmbH) }\end{array}$ \\
\hline & & & & & Mitgliedschaft & DGVS, DEGUM \\
\hline klinisches Bild & AG-Mitglied & Frau & Dr. med. & Mecke & keine & \\
\hline Pathologie & AG-Mitglied & Frau & & Beisel & keine & \\
\hline Pathologie & AG-Mitglied & Herrn & Prof. Dr. med. & Bläker & Honorare & Astra Zeneca \\
\hline & & & & & Finanzielle Zuwendungen & Astra Zeneca \\
\hline Pathologie & AG-Mitglied & Herrn & Prof. Dr. med. & Fend & Finanzielle Zuwendungen & Mausmodelle \\
\hline & & & & & Mitgliedschaft & BV Pathologie \\
\hline Pathologie & AG-Mitglied & Frau & & Mlosh & keine & \\
\hline Pathologie & AG-Mitglied & Herrn & $\begin{array}{l}\text { Prof. Dr. Dr. } \\
\text { med. }\end{array}$ & Stein & Berater- und Gutachtertätigkeit & $\begin{array}{l}\text { Abbott, Dr. Schär, Immundiagnostik, } \\
\text { MSD, Pharmocosmos, Shire, Takeda, } \\
\text { Vifor }\end{array}$ \\
\hline & & & & & Honorare & $\begin{array}{l}\text { Abbott, Dr. Schär, Immundiagnostik, } \\
\text { MSD, Ferring, Pharmocosmos, Shire, } \\
\text { Takeda, Vifor }\end{array}$ \\
\hline & & & & & Finanzielle Zuwendungen & Dr. Schär, Immundiagnostik \\
\hline $\begin{array}{l}\text { refraktäre } \\
\text { Zöliakie }\end{array}$ & AG-Mitglied & Herrn & Dr. med. & Felber & Mitgliedschaft & DGVS, DEGUM \\
\hline
\end{tabular}




\begin{tabular}{|c|c|c|c|c|c|c|}
\hline \multicolumn{7}{|c|}{ Interessenkonflikte (Fortsetzung) } \\
\hline AG & Funktion & Anrede & Titel & Name & Welche Konflikte? & mit wem? \\
\hline $\begin{array}{l}\text { refraktäre } \\
\text { Zöliakie }\end{array}$ & AG-Mitglied & Herrn & & Fessler & Mitgliedschaft & $\begin{array}{l}\text { DZG, gewählt. Mitglied im Mitglieder- } \\
\text { ausschuss DZG }\end{array}$ \\
\hline $\begin{array}{l}\text { refraktäre } \\
\text { Zöliakie }\end{array}$ & AG-Mitglied & Herrn & Prof. Dr. med. & Germer & keine & \\
\hline $\begin{array}{l}\text { refraktäre } \\
\text { Zöliakie }\end{array}$ & AG-Mitglied & Frau & & Oelhoff & Mitgliedschaft & Selbsthilfe-Vertrtung DZG \\
\hline $\begin{array}{l}\text { refraktäre } \\
\text { Zöliakie }\end{array}$ & AG-Mitglied & Herrn & Prof. Dr. med. & Schäfer & keine & \\
\hline \multirow{3}{*}{$\begin{array}{l}\text { refraktäre } \\
\text { Zöliakie }\end{array}$} & \multirow[t]{3}{*}{ AG-Mitglied } & \multirow[t]{3}{*}{ Herrn } & \multirow[t]{3}{*}{ Dr. med. } & \multirow[t]{3}{*}{ Schumann } & Berater- und Gutachtertätigkeit & Dr. Schär \\
\hline & & & & & Honorare & Dr. Schär \\
\hline & & & & & Mitgliedschaft & DGVS, DGIM \\
\hline Therapie & AG-Mitglied & Frau & & Brandstätter & Mitgliedschaft & $\begin{array}{l}\text { Deutsche Zöliakiegesellschaft, Ehren- } \\
\text { amtl. DZG-Zöliakieberaterin und Kon- } \\
\text { taktperson von Betroffenen }\end{array}$ \\
\hline Therapie & AG-Mitglied & Frau & $\begin{array}{l}\text { PD Dr. rer. } \\
\text { nat. }\end{array}$ & Dieterich & keine & \\
\hline \multirow[t]{2}{*}{ Therapie } & \multirow[t]{2}{*}{ AG-Mitglied } & \multirow[t]{2}{*}{ Herrn } & & \multirow[t]{2}{*}{ Kühnau } & Mitgliedschaft & Vorsitzender der DZG (Ehrenamt) \\
\hline & & & & & Polit., akadem. Wissen. Persönl. & $\begin{array}{l}\text { persönliches Interesse, Zöliakiebetroffe- } \\
\text { ner }\end{array}$ \\
\hline \multirow[t]{3}{*}{ Therapie } & \multirow[t]{3}{*}{ AG-Mitglied } & \multirow[t]{2}{*}{ Herrn } & \multirow[t]{2}{*}{ PD Dr. med. } & \multirow{2}{*}{$\begin{array}{l}\text { von Schön- } \\
\text { feld }\end{array}$} & Besitz von & Aktien Mayer und BASF, Fonds DWS \\
\hline & & & & & Mitgliedschaft & DGVS, BDI \\
\hline & & Frau & PD Dr. med. & Lynen Jansen & Mitgliedschaft & DGVS \\
\hline
\end{tabular}

\section{Literatur}

1 Riddle MS, Murray JA, Porter CK. The incidence and risk of celiac disease in a healthy US adult population. The American journal of gastroenterology 2012; 107: 1248 - 1255. DOI: 10.1038/ajg.2012.130

2 White LE et al. The rising incidence of celiac disease in Scotland. Pediatrics 2013; 132: e924-e931. DOI: 10.1542/peds.2013-0932

3 Ress K, Luts K, Rago T et al. Nationwide study of childhood celiac disease incidence over a 35-year period in Estonia. European journal of pediatrics 2012; 171: 1823-1828. DOI: 10.1007/s00431-012-1835-0

4 Ludvigsson JF et al. Increasing incidence of celiac disease in a North American population. The American journal of gastroenterology 2013; 108: 818 -824. DOI: $10.1038 /$ ajg.2013.60

5 Zanoni $G$ et al. In celiac disease, a subset of autoantibodies against transglutaminase binds toll-like receptor 4 and induces activation of monocytes. PLoS medicine 2006; 3: e358. DOI: 10.1371/journal. pmed.0030358

6 Ivarsson A, Hernell $O$, Stenlund $H$ et al. Breast-feeding protects against celiac disease. The American journal of clinical nutrition 2002; 75 : 914-921

7 Stordal K, White RA, Eggesbo M. Early feeding and risk of celiac disease in a prospective birth cohort. Pediatrics 2013; 132: e1202-1209. DOI: $10.1542 /$ peds.2013-1752

8 Wingren $\mathrm{CJ}$ et al. Coeliac disease in children: a social epidemiological study in Sweden. Acta paediatrica 2012 (Oslo, Norway: 1992) 101: 185-191. DOI: 10.1111/j.1651-2227.2011.02434.x

9 Olen O, Bihagen E, Rasmussen F et al. Socioeconomic position and education in patients with coeliac disease. Digestive and liver disease: official journal of the Italian Society of Gastroenterology and the Italian Association for the Study of the Liver 2012; 44: 471-476. DOI: 10.1016/j.dld.2012.01.006

10 Kratzer $W$ et al. Prevalence of celiac disease in Germany: a prospective follow-up study. World journal of gastroenterology 2013; WJG 19: $2612-2620$

11 Aziz I et al. A UK study assessing the population prevalence of self-reported gluten sensitivity and referral characteristics to secondary care. Eur J Gastroenterol Hepatol 2014; 26: 33-39

12 Cosnes J et al. Incidence of autoimmune diseases in celiac disease: protective effect of the gluten-free diet. Clinical gastroenterology and hepatology: the official clinical practice journal of the American Gastroenterological Association 2008; 6: 753-758. DOI: 10.1016/j. cgh.2007.12.022
13 Husby S et al. European Society for Pediatric Gastroenterology, Hepatology, and Nutrition guidelines for the diagnosis of coeliac disease. Journal of pediatric gastroenterology and nutrition 2012; 54: 136-160. DOI: 10.1097/MPG.0b013e31821a23d0

14 Rubio-Tapia A, Hill ID, Kelly CP et al. ACG clinical guidelines: diagnosis and management of celiac disease. The American journal of gastroenterology 2013; 108: 656 - 676 quiz 677 DOI: doi:10.1038/ajg.2013.79

15 Bai JC et al. World Gastroenterology Organisation global guidelines on celiac disease. Journal of clinical gastroenterology 2013; 47: 121 - 126. DOI: 10.1097/MCG.0b013e31827a6f83

16 Lieb KKD, Koch K, Baethge C et al. Interessenskonflikte in der Medizin: Mit Transparenz Vertrauen stärken. Dtsch Arztebl 2011; 108 (6): A256-A260

17 Ludvigsson JF et al. The Oslo definitions for coeliac disease and related terms. Gut 2013; 62: 43 - 52. DOI: 10.1136/gutjnl-2011-301346

18 Mehta G, Taslaq S, Littleford S et al. The changing face of coeliac disease. British journal of hospital medicine (London, England: 2005) 2008; 69: $84-87$

19 Zawahir S, Safta A, Fasano A. Pediatric celiac disease. Current opinion in pediatrics 2009; 21: 655 -660. DOI: 10.1097/MOP.0b013e32832f5b9d

20 Fasano A. Celiac disease: the past, the present, the future. Pediatrics 2001; 107: 768 - 770

21 Reilly NR et al. Celiac disease in normal-weight and overweight children: clinical features and growth outcomes following a gluten-free diet. Journal of pediatric gastroenterology and nutrition 2011; 53: 528 -531. DOI: 10.1097/MPG.0b013e3182276d5e

22 Corazza GR et al. Subclinical celiac sprue. Increasing occurrence and clues to its diagnosis. Journal of clinical gastroenterology 1993; 16: $16-21$

23 Bottaro G, Cataldo F, Rotolo $N$ et al. The clinical pattern of subclinical/ silent celiac disease: an analysis on 1026 consecutive cases. The American journal of gastroenterology 1999; 94: $691-696$. DOI: 10.1111/ j.1572-0241.1999.00938.x

24 Meloni G, Dore A, Fanciulli G et al. Subclinical coeliac disease in schoolchildren from northern Sardinia. Lancet 1999; 353: 37. DOI: 10.1016/ s0140-6736(05)74871-6

25 Lebwohl B et al. Mucosal healing and risk for lymphoproliferative malignancy in celiac disease: a population-based cohort study. Annals of internal medicine 2013; 159: 169-175. DOI: 10.7326/0003-4819159-3-201308060-00006

26 Marine $M$ et al. Impact of mass screening for gluten-sensitive enteropathy in working population. World journal of gastroenterology 2009; 15: $1331-1338$ 
27 Rosen A et al. Balancing health benefits and social sacrifices: a qualitative study of how screening-detected celiac disease impacts adolescents' quality of life. BMC pediatrics 2011; 11: 32. DOI: 10.1186/ 1471-2431-11-32

28 Nordyke $\mathrm{K}$ et al. Health-related quality-of-life in children with coeliac disease, measured prior to receiving their diagnosis through screening. Journal of medical screening 2011; 18: 187 -192. DOI: 10.1258 / jms.2011.011081

29 Vilppula A et al. Clinical benefit of gluten-free diet in screen-detected older celiac disease patients. BMC gastroenterology 2011; 11: 136 . DOI: $10.1186 / 1471-230 x-11-136$

30 Paavola A et al. Gastrointestinal symptoms and quality of life in screendetected celiac disease. Digestive and liver disease: official journal of the Italian Society of Gastroenterology and the Italian Association for the Study of the Liver 2012; 44: 814 -818. DOI: 10.1016/j.dld.2012.04.019

31 Aziz I, Sanders DS. Are we diagnosing too many people with coeliac disease? The Proceedings of the Nutrition Society 2012; 71: 538 544. DOI: $10.1017 / \mathrm{s} 0029665112000262$

32 Nordyke K et al. Health-related quality of life in adolescents with screening-detected celiac disease, before and one year after diagnosis and initiation of gluten-free diet, a prospective nested case-referent study. BMC public health 2013; 13: 142. DOI: 10.1186/1471-2458-13-142

33 Biagi $F$ et al. Intraepithelial lymphocytes in the villous tip: do they indicate potential coeliac disease? Journal of clinical pathology 2004; 57 : 835 - 839. DOI: 10.1136/jcp.2003.013607

34 Biagi $F$ et al. Prevalence and natural history of potential celiac disease in adult patients. Scandinavian journal of gastroenterology 2013; 48: 537 - 542. DOI: 10.3109/00365521.2013.777470

35 Inomata $N$. Wheat allergy. Current opinion in allergy and clinical immunology 2009; 9: 238-243. DOI: 10.1097/ACI.0b013e32832aa5bc

36 Junker $Y$ et al. Wheat amylase trypsin inhibitors drive intestinal inflammation via activation of toll-like receptor 4 . The Journal of experimental medicine 2012; 209: 2395 - 2408. DOI: 10.1084/jem.20102660

37 Biesiekierski JR et al. No effects of gluten in patients with self-reported non-celiac gluten sensitivity after dietary reduction of fermentable, poorly absorbed, short-chain carbohydrates. Gastroenterology 2013; 145: 320 - 328 e321-e323 DOI: 10.1053/j.gastro.2013.04.051

38 Ford RP. The gluten syndrome: a neurological disease. Medical hypotheses 2009; 73: 438 -440. DOI: 10.1016/j.mehy.2009.03.037

39 Lundin KE, Alaedini A. Non-celiac gluten sensitivity. Gastrointestinal endoscopy clinics of North America 2012; 22: 723 -734. DOI: 10.1016/j. giec.2012.07.006

40 Ukkola A et al. Changes in body mass index on a gluten-free diet in coeliac disease: a nationwide study. European journal of internal medicine 2012; 23: 384 - 388. DOI: 10.1016/j.ejim.2011.12.012

41 Choi JM et al. Increased prevalence of celiac disease in patients with unexplained infertility in the United States. The Journal of reproductive medicine 2011; 56: 199-203

42 Tata LJ et al. Fertility and pregnancy-related events in women with celiac disease: a population-based cohort study. Gastroenterology 2005; 128: $849-855$

43 Ludvigsson JF, Montgomery SM, Ekbom A. Celiac disease and risk of adverse fetal outcome: a population-based cohort study. Gastroenterology 2005; 129: 454-463. DOI: 10.1016/j.gastro.2005.05.065

44 Ludvigsson JF, Montgomery SM, Ekbom A. Coeliac disease in the father and risk of adverse pregnancy outcome: a population-based cohort study. Scandinavian journal of gastroenterology 2006; 41: 178-185. DOI: $10.1080 / 00365520510024124$

45 Koletzko S. Prevalence of coeliac disease in diabetic children and adolescents. A multicentre study. European journal of pediatrics 1988; 148: $113-117$

46 Larsson $\mathrm{K}$ et al. Annual screening detects celiac disease in children with type 1 diabetes. Pediatric diabetes 2008; 9: 354 -359. DOI: 10.1111/ j.1399-5448.2008.00367.x

47 Ch'ng CL, Jones MK, Kingham JG. Celiac disease and autoimmune thyroid disease. Clinical medicine \& research 2007; 5: 184-192. DOI: $10.3121 / \mathrm{cmr} .2007 .738$

48 Drastich P et al. Celiac disease markers in patients with liver diseases: a single center large scale screening study. World journal of gastroenterology 2012; 18: 6255 - 6262. DOI: 10.3748/wjg.v18.i43.6255

49 Luft LM, Barr SG, Martin LO et al. Autoantibodies to tissue transglutaminase in Sjogren's syndrome and related rheumatic diseases. The Journal of rheumatology 2003; 30: 2613-2619

50 Iltanen $S$ et al. Celiac disease and markers of celiac disease latency in patients with primary Sjogren's syndrome. The American journal of gastroenterology 1999; 94: 1042-1046. DOI: 10.1111/j.15720241.1999.01011.x

51 Elfstrom P, Montgomery SM, Kampe 0 et al. Risk of primary adrenal insufficiency in patients with celiac disease. The Journal of clinical endocrinology and metabolism 2007; 92: 3595-3598. DOI: 10.1210/ jc.2007-0960

52 Roche Herrero MC et al. The prevalence of headache in a population of patients with coeliac disease. Revista de neurologia 2001; 32: 301 309

53 Dimitrova AK et al. Prevalence of migraine in patients with celiac disease and inflammatory bowel disease. Headache 2013; 53: $344-355$. DOI: doi:10.1111/j.1526-4610.2012.02260.x

54 Ludvigsson JF, Zingone F, Tomson $T$ et al. Increased risk of epilepsy in biopsy-verified celiac disease: a population-based cohort study. Neurology 2012; 78: 1401 -1407. DOI: 10.1212/WNL.0b013e3182544728

55 Smith DF, Gerdes LU. Meta-analysis on anxiety and depression in adult celiac disease. Acta psychiatrica Scandinavica 2012; 125: 189-193. DOI: $10.1111 /$ j.1600-0447.2011.01795.x

56 Hauser W, Janke KH, Klump B et al. Anxiety and depression in adult patients with celiac disease on a gluten-free diet. World journal of gastroenterology 2010; 16: 2780 - 2787

57 Sticherling $M$, Erfurt-Berge C. Autoimmune blistering diseases of the skin. Autoimmunity reviews 2012; 11: 226-230. DOI: 10.1016/j.autrev.2011.05.017

58 Ludvigsson JF, Lindelof B, Zingone $F$ et al. Psoriasis in a nationwide cohort study of patients with celiac disease. The Journal of investigative dermatology 2011; 131: 2010 - 2016. DOI: 10.1038/jid.2011.162

59 George EK et al. High frequency of celiac disease in Down syndrome. The Journal of pediatrics 1996; 128: $555-557$

60 Gale L, Wimalaratna H, Brotodiharjo A et al. Down's syndrome is strongly associated with coeliac disease. Gut 1997; 40: $492-496$

61 Bonamico $M$ et al. Prevalence and clinical picture of celiac disease in Turner syndrome. The Journal of clinical endocrinology and metabolism 2002; 87: 5495-5498

62 Ludvigsson JF, Hemminki K, Wahlstrom J et al. Celiac disease confers a 1.6-fold increased risk of asthma: a nationwide population-based cohort study. The Journal of allergy and clinical immunology 2011; 127 : 1071 - 1073. DOI: 10.1016/j.jaci.2010.12.1076

63 Rubio-Tapia A, Murray JA. The liver in celiac disease. Hepatology (Baltimore, Md.) 2007; 46: 1650 -1658. DOI: 10.1002/hep.21949

64 Sainsbury A, Sanders DS, Ford AC. Meta-analysis: Coeliac disease and hypertransaminasaemia. Alimentary pharmacology \& therapeutics 2001; 34: 33-40. DOI: 10.1111/j.1365-2036.2011.04685.x

65 Kaukinen $K$ et al. Celiac disease in patients with severe liver disease: gluten-free diet may reverse hepatic failure. Gastroenterology 2002; 122: $881-888$

66 Cataldo F, Marino V, Bottaro G et al. Celiac disease and selective immunoglobulin A deficiency. The Journal of pediatrics 1997; 131: $306-308$

67 Heneghan MA, Stevens FM, Cryan EM et al. Celiac sprue and immunodeficiency states: a 25-year review. Journal of clinical gastroenterology 1997; 25: $421-425$

68 Taubman B, Mamula P, Sherry DD. Prevalence of asymptomatic celiac disease in children with fibromyalgia: a pilot study. Pediatric rheumatology online journal 2011; 9: 11. DOI: 10.1186/1546-0096-9-11

69 Walters JR, Banks LM, Butcher GP et al. Detection of low bone mineral density by dual energy $\times$ ray absorptiometry in unsuspected suboptimally treated coeliac disease. Gut 1995; 37: 220-224

70 Thorn $M$ et al. Microscopic colitis in Uppsala health region, a population-based prospective study 2005-2009. Scandinavian journal of gastroenterology 2013; 48: 825 - 830. DOI: 10.3109/00365521.2013.800993

71 Ford AC et al. Yield of diagnostic tests for celiac disease in individuals with symptoms suggestive of irritable bowel syndrome: systematic review and meta-analysis. Archives of internal medicine 2009; 169 : 651 -658. DOI: 10.1001/archinternmed.2009.22

72 Card TR, Siffledeen J, West J et al. An excess of prior irritable bowel syndrome diagnoses or treatments in Celiac disease: evidence of diagnostic delay. Scandinavian journal of gastroenterology 2013; 48: 801 807. DOI: 10.3109/00365521.2013.786130

73 Catassi $C$ et al. Risk of non-Hodgkin lymphoma in celiac disease. Journal of the American Medical Association 2002; 287: 1413-1419

74 Askling J et al. Cancer incidence in a population-based cohort of individuals hospitalized with celiac disease or dermatitis herpetiformis. Gastroenterology 2002; 123: 1428-1435 
75 Smedby KE et al. Malignant lymphomas in coeliac disease: evidence of increased risks for lymphoma types other than enteropathy-type T cell lymphoma. Gut 2005; 54: 54 -59. DOI: 10.1136/gut.2003.032094

76 Elfstrom $P$ et al. Risk of lymphoproliferative malignancy in relation to small intestinal histopathology among patients with celiac disease. Journal of the National Cancer Institute 2011; 103: 436-444. DOI: 10. 1093/jnci/djq564

77 Catassi C et al. Detection of Celiac disease in primary care: a multicenter case-finding study in North America. The American journal of gastroenterology 2007; 102: 1454 -1460. DOI: 10.1111/j.1572-0241. 2007.01173.x

78 Denham JM, Hill ID. Celiac disease and autoimmunity: review and controversies. Current allergy and asthma reports 2013; 13: 347-353. DOI: $10.1007 / \mathrm{s} 11882-013-0352-1$

79 Camarca ME et al. Celiac disease in type 1 diabetes mellitus. Italian journal of pediatrics 2012; 38: 10. DOI: 10.1186/1824-7288-38-10

80 Iqbal T, Zaidi MA, Wells GA et al. Celiac disease arthropathy and autoimmunity study. Journal of gastroenterology and hepatology 2013; 28: 99 -105. DOI: 10.1111/j.1440-1746.2012.07272.x

81 Cooke WT, Smith WT. Neurological disorders associated with adult coeliac disease. Brain: a journal of neurology 1966; 89: 683-722

82 Cash BD et al. The prevalence of celiac disease among patients with nonconstipated irritable bowel syndrome is similar to controls. Gastroenterology 2011; 141: 1187 - 1193. DOI: 10.1053/j.gastro.2011.06.084

83 Mohseninejad L, Feenstra T, van der Horst HE et al. Targeted screening for Coeliac Disease among irritable bowel syndrome patients: analysis of cost-effectiveness and value of information. The European journal of health economics: HEPAC: health economics in prevention and care 2013; 14: 947 - 957. DOI: 10.1007/s10198-012-0441-4

84 Green PH et al. Risk of malignancy in patients with celiac disease. The American journal of medicine 2003; 115: 191 -195

85 Casella $G$ et al. Prevalence of celiac disease in inflammatory bowel diseases: An IG-IBD multicentre study. Digestive and liver disease: official journal of the Italian Society of Gastroenterology and the Italian Association for the Study of the Liver 2010; 42: 175-178. DOI: 10.1016/j. dld.2009.08.005

86 Pereyra L et al. Risk of colorectal neoplasia in patients with celiac disease: A multicenter study. J Crohns Colitis 2013; 7: e672 - e677

87 Zipser RD, Patel S, Yahya KZ et al. Presentations of adult celiac disease in a nationwide patient support group. Digestive diseases and sciences 2003; 48: $761-764$

88 Kabbani TA et al. Patients with celiac disease have a lower prevalence of non-insulin-dependent diabetes mellitus and metabolic syndrome. Gastroenterology 2013; 144: 912 -917 e911 DOI: 10.1053/j.gastro.2013.01.033

89 Sardy M, Karpati S, Merkl B et al. Epidermal transglutaminase (TGase 3) is the autoantigen of dermatitis herpetiformis. The Journal of experimental medicine 2002; 195: 747 - 757

90 Donaldson MR et al. Epidermal transglutaminase deposits in perilesional and uninvolved skin in patients with dermatitis herpetiformis. The Journal of investigative dermatology 2007; 127: 1268-1271. DOI: $10.1038 /$ sj.jid.5700682

91 Giersiepen Ket al. Accuracy of diagnostic antibody tests for coeliac disease in children: summary of an evidence report. Journal of pediatric gastroenterology and nutrition 2012; 54: 229-241. DOI: 10.1097/ MPG.0b013e318216f2e5

92 Leffler DA, Schuppan D. Update on serologic testing in celiac disease. The American journal of gastroenterology 2010; 105: 2520-2524. DOI: 10.1038/ajg.2010.276

93 Kurppa K et al. Endomysial antibodies predict celiac disease irrespective of the titers or clinical presentation. World journal of gastroenterology 2012; 18: 2511 - 2516. DOI: 10.3748/wjg.v18.i20.2511

$94 \mathrm{Katz} \mathrm{KD}$ et al. Screening for celiac disease in a North American population: sequential serology and gastrointestinal symptoms. The American journal of gastroenterology 2011; 106: 1333-1339. DOI: $10.1038 /$ ajg.2011.21

95 Panetta $F$ et al. Clinical accuracy of anti-tissue transglutaminase as screening test for celiac disease under 2 years. Acta paediatrica (Oslo, Norway: 1992) 2011; 100: 728-731. DOI: 10.1111/j.16512227.2010.02124.x

96 Hojsak I et al. Celiac disease screening assays for children younger than 3 years of age: the performance of three serological tests. Digestive diseases and sciences 2012; 57: 127-132. DOI: 10.1007/s10620-0111857-x
97 Rashtak S, Ettore MW, Homburger HA et al. Comparative usefulness of deamidated gliadin antibodies in the diagnosis of celiac disease. Clinical gastroenterology and hepatology: the official clinical practice journal of the American Gastroenterological Association 2008; 6: 426-432 quiz 370 DOI: 10.1016/j.cgh.2007.12.030

98 Prause $C$ et al. Antibodies against deamidated gliadin as new and accurate biomarkers of childhood coeliac disease. Journal of pediatric gastroenterology and nutrition 2009; 49: 52 - 58. DOI: 10.1097/MPG 0b013e318195dae3

99 Niveloni $S$ et al. Antibodies against synthetic deamidated gliadin peptides as predictors of celiac disease: prospective assessment in an adult population with a high pretest probability of disease. Clinical chemistry 2007; 53: 2186 - 2192. DOI: 10.1373/clinchem.2006.081364

100 McGowan KE, Lyon ME, Butzner JD. Celiac disease and IgA deficiency: complications of serological testing approaches encountered in the clinic. Clinical chemistry 2008; 54: 1203 -1209

101 Villalta $D$ et al. IgG antibodies against deamidated gliadin peptides for diagnosis of celiac disease in patients with IgA deficiency. Clinical chemistry 2010; 56: 464 - 468. DOI: 10.1373/clinchem.2009.128132

102 Kappler M, Krauss-Etschmann S, Diehl V et al. Detection of secretory IgA antibodies against gliadin and human tissue transglutaminase in stool to screen for coeliac disease in children: validation study. BMJ (Clinical research ed.) 2006; 332: 213 -214. DOI: 10.1136/bmj. 38688.654028.AE

103 Hogen Esch CE et al. Specific celiac disease antibodies in children on a gluten-free diet. Pediatrics 2011; 128: 547 -552. DOI: 10.1542/peds. 2010-3762

104 Leffler D et al. Kinetics of the histological, serological and symptomatic responses to gluten challenge in adults with coeliac disease. Gut 2013; 62: 996 -1004. DOI: 10.1136/gutjnl-2012-302196

105 Fasano A et al. Prevalence of celiac disease in at-risk and not-at-risk groups in the United States: a large multicenter study. Archives of internal medicine; 2003; 163: 286-292

106 Goldberg D, Kryszak D, Fasano A et al. Screening for celiac disease in family members: is follow-up testing necessary? Digestive diseases and sciences; 2007; 52: 1082-1086. DOI: 10.1007/s10620-0069518-1

107 Bybrant MC, Ortqvist E, Lantz S et al. High prevalence of celiac disease in Swedish children and adolescents with type 1 diabetes and the relation to the Swedish epidemic of celiac disease: a cohort study. Scand J Gastroenterol 2014; 49: 52 - 58

108 Leeds JS, Hopper $A D$, Hadjivassiliou M et al. High prevalence of microvascular complications in adults with type 1 diabetes and newly diagnosed celiac disease. Diabetes care 2011; 34: 2158-2163. DOI: $10.2337 / \mathrm{dc} 11-0149$

109 Abid N, McGlone O, Cardwell C et al. Clinical and metabolic effects of gluten free diet in children with type 1 diabetes and coeliac disease. Pediatric diabetes 2011; 12: 322 -325. DOI: 10.1111/j.1399-5448. 2010.00700.x

110 Lionetti E et al. Prevalence and natural history of potential celiac disease in at-family-risk infants prospectively investigated from birth. The Journal of pediatrics 2012; 161: 908 -914. DOI: 10.1016/j.jpeds. 2012.05.008

111 Rubio-Tapia A et al. Predictors of family risk for celiac disease: a population-based study. Clinical gastroenterology and hepatology: the official clinical practice journal of the American Gastroenterological Association 2008; 6: 983 -987. DOI: 10.1016/j.cgh.2008.04.008

112 Kinos $S$ et al. Burden of illness in screen-detected children with celiac disease and their families. Journal of pediatric gastroenterology and nutrition 2012; 55: 412 - 416. DOI: 10.1097/MPG.0b013e31825f18ff

113 Biagi F et al. The incidence of coeliac disease in adult first degree relatives. Digestive and liver disease: official journal of the Italian Society of Gastroenterology and the Italian Association for the Study of the Liver 2008; 40: 97 -100. DOI: 10.1016/j.dld.2007.10.004

114 Megiorni F et al. HLA-DQ and risk gradient for celiac disease. Human immunology 2009; 70: 55 - 59. DOI: 10.1016/j.humimm.2008.10.018

115 Karell $K$ et al. HLA types in celiac disease patients not carrying the DQA $1{ }^{*} 05-\mathrm{DQB} 1{ }^{*} 02$ (DQ2) heterodimer: results from the European Genetics Cluster on Celiac Disease. Human immunology 2003; 64: $469-477$

116 Vecsei A et al. Influence of age and genetic risk on anti-tissue transglutaminase IgA titers. Journal of pediatric gastroenterology and nutrition 2009; 48: 544-549. DOI: 10.1097/MPG.0b013e31818c5ff6 
117 Vivas S et al. Duodenal biopsy may be avoided when high transglutaminase antibody titers are present. World journal of gastroenterology 2009; $15: 4775-4780$

118 Clouzeau-Girard H et al. HLA-DQ genotyping combined with serological markers for the diagnosis of celiac disease: is intestinal biopsy still mandatory? Journal of pediatric gastroenterology and nutrition 2011; 52: 729 - 733. DOI: 10.1097/MPG.0b013e31820a724d

119 Klapp $G$ et al. Celiac disease: the new proposed ESPGHAN diagnostic criteria do work well in a selected population. Journal of pediatric gastroenterology and nutrition 2013; 56: 251 -256. DOI: 10.1097/ MPG.0b013e318279887b

120 Kurppa K et al. Utility of the new ESPGHAN criteria for the diagnosis of celiac disease in at-risk groups. Journal of pediatric gastroenterology and nutrition 2012; 54: 387-391. DOI: 10.1097/MPG.0b013 e3182407c6b

121 Hill PG, Holmes GK. Coeliac disease: a biopsy is not always necessary for diagnosis. Alimentary pharmacology \& therapeutics 2008; 27: 572-577. DOI: 10.1111/j.1365-2036.2008.03609.x

122 Dahlbom I et al. Prediction of clinical and mucosal severity of coeliac disease and dermatitis herpetiformis by quantification of IgA/IgG serum antibodies to tissue transglutaminase. Journal of pediatric gastroenterology and nutrition 2010; 50: 140-146. DOI: 10.1097/ MPG.0b013e3181a81384

123 Zanini $B$ et al. High tissue-transglutaminase antibody level predicts small intestinal villous atrophy in adult patients at high risk of celiac disease. Digestive and liver disease: official journal of the Italian Society of Gastroenterology and the Italian Association for the Study of the Liver 2012; 44: 280-285. DOI: 10.1016/j.dld.2011.10.013

124 Fasano A, Catassi C. Clinical practice. Celiac disease. The New England journal of medicine 2012; 367: 2419-2426. DOI: 10.1056/NEJM cp1113994

125 Tosco A et al. Natural history of potential celiac disease in children. Clinical gastroenterology and hepatology: the official clinical practice journal of the American Gastroenterological Association 2011; 9: 320 - 325 quiz e336 DOI: 10.1016/j.cgh.2010.09.006

126 Harper JW, Holleran SF, Ramakrishnan R et al. Anemia in celiac disease is multifactorial in etiology. American journal of hematology 2007; 82: 996 -1000. DOI: 10.1002/ajh.20996

127 Garcia-Manzanares A, Lucendo AJ. Nutritional and dietary aspects of celiac disease. Nutrition in clinical practice: official publication of the American Society for Parenteral and Enteral Nutrition 2011; 26: 163 - 173. DOI: $10.1177 / 0884533611399773$

128 Casella S et al. Celiac disease in elderly adults: clinical, serological, and histological characteristics and the effect of a gluten-free diet. Journal of the American Geriatrics Society 2012; 60: 1064-1069. DOI: 10. 1111/j.1532-5415.2012.03997.x

129 Garcia-Manzanares A, Tenias JM, Lucendo AJ. Bone mineral density directly correlates with duodenal Marsh stage in newly diagnosed adult celiac patients. Scandinavian journal of gastroenterology 2012; 47: 927-936. DOI: 10.3109/00365521.2012.688217

130 Cassio A et al. Long-term clinical significance of thyroid autoimmunity in children with celiac disease. The Journal of pediatrics 2010; 156 : 292 -295. DOI: 10.1016/j.jpeds.2009.08.047

131 Diamanti $A$ et al. Thyroid autoimmunity in children with coeliac disease: a prospective survey. Archives of disease in childhood 2011; 96: 1038 -1041. DOI: 10.1136/archdischild-2011-300595

132 Barret $M$ et al. Diagnostic yield of capsule endoscopy in refractory celiac disease. The American journal of gastroenterology 2012; 107 : 1546-1553. DOI: 10.1038/ajg.2012.199

133 Kurien $M$ et al. Capsule endoscopy in adult celiac disease: a potential role in equivocal cases of celiac disease? Gastrointestinal endoscopy 2013; 77: 227 - 232. DOI: 10.1016/j.gie.2012.09.031

134 Rokkas T, Niv Y. The role of video capsule endoscopy in the diagnosis of celiac disease: a meta-analysis. European journal of gastroenterology \& hepatology 2012; 24: 303 -308. DOI: 10.1097/MEG.0b013 e32834fa914

135 Wolters VM et al. Is gluten challenge really necessary for the diagnosis of coeliac disease in children younger than age 2 years? Journal of pediatric gastroenterology and nutrition 2009; 48: 566-570. DOI: 10 . 1097/MPG.0b013e31818c526b

136 Boyce JA et al. Guidelines for the Diagnosis and Management of Food Allergy in the United States: Summary of the NIAID-Sponsored Expert Panel Report. The Journal of allergy and clinical immunology 2010; 126: 1105 -1118. DOI: 10.1016/j.jaci.2010.10.008
137 Biesiekierski JR et al. Gluten causes gastrointestinal symptoms in subjects without celiac disease: a double-blind randomized placebocontrolled trial. The American journal of gastroenterology 2011; 106: 508 - 514 quiz 515 DOI: 10.1038/ajg.2010.487

138 Carroccio A et al. Non-celiac wheat sensitivity diagnosed by doubleblind placebo-controlled challenge: exploring a new clinical entity. The American journal of gastroenterology 2012; 107: 1898-1906 quiz 1907 DOI: 10.1038/ajg.2012.236

139 Tuire I et al. Persistent duodenal intraepithelial lymphocytosis despite a long-term strict gluten-free diet in celiac disease. The American journal of gastroenterology 2012; 107: 1563-1569. DOI: 10.1038/ ajg. 2012.220

140 Taavela J et al. Degree of damage to the small bowel and serum antibody titers correlate with clinical presentation of patients with celiac disease. Clinical gastroenterology and hepatology: the official clinical practice journal of the American Gastroenterological Association 2013; 11: 166 -171 e161 DOI: 10.1016/j.cgh.2012.09.030

141 Yachha SK et al. Effect of a gluten-free diet on growth and small-bowel histology in children with celiac disease in India. Journal of gastroenterology and hepatology 2007; 22: 1300-1305. DOI: 10.1111/ j.1440-1746.2007.04929.x

142 Aydogdu $S$ et al. Long-term effect of gluten-free diet on growth velocity in Turkish children with celiac disease. Digestive diseases and sciences 2009; 54: 2183-2187. DOI: 10.1007/s10620-008-0596-0

143 Weiss $B$ et al. Is adult height of patients with celiac disease influenced by delayed diagnosis? The American journal of gastroenterology; 2008; 103: 1770 - 1774. DOI: 10.1111/j.1572-0241.2008.01844.x

144 Artz E, Warren-Ulanch J, Becker D et al. Seropositivity to celiac antigens in asymptomatic children with type 1 diabetes mellitus: association with weight, height, and bone mineralization. Pediatric diabetes 2008; 9: 277 - 284. DOI: 10.1111/j.1399-5448.2008.00386.x

145 Clinical utility of serologic testing for celiac disease in asymptomatic patients: an evidence-based analysis. Ontario health technology assessment series 2001; 11: $1-63$

146 Bettendorf $M$ et al. Prevalence of autoantibodies associated with thyroid and celiac disease in Ullrich-Turner syndrome in relation to adult height after growth hormone treatment. Journal of pediatric endocrinology \& metabolism 2006; 19: 149-154

147 Khashan AS et al. The impact of maternal celiac disease on birthweight and preterm birth: a Danish population-based cohort study. Human reproduction (Oxford, England) 2010; 25: 528 - 534. DOI: 10. 1093/humrep/dep409

148 Kumar A et al. Latent celiac disease in reproductive performance of women. Fertility and sterility 2011; 95: 922-927. DOI: 10.1016/j. fertnstert.2010.11.005

149 Ozgor B, Selimoglu MA. Coeliac disease and reproductive disorders Scandinavian journal of gastroenterology 2010; 45: 395-402. DOI: $10.3109 / 00365520903508902$

150 Matysiak-Budnik $T$ et al. Long-term follow-up of 61 coeliac patients diagnosed in childhood: evolution toward latency is possible on a normal diet. Gut 2007; 56: 1379-1386. DOI: 10.1136/gut.2006. 100511

151 Hopman EG et al. Gluten tolerance in adult patients with celiac disease 20 years after diagnosis? European journal of gastroenterology \& hepatology 2008; 20: 423 -429. DOI: 10.1097/MEG.0b013e3282f4de6e

152 Koerner TB et al. Gluten contamination of naturally gluten-free flours and starches used by Canadians with celiac disease. Food Addit Contam Part A Chem Anal Control Expo Risk Assess 2013; 30: 2017 - 2021

153 Catassi $C$ et al. A prospective, double-blind, placebo-controlled trial to establish a safe gluten threshold for patients with celiac disease. The American journal of clinical nutrition 2007; 85: 160-166

154 Akobeng AK, Thomas AG. Systematic review: tolerable amount of gluten for people with coeliac disease. Alimentary pharmacology \& therapeutics 2008; 27: 1044-1052. DOI: 10.1111/j.1365-2036.2008. 03669.x

155 Hollon JR, Cureton PA, Martin ML et al. Trace gluten contamination may play a role in mucosal and clinical recovery in a subgroup of diet-adherent non-responsive celiac disease patients. BMC gastroenterology 2013; 13: 40. DOI: 10.1186/1471-230x-13-40

156 Sollid LM, Qiao SW, Anderson RP et al. Nomenclature and listing of celiac disease relevant gluten T-cell epitopes restricted by HLA-DQ molecules. Immunogenetics 2012; 64: 455 -460. DOI: 10.1007/s00251012-0599-z 
157 Thompson T. Gluten contamination of commercial oat products in the United States. The New England journal of medicine 2004; 351: 2021 - 2022. DOI: 10.1056/nejm200411043511924

158 Koerner TB et al. Gluten contamination in the Canadian commercial oat supply. Food Addit Contam Part A Chem Anal Control Expo Risk Assess 2011; 28: 705-710

159 Sey MS, Parfitt J, Gregor J. Prospective study of clinical and histological safety of pure and uncontaminated Canadian oats in the management of celiac disease. JPEN. Journal of parenteral and enteral nutrition 2011; 35: 459-464. DOI: 10.1177/0148607110387800

160 Haboubi NY, Taylor S, Jones S. Coeliac disease and oats: a systematic review. Postgraduate medical journal 2006; 82: 672-678. DOI: 10. 1136/pgmj.2006.045443

161 Pulido OM et al. Introduction of oats in the diet of individuals with celiac disease: a systematic review. Advances in food and nutrition research 2009; 57: 235 -285. DOI: 10.1016/s1043-4526(09)57006-4

162 Garsed K, Scott BB. Can oats be taken in a gluten-free diet? A systematic review. Scandinavian journal of gastroenterology 2007; 42: 171 178. DOI: $10.1080 / 00365520600863944$

163 Koskinen 0 et al. Oats do not induce systemic or mucosal autoantibody response in children with coeliac disease. Journal of pediatric gastroenterology and nutrition 2009; 48: 559-565. DOI: 10.1097/ MPG.0b013e3181668635

164 Mattar R, de Campos Mazo DF, Carrilho FJ. Lactose intolerance: diagnosis, genetic, and clinical factors. Clinical and experimental gastroenterology 2012; 5: 113 -121. DOI: 10.2147/ceg.s32368

165 Raithel $M$ et al. Kohlenhydratmalassimilation häufig vorkommender Mono- und Disaccharide: Abgestuftes diagnostisches Vorgehen und Differenzialdiagnosen. Dtsch Arztebl 2013; 110: 775 - 782

166 Wierdsma NJ, van Bokhorst-de van der Schueren MA, Berkenpas M et al. Vitamin and mineral deficiencies are highly prevalent in newly diagnosed celiac disease patients. Nutrients 2013; 5: 3975-3992. DOI: 10.3390/nu5103975

167 Abu DayaH, Lebwohl B, Lewis SK et al. Celiac disease patients presenting with anemia have more severe disease than those presenting with diarrhea. Clinical gastroenterology and hepatology: the official clinical practice journal of the American Gastroenterological Association 2013; 11: 1472-1477. DOI: 10.1016/j.cgh.2013.05.030

168 Annibale $B$ et al. Efficacy of gluten-free diet alone on recovery from iron deficiency anemia in adult celiac patients. The American journal of gastroenterology 2001; 96: 132 -137. DOI: 10.1111/j.1572-0241. 2001.03463.x

169 Lucendo AJ, Garcia-Manzanares A. Bone mineral density in adult coeliac disease: An updated review. Revista espanola de enfermedades digestivas: organo oficial de la Sociedad Espanola de Patologia Digestiva 2013; 105: 154-162

170 Szymczak J, Bohdanowicz-Pawlak A, Waszczuk E et al. Low bone mineral density in adult patients with coeliac disease. Endokrynologia Polska 2012; 63: 270-276

171 Passananti $V$ et al. Bone mass in women with celiac disease: role of exercise and gluten-free diet. Digestive and liver disease: official journal of the Italian Society of Gastroenterology and the Italian Association for the Study of the Liver 2012; 44: 379-383. DOI: 10.1016/j. dld.2011.12.012

172 V CDO. e. DVO-Leitlinie 2009 zur Prophylaxe, Diagnostik und Therapie der Osteoporose bei Erwachsenen. Langfassung. Osteologie 2009; 18: $304-328$

173 Shepherd SJ, Gibson PR. Nutritional inadequacies of the gluten-free diet in both recently-diagnosed and long-term patients with coeliac disease. Journal of human nutrition and dietetics: the official journal of the British Dietetic Association 2013; 26: 349 -358. DOI: 10.1111/ jhn.12018

174 Martin J, Geisel T, Maresch C et al. Inadequate nutrient intake in patients with celiac disease: results from a german dietary survey. Digestion 2013; 87: 240 -246. DOI: 10.1159/000348850

175 Wild D, Robins GG, Burley VJ et al. Evidence of high sugar intake, and low fibre and mineral intake, in the gluten-free diet. Alimentary pharmacology \& therapeutics 2010; 32: 573-581. DOI: $10.1111 /$ j.1365-2036.2010.04386.x

176 Ohlund K, Olsson CHernell O, Ohlund I. Dietary shortcomings in children on a gluten-free diet. Journal of human nutrition and dietetics: the official journal of the British Dietetic Association 2010; 23: 294 300. DOI: 10.1111/j.1365-277X.2010.01060.X
177 Mozer-Glassberg Y et al. Follow-up of children with celiac disease lost in translation? Digestion 2011; 83: 283-287. DOI: 10.1159/ 000320714

178 Jacobsson LR, Friedrichsen M, Goransson A et al. Impact of an active patient education program on gastrointestinal symptoms in women with celiac disease following a gluten-free diet: a randomized controlled trial. Gastroenterology nursing: the official journal of the Society of Gastroenterology Nurses and Associates 2012; 35: 200 - 206. DOI: 10.1097/SGA.0b013e318255fe3a

179 Zanini B et al. Five year time course of celiac disease serology during gluten free diet: results of a community based "CD-Watch" program. Digestive and liver disease: official journal of the Italian Society of Gastroenterology and the Italian Association for the Study of the Liver 2010; 42: 865 -870. DOI: 10.1016/j.dld.2010.05.009

180 Silvester JA, Rashid M. Long-term follow-up of individuals with celiac disease: an evaluation of current practice guidelines. Canadian journal of gastroenterology = Journal canadien de gastroenterologie 2007; $21: 557-564$

181 Nachman $F$ et al. Serological tests for celiac disease as indicators of long-term compliance with the gluten-free diet. European journal of gastroenterology \& hepatology 2011; 23: 473-480. DOI: 10.1097/ MEG.0b013e328346e0f1

182 Candon S, Mauvais FX, Garnier-Lengline $H$ et al. Monitoring of antitransglutaminase autoantibodies in pediatric celiac disease using a sensitive radiobinding assay. Journal of pediatric gastroenterology and nutrition 2012; 54: 392 -396. DOI: 10.1097/MPG.0b013 e318232c459

183 Aziz I, Evans KE, Papageorgiou V et al. Are patients with coeliac disease seeking alternative therapies to a gluten-free diet? Journal of gastrointestinal and liver diseases 2011; 20: 27-31

184 Kaukinen K, Lindfors K, Maki M. Advances in the treatment of coeliac disease: an immunopathogenic perspective. Nat Rev Gastroenterol Hepatol 2014; 11: $36-44$

185 Lindfors $K$ et al. Future treatment strategies for celiac disease. Expert opinion on therapeutic targets 2012; 16: $665-675$. DOI: $10.1517 /$ 14728222.2012 .688808

186 Mukherjee $R$, Kelly CP, Schuppan D. Nondietary therapies for celiac disease. Gastrointestinal endoscopy clinics of North America 2012 22: 811 -831. DOI: $10.1016 /$ j.giec.2012.09.001

187 Szajewska $H$ et al. Systematic review: early infant feeding and the prevention of coeliac disease. Alimentary pharmacology \& therapeutics 2012; 36: 607 -618. DOI: 10.1111/apt.12023

188 Akobeng AK, Ramanan AV, Buchan I et al. Effect of breast feeding on risk of coeliac disease: a systematic review and meta-analysis of observational studies. Archives of disease in childhood 2006; 91: 39 43. DOI: $10.1136 /$ adc.2005.082016

189 Norris JM et al. Risk of celiac disease autoimmunity and timing of gluten introduction in the diet of infants at increased risk of disease. Journal of the American Medical Association 2005; 293: 2343 - 2351. DOI: $10.1001 /$ jama.293.19.2343

190 Persson LA, Ivarsson A, Hernell O. Breast-feeding protects against celiac disease in childhood - epidemiological evidence. Advances in experimental medicine and biology 2002; 503: 115-123

191 Ivarsson A et al. Prevalence of childhood celiac disease and changes in infant feeding. Pediatrics 2013; 131: e687-694. DOI: 10.1542/ peds.2012-1015

192 Hogen Esch CE et al. The PreventCD Study design: towards new strategies for the prevention of coeliac disease. European journal of gastroenterology \& hepatology 2010; 22: 1424-1430. DOI: 10.1097/ MEG.0b013e32833fe9ae

$193 \mathrm{Mehl}$ A et al. The atopy patch test in the diagnostic workup of suspected food-related symptoms in children. The Journal of allergy and clinical immunology 2006; 118: 923 -929. DOI: 10.1016/j.jaci.2006. 07.003

194 Beyer $K$ et al. The role of wheat omega-5 gliadin IgE antibodies as a diagnostic tool for wheat allergy in childhood. The Journal of allergy and clinical immunology 2008; 122: 419-421. DOI: 10.1016/j.jaci.2008.06.006

195 Hill ID et al. Guideline for the diagnosis and treatment of celiac disease in children: recommendations of the North American Society for Pediatric Gastroenterology, Hepatology and Nutrition. Journal of pediatric gastroenterology and nutrition 2005; 40: 1-19

196 Branski D, Faber J, Freier S et al. Histologic evaluation of endoscopic versus suction biopsies of small intestinal mucosae in children with 
and without celiac disease. Journal of pediatric gastroenterology and nutrition 1998; 27: 6-11

197 Oderda $\mathrm{G}$ et al. Endoscopic and histologic findings in the upper gastrointestinal tract of children with coeliac disease. Journal of pediatric gastroenterology and nutrition 1993; 16: 172 - 177

198 Abdulkarim AS, Burgart LJ, See J et al. Etiology of nonresponsive celiac disease: results of a systematic approach. The American journal of gastroenterology 2002; 97: 2016-2021. DOI: 10.1111/j.1572-0241. 2002.05917.x

199 Leffler DA et al. Etiologies and predictors of diagnosis in nonresponsive celiac disease. Clinical gastroenterology and hepatology: the official clinical practice journal of the American Gastroenterological Association 2007; 5: 445 - 450. DOI: 10.1016/j.cgh.2006.12.006

200 Mooney PD, Evans KE, Singh S et al. Treatment failure in coeliac disease: a practical guide to investigation and treatment of non-responsive and refractory coeliac disease. Journal of gastrointestinal and liver diseases 2012; 21: 197-203

201 Nijeboer P, van Wanrooij RL, Tack GJ et al. Update on the diagnosis and management of refractory coeliac disease. Gastroenterology research and practice 2013; 2013: 518483. DOI: 10.1155/2013/518483

202 Rubio-Tapia A, Murray JA. Classification and management of refractory coeliac disease. Gut 2010; 59: 547-557. DOI: 10.1136/gut.2009. 195131

203 Rashid M, MacDonald A. Importance of duodenal bulb biopsies in children for diagnosis of celiac disease in clinical practice. BMC gastroenterology 2009; 9: 78. DOI: 10.1186/1471-230x-9-78

204 Ravelli $A$ et al. How patchy is patchy villous atrophy? distribution pattern of histological lesions in the duodenum of children with celiac disease. The American journal of gastroenterology 2010; 105: 2103-2110. DOI: 10.1038/ajg.2010.153

205 Bonamico $M$ et al. Duodenal bulb biopsies in celiac disease: a multicenter study. Journal of pediatric gastroenterology and nutrition 2008; 47: 618-622

206 Green PH, Cellier C. Celiac disease. The New England journal of medicine 2007; 357: 1731 -1743. DOI: 10.1056/NEJMra071600

207 Rostom A, Murray JA, Kagnoff MF. American Gastroenterological Association (AGA) Institute technical review on the diagnosis and management of celiac disease. Gastroenterology 2006; 131: 1981-2002. DOI: $10.1053 /$ j.gastro.2006.10.004

208 Lebwohl B, Kapel RC, Neugut AI et al. Adherence to biopsy guidelines increases celiac disease diagnosis. Gastrointestinal endoscopy 2011; 74: 103 - 109. DOI: 10.1016/j.gie.2011.03.1236

209 Oberhuber G, Granditsch G, Vogelsang $H$. The histopathology of coeliac disease: time for a standardized report scheme for pathologists. European journal of gastroenterology \& hepatology 1999; 11: 11851194

210 Villanacci V, Ceppa P, Tavani E et al. Coeliac disease: the histology report. Digestive and liver disease: official journal of the Italian Society of Gastroenterology and the Italian Association for the Study of the Liver 2011; 43 (Suppl 4): S385-S395. DOI: 10.1016/s15908658(11)60594-X

211 Pellegrino $S$ et al. Redefining the intraepithelial lymphocytes threshold to diagnose gluten sensitivity in patients with architecturally normal duodenal histology. Alimentary pharmacology \& therapeutics 2011; 33: 697-706. DOI: 10.1111/j.1365-2036.2011.04578.x

212 Walker MM et al. Detection of celiac disease and lymphocytic enteropathy by parallel serology and histopathology in a population-based study. Gastroenterology 2010; 139: $112-119$. DOI: 10.1053/j.gastro.2010.04.007

213 Dickson BC, Streutker CJ, Chetty R. Coeliac disease: an update for pathologists. Journal of clinical pathology 2006; 59: 1008-1016. DOI: $10.1136 /$ jcp. 2005.035345

214 Rubio-Tapia A et al. Clinical staging and survival in refractory celiac disease: a single center experience. Gastroenterology 2009; 136: 99-107 quiz 352-103 DOI: 10.1053/j.gastro.2008.10.013

215 Malamut $G$ et al. Presentation and long-term follow-up of refractory celiac disease: comparison of type I with type II. Gastroenterology 2009; 136: 81 -90. DOI: 10.1053/j.gastro.2008.09.069

216 Roshan $B$ et al. The incidence and clinical spectrum of refractory celiac disease in a north american referral center. The American journal of gastroenterology 2011; 106: 923 - 928. DOI: 10.1038/ajg.2011.104

217 Ashton-Key M, Diss TC, Pan L et al. Molecular analysis of T-cell clonality in ulcerative jejunitis and enteropathy-associated T-cell lymphoma. The American journal of pathology 1997; 151: $493-498$
218 Cellier $C$ et al. Refractory sprue, coeliac disease, and enteropathyassociated T-cell lymphoma. French Coeliac Disease Study Group. Lancet 2000; 356: 203-208

219 Patey-Mariaud De Serre $N$ et al. Distinction between coeliac disease and refractory sprue: a simple immunohistochemical method. Histopathology 2000; 37: 70-77

220 de Mascarel A et al. Mucosal intraepithelial T-lymphocytes in refractory celiac disease: a neoplastic population with a variable CD8 phenotype. The American journal of surgical pathology 2008; 32: 744-751. DOI: 10.1097/PAS.0b013e318159b478

221 Daum S et al. High rates of complications and substantial mortality in both types of refractory sprue. European journal of gastroenterology \& hepatology 2009; 21: 66 - 70. DOI: 10.1097/MEG.0b013e328307c20c

222 Grainge MJ, West J, Solaymani-Dodaran $M$ et al. The long-term risk of malignancy following a diagnosis of coeliac disease or dermatitis herpetiformis: a cohort study. Alimentary pharmacology \& therapeutics 2012; 35: 730 - 739. DOI: 10.1111/j.1365-2036.2012.04998.x

223 Holmes GK et al. Coeliac disease, gluten-free diet, and malignancy. Gut 1976; 17: 612-619

224 Al-toma A, Verbeek WH, Mulder CJ. The management of complicated celiac disease. Digestive diseases (Basel, Switzerland) 2007; 25: 230-236. DOI: 10.1159/000103891

225 Daum S et al. Intestinal non-Hodgkin's lymphoma: a multicenter prospective clinical study from the German Study Group on Intestinal non-Hodgkin's Lymphoma. Journal of clinical oncology: official journal of the American Society of Clinical Oncology 2003; 21: $2740-$ 2746. DOI: $10.1200 /$ jco.2003.06.026

226 Daum S, Cellier C, Mulder CJ. Refractory coeliac disease. Best practice \& research. Clinical gastroenterology 2005; 19: 413-424. DOI: 10.1016/ j.bpg.2005.02.001

227 Daum S et al. Frequency of clonal intraepithelial T lymphocyte proliferations in enteropathy-type intestinal $\mathrm{T}$ cell lymphoma, coeliac disease, and refractory sprue. Gut 2001; 49: 804-812

228 O'Shea $U$ et al. Investigation of molecular markers in the diagnosis of refractory coeliac disease in a large patient cohort. Journal of clinical pathology 2008; 61: 1200-1202. DOI: 10.1136/jcp.2008.058404

229 Delabie J et al. Enteropathy-associated T-cell lymphoma: clinical and histological findings from the international peripheral T-cell lymphoma project. Blood 2011; 118: 148 -155. DOI: 10.1182/blood-201102-335216

230 Malamut $\mathrm{G}$ et al. Enteropathy associated $\mathrm{T}$ cell lymphoma in celiac disease: a large retrospective study. Digestive and liver disease: official journal of the Italian Society of Gastroenterology and the Italian Association for the Study of the Liver 2013; 45: 377-384. DOI: $10.1016 /$ j.dld.2012.12.001

231 Wahab PJ, Meijer JW, Mulder CJ. Histologic follow-up of people with celiac disease on a gluten-free diet: slow and incomplete recovery. American journal of clinical pathology 2002; 118: 459-463. DOI: $10.1309 /$ evxt-851x-whlc-rlx9

232 Verbeek $W H$ et al. Flow cytometric determination of aberrant intraepithelial lymphocytes predicts T-cell lymphoma development more accurately than T-cell clonality analysis in Refractory Celiac Disease. Clinical immunology (Orlando, Fla.) 2008; 126: 48 -56. DOI: 10.1016/ j.clim.2007.09.002

233 Daum $S$ et al. Capsule endoscopy in refractory celiac disease. Endoscopy 2007; 39: 455 - 458. DOI: 10.1055/s-2007-966239

234 Mallant $M$ et al. Abdominal computed tomography in refractory coeliac disease and enteropathy associated T-cell lymphoma. World journal of gastroenterology 2007; 13: $1696-1700$

235 Van Weyenberg SJ et al. MR enteroclysis in refractory celiac disease: proposal and validation of a severity scoring system. Radiology 2011; 259: 151 - 161. DOI: 10.1148/radiol.11101808

236 Van Weyenberg SJ, Smits F, Jacobs MA et al. Video capsule endoscopy in patients with nonresponsive celiac disease. Journal of clinical gastroenterology 2013; 47: 393-399. DOI: 10.1097/MCG.0b013 e31826bea12

237 Cellier $C$ et al. Push enteroscopy in celiac sprue and refractory sprue. Gastrointestinal endoscopy 1999; 50: 613-617

238 Atlas DS, Rubio-Tapia A, Van Dyke CT et al. Capsule endoscopy in nonresponsive celiac disease. Gastrointestinal endoscopy 2011; 74: 1315 - 1322. DOI: 10.1016/j.gie.2011.05.049

239 Van Weyenberg SJ et al. Comparison of MR enteroclysis with video capsule endoscopy in the investigation of small-intestinal disease. Abdominal imaging 2013; 38: 42 -51. DOI: 10.1007/s00261-0129892-4 
240 Rettenbacher T, Hollerweger A, Macheiner P et al. Adult celiac disease: US signs. Radiology 1999; 211: 389-394. DOI: 10.1148/radiology.211.2.r99ma39389

241 Hadithi $M$ et al. 18F-FDG PET versus CT for the detection of enteropathy-associated T-cell lymphoma in refractory celiac disease. Journal of nuclear medicine: official publication, Society of Nuclear Medicine 2006; 47: 1622 - 1627

242 Olaussen RW et al. Effect of elemental diet on mucosal immunopathology and clinical symptoms in type 1 refractory celiac disease. Clinical gastroenterology and hepatology: the official clinical practice journal of the American Gastroenterological Association 2005; 3: 875-885

$243 \mathrm{Brar} P$ et al. Budesonide in the treatment of refractory celiac disease. The American journal of gastroenterology 2007; 102: 2265-2269. DOI: $10.1111 / \mathrm{j} .1572-0241.2007 .01380 . \mathrm{x}$

244 Daum $S$ et al. Therapy with budesonide in patients with refractory sprue. Digestion 2006; 73: 60-68. DOI: 10.1159/000092639

245 Goerres MS et al. Azathioprine and prednisone combination therapy in refractory coeliac disease. Alimentary pharmacology \& therapeutics 2003; 18: 487-494

246 Tack GJ, van Asseldonk DP, van Wanrooij RL et al. Tioguanine in the treatment of refractory coeliac disease - a single centre experience. Alimentary pharmacology \& therapeutics 2012; 36: 274-281. DOI: $10.1111 /$ j.1365-2036.2012.05154.x

247 Gillett HR et al. Successful infliximab treatment for steroid-refractory celiac disease: a case report. Gastroenterology 2002; 122: 800 - 805

248 Daum $S$ et al. Adult autoimmune enteropathy treated successfully with tacrolimus. Digestion 2003; 68: 86-90. DOI: 74520

$249 \mathrm{Jamma} S$ et al. Small intestinal release mesalamine for the treatment of refractory celiac disease type I. Journal of clinical gastroenterology 2011; 45: 30 - 33. DOI: 10.1097/MCG.0b013e3181f42401

$250 \mathrm{Al}$-Toma $\mathrm{A}$ et al. Cladribine therapy in refractory celiac disease with aberrant T cells. Clinical gastroenterology and hepatology: the official clinical practice journal of the American Gastroenterological Association 2006; 4: 1322 - 1327 quiz 1300 DOI: 10.1016/j.cgh.2006.07.007

251 Tack GJ et al. Evaluation of Cladribine treatment in refractory celiac disease type II. World journal of gastroenterology 2011; 17: 506513. DOI: $10.3748 /$ wjg.v17.i4.506

252 Hadjibabaie $M$ et al. Evaluation of nutritional status in patients undergoing hematopoietic SCT. Bone marrow transplantation 2008; 42: 469-473. DOI: 10.1038/bmt.2008.188
253 Verbeek WH, Mulder CJ, Zweegman S. Alemtuzumab for refractory celiac disease. The New England journal of medicine 2006; 355: 1396 1397 author reply 1397 DOI: 10.1056/NEJMc061784

254 Vivas S, Ruiz de Morales JM, Ramos F et al. Alemtuzumab for refractory celiac disease in a patient at risk for enteropathy-associated T-cell lymphoma. The New England journal of medicine 2006; 354: $2514-$ 2515. DOI: $10.1056 / \mathrm{NEJMc053129}$

255 Tack GJ et al. Auto-SCT in refractory celiac disease type II patients unresponsive to cladribine therapy. Bone marrow transplantation 2011; 46: 840-846. DOI: 10.1038/bmt.2010.199

256 Bachle T, Ruhl U, Ott G et al. Enteropathy-associated T-cell lymphoma. Manifestation as diet-refractory coeliac disease and ulcerating jejunitis. Deutsche medizinische Wochenschrift (1946) 2001; 126: 1460 1463. DOI: $10.1055 / \mathrm{s}-2001-19212$

257 Chott $A$ et al. Most CD56+ intestinal lymphomas are CD8+CD5-T-cell lymphomas of monomorphic small to medium size histology. The American journal of pathology 1998; 153: 1483-1490. DOI: 10. 1016/s0002-9440(10)65736-7

258 Chan JK et al. Type II enteropathy-associated T-cell lymphoma: a distinct aggressive lymphoma with frequent gammadelta T-cell receptor expression. The American journal of surgical pathology 2011; 35: 1557 -1569. DOI: 10.1097/PAS.0b013e318222dfcd

259 Al-Toma A et al. Disappointing outcome of autologous stem cell transplantation for enteropathy-associated T-cell lymphoma. Digestive and liver disease: official journal of the Italian Society of Gastroenterology and the Italian Association for the Study of the Liver 2007; 39: 634-641. DOI: 10.1016/j.dld.2007.03.009

260 Raderer $M$ et $a l$. Second line chemotherapy in patients with enteropathy-associated T cell lymphoma: a retrospective single center analysis. Annals of hematology 2012; 91: 57-61. DOI: 10.1007/s00277011-1236-x

261 Goldberg JD et al. T cell-depleted stem cell transplantation for adults with high-risk acute lymphoblastic leukemia: long-term survival for patients in first complete remission with a decreased risk of graftversus-host disease. Biology of blood and marrow transplantation: journal of the American Society for Blood and Marrow Transplantation 2013; 19: 208 - 213. DOI: 10.1016/j.bbmt.2012.09.003 